ANN. ZOOTECH.

\title{
INFLUENCE DE QUELQUES FACTEURS ALIMENTAIRES, SAISONNIERS ET ENDOCRINIENS SUR LE MÉTABOLISME DE Ca, P, K, Na CHEZ 2 COUPLES DE JUMELLES BOVINES UNIVITELLINES
}

PAR

\author{
M. BROCHART, P. LARVOR et B. VISSAC (I). \\ Laboratoires de recherches de Zootechnie. \\ École nationale vétérinaire, Alfort \\ et Institut national agronomique, Paris.
}

\section{PLAN DU MÉMOIRE}

\section{I. - Introduction.}

II. - Matériel et méthodes.

III. - Résultats.

A. Généralités. Interprétation statistique globale.

B. Influence des facteurs saisonniers.

C. Influence des facteurs alimentaires.

D. Relations entre les variables sanguines, urinaires et fécales.

E. Relations entre la composition des poils et les autres variables.

F. Généralisation des résultats obtenus.

\section{IV. - Discussion générale.}

V. - Résumé.

\section{I. - INTRODUCTION}

L'étude globale du métabolisme minéral des bovins est une entreprise difficile, et qui nécessite généralement la mise en ouvre de moyens importants. La méthode des bilans exige une main d'œuvre abondante et un minimum d'installations techniques. De plus, une étude critique serrée de cette méthode (DUNCAN, I958) montre que, lorsquelle est poursuivie pendant une période de plusieurs mois, les chiffres de rétention obtenus sont sans rapport avec la réalité.

(1) Avec la collaboration technique de Mme N. Berthrlot, et de M. C. Roth. Remis pour publication en Juillet 1959 . 
Pour ces deux raisons, une étude du métabolisme minéral portant sur une année ne pouvait être envisagée par la méthode des bilans. Un travail préliminaire sur le rythme nycthéméral de la concentration urinaire et fécale des bovins (LARVor et BROCHART, I959) nous a permis d'établir qu'une mesure qualitative de concentration minérale urinaire et fécale, effectuée sur un échantillon prélevé à une heure où les variations de concentration sont faibles, permet de se faire une idée très approximative, mais néanmoins intéressante, du niveau d'élimination des minéraux dosés.

Une autre voie d'approche dans 1'exploration du métabolisme minéral peut être cherchée dans l'analyse directe de l'organisme animal, ou d'une fraction représentative et aisément prélevable de cet organisme. On connait depuis longtemps l'intérêt que présente l'étude des variations de la composition sanguine ; cette méthode a cependant l'inconvénient de ne refléter bien souvent qu'un aspect très fugace du métabolisme minéral, et demande à être complétée par l'analyse d'une fraction plus stable de l'organisme, susceptible de caractériser une période nutritionnelle plus longue.

L'un de nous (BROCHART, I957) a appliqué l'analyse du calcium et du phosphore du poil à l'étude de la nutrition phosphocalcique de la vache hollandaise ; au cours de la présente étude nous avons essayé d'étendre la méthode au cas de la vache normande, et à d'autres minéraux.

Par ailleurs, il nous a semblé intéressant de préciser un certain nombre de "constantes " biochimiques des bovins, pour lesquelles on ne dispose jusqu'à présent que de renseignements fragmentaires, et qu'il est cependant nécessaire de connaître pour pouvoir délimiter les domaines respectifs des valeurs physiologiques et pathologiques des minéraux plasmatiques.

\section{II. - MATÉRIEL ET MÉTHODES}

Nos recherches ont porté sur deux couples de jumelles univitellines de race normande, qui seront désignées, pour le premier couple, par les chiffres I et III, et, pour le deuxième couple, par les lettres E et S. Au cours des recherches qui sont décrites dans ce travail, l'alimentation a été parfois différente selon les couples, mais identique pour les deux sujets d'un même couple.

Les critères de la gemellité vraie étaient :

- La similitude morphologique étroite (notamment répartition des taches).

- La similitude des courbes de croissance, l'alimentation étant jdentique à l'intérieur de chaque couple. 
- I'identité des groupes sanguins, déterminée par le I aboratoire des Groupes sanguins des bovidés, de Jouy-en-Josas.

- Ia ressemblance frappante des courbes de lactation des vaches I. et III, malgré un déphasage de 3 semaines dans la date des vêlages.

I.e couple I-III avait 35 mois au début de l'expérience. Ces vaches ont eu leur premier vélage en cours d'expérience, la vache I, le If février $5^{8}$ et la vache III, le 3 mars 58 . I a production laitière mensuelle a été de février à juin I958, de I5, I5, I4, I3 et I I,5 litres.

Le couple E-S avait 27 mois au début de l'expérience. Du fait d'un retard notable de développement, la saillie a été retardée ; par la suite, nous n'avons pu réussir à obtenir de gestations synchrones, ce qui nous a obligé à provoquer, le I 8 mars, chez la vache $\mathrm{S}\left(3^{\mathrm{e}}\right.$ mois de gestation) un avortement, qui a été suivi d'une faible lactation de quelques jours.

Les animaux étaient entretenus en stabulation permanente; ils recevaient directement la lumière par des fenêtres situées de face. L'abreuvement était automatique. I,es repas étaient distribués à 9 heures et à I7 heures, les rations du matin et du soir étant identiques.

Ces animaux ont été suivis toutes les semaines pendant un an, de juin I957 à juin I95. I. Ia ration a été analysée au point de vue minéral (Ca, P, Na et $\mathrm{K}$ ) ; les "refus " ayant été pratiquement nuls, la quantité de minéraux absorbés a pu être calculée avec une précision satisfaisante. I,e seul élément non contrôlé de la ration a été la quantité de paille ingérée, qui n'a guère dépassé $2 \mathrm{~kg}$, soit des quantités de $\mathrm{Ca}=6 \mathrm{~g}, \mathrm{P}=\mathrm{I}, 5 \mathrm{~g}$, $\mathrm{Na}=0,6 \mathrm{~g}, \mathrm{~K}=$ Io $\mathrm{g}$, représentant donc une faible fraction de la quantité totale de chaque élément ingéré (respectivenent en movenne, pour Ca, P, Na, K: 6 p. I00, 5 1). Ioo, 5 p. IoO, Io p. IOO).

I.es prélèvements étaient faits :

- Pour le sang, à jeun, à 9 heures du matin, par ponction de la jugulaire et remplissage de trois tubes à centrifugation, dont l'un contenait $200 \mathrm{mg}$ de $\mathrm{F} \mathrm{Na}$ (Io mg par ml de sang), le second une goutte d'héparine pour la préparation du plasma $\left(^{1}\right)$, le troisième, sans additif, était destiné à la récolte du sérum.

Le phosphore minéral était dosé dans le sang fluoruré, le Ca et le P total dans le sérum (suivant des méthodes déjà décrites; BRochar'I, I957). I,e sang hépariné était centrifugé aussi rapidement que possible (20 mn environ) après la récolte, pour éviter les échanges d'électrolytes entre le plasma et les globules, échanges qui sont susceptibles de modifier la teneur du plasma en $\mathrm{Na}$ et surtout en $\mathrm{K}$ et en $\mathrm{Cl}$ (Guillatmin et Vignes, ig28 ; Gulllaumin, I930 ; Duliere, I93I ; I Euller, I933 ; Higocnet, I937). Na et $\mathrm{K}$ étaient ensuite dosés par spectrophotométrie

(1) Nous teuons à remercier iri les laboratoires Hoffmann La Roche qui nous ont gracieusement foumi l'hejarine. 
de flamme, après dilution au I/roo dans de l'ean distillée, et par comparaison avec deux étalons qui encadraient les valeurs les plus couramment tronvées.
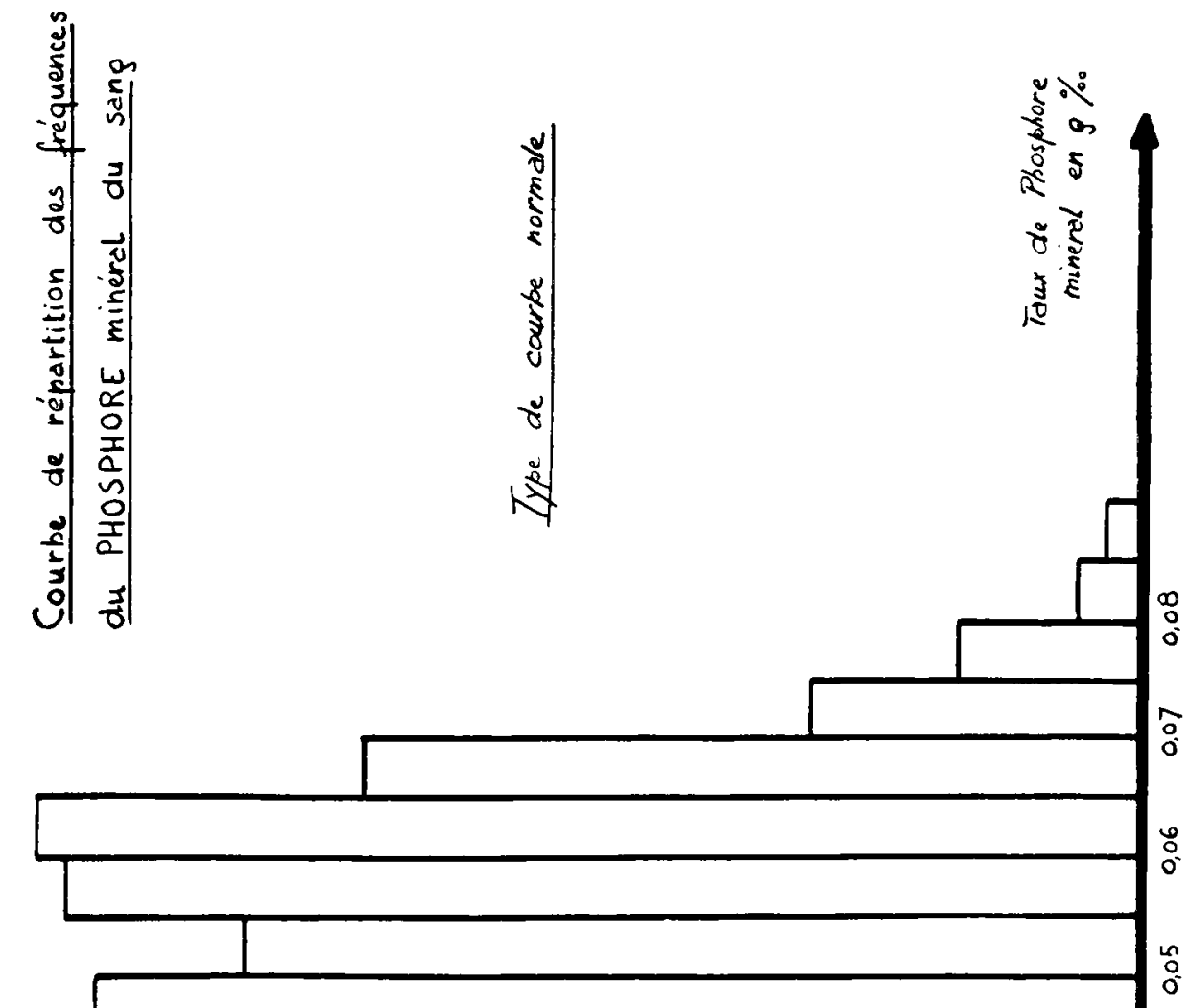

$\stackrel{\text { Ln }}{0}$
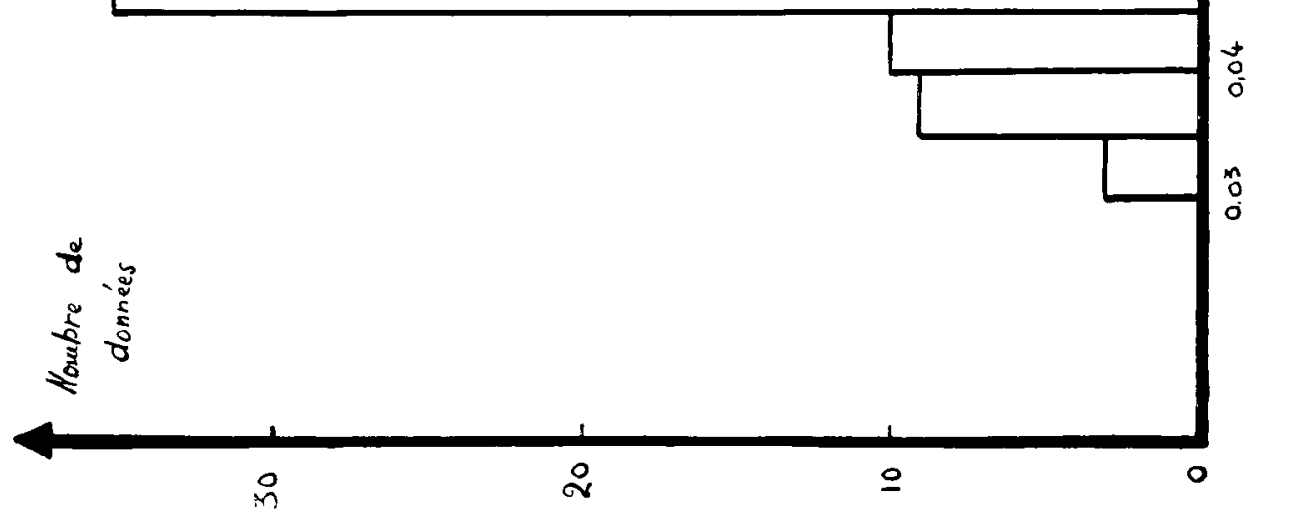

- Pour l'urine, prélèvement à If heures à l'aide d'une sonde ; dosage de $\mathrm{Ca}$ et $\mathrm{P}$.

- Pour les fèces, prélèvement dans la matinée, directement dans le 
rectum, deshydratation à l'étuve, broyage, minéralisation 16 heures à $55^{\circ}$, et dosage de $\mathrm{Ca}$ et $\mathrm{P}$.

Une étude préalable (LARVOR et BROCHART, I959) nous a montré que les résultats des dosages des prélèvements réalisés aux heures indiquées étaient en corrélation hautement significative avec la moyenne du nycthémère. Les données obtenues ont été comparées avec les conditions météréologiques principales (température, pression atmosphérique, durée du jour, hygrométrie), qui nous ont été fournies par l'Observatoire Géophysique du Parc Saint Maur, dont le microclimat se rapproche beaucoup du nôtre (1).

Le poil du chignon, de couleur blanche, était prélevé tous les deux mois, et dosé pour $\mathrm{Ca}, \mathrm{P}, \mathrm{K}, \mathrm{Na}, \mathrm{Mg}$.

Nous nous sommes aperçus, en cours d'expérience, que la technique de lavage des poils par le lauryl sulfate d'ammonium entrainait des pertes de cathions importantes. Cependant, nous l'avons gardée jusqu'à la fin de la période expérimentale pour que les résultats soient comparables. Seule une étude plus poussée pourra nous permettre ultérieurement de décider de la technique de lavage à adopter définitivement.

\section{III. - RÉSULTATS}

\section{A. Généralités. Interprétation statistique globale.}

L'analyse globale des résultats a porté sur 26 variables, et 216 observations par variable (une par semaine, en général, pendant un an, pour chacune des 4 jumelles soumises à l'expérience). Elle a été réalisée sur ordinateur I. B. M. 704.

Cette interprétation statistique qui vise à étudier les relations existant entre les teneurs en minéraux de l'alimentation, du sang, de l'urine, des fèces, des poils, et les conditions climatiques, et à en dégager les mécanismes physiologiques, a été poursuivie par les méthodes courantes d'analyse multidimensionnelle (MORICE et CharTIER, I954). Elle a comporté logiquement 3 parties.

\section{$I^{0}$ Étude des courbes de répartition des fréquences de chaque variable.}

Une condition essentielle de validité des calculs statistiques qui seront réalisés est que les variables étudiées se répartissent suivant une courbe de IAPLACE-Gauss, ou courbe normale (fig. I). Lorsqu'il n'en est pas ainsi, on peut satisfaire indirectement à cette condition, en étudiant

(1) Nous tenons à remercier ici Monsieur le Directeur de l'observatoire Géophysique du Parc Saint Maur, qui a bien voulu nous autoriser à relever ces données. 
non la variable elle-même $x$, mais une fonction $f(x)$ convenablement choisie de cette variable (BARTLETT, I947).

\section{TABLEAU I}

Caractéristiques de la distribution des principales variables étudiées.

\begin{tabular}{|c|c|c|c|c|c|c|}
\hline \multirow[t]{2}{*}{ Variable } & \multirow[t]{2}{*}{$\begin{array}{l}\text { Unité } \\
\text { choisie }\end{array}$} & \multirow[t]{2}{*}{$\begin{array}{l}\text { Transfor- } \\
\text { mation } \\
\text { utilisée }\end{array}$} & \multirow[t]{2}{*}{ 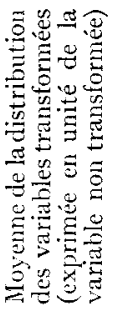 } & \multicolumn{2}{|c|}{$\begin{array}{c}\text { Dispersion de la dis- } \\
\text { tribution des valeurs } \\
\text { transformées (valeurs } \\
\text { extrêmes correspondant } \\
\text { à un intervalle } \\
\text { de confiance de } 95 \% \text { et } \\
\text { exprimées en unités } \\
\text { de la variable } \\
\text { non transformée) }\end{array}$} & \multirow{2}{*}{$\begin{array}{c}\text { Coefficient } \\
\text { de } \\
\text { variation } \\
\text { à partir } \\
\text { de la dis- } \\
\text { tribution } \\
\text { des va- } \\
\text { riables } \\
\text { trans- } \\
\text { formées } \\
(\%)(1)\end{array}$} \\
\hline & & & & minimum & maximum & \\
\hline Tenıpérature & degré $C$ & - & 8,03 & $-4,12$ & $+20,18$ & 2,16 \\
\hline Pression atmosph. .. & $m \mathrm{Hg}$ & - & 758,70 & 745,39 & $77^{2}, \mathrm{OI}$ & 0,88 \\
\hline Durée du jour.... & minute & 一 & 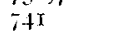 & 410 & I 072 & 22,27 \\
\hline Hygrométrie . . . . . & degré & - & 87,40 & 69,12 & 100 & 10,00 \\
\hline $\mathrm{K}$ alimentaire ...... & $\mathrm{g}$ & $\log$ & 109,2 & $5^{6,5}$ & 204,2 & 31,80 \\
\hline Na alimentaire .... & $s$ & - & 32,8 & 0 & $68, \mathrm{I}$ & 53,78 \\
\hline Ca alimentaire .... & 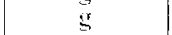 & $\log$ & 106,3 & $5^{2,}, \mathrm{I}$ & 239,6 & 36,88 \\
\hline$P$ alimentaire.... & $g$ & $\log$ & 43,7 & 22,8 & 83,7 & 33,09 \\
\hline $\mathrm{K}$ plasma........... & $\mathrm{g} /$ litre & - & 0,1854 & 0,156 & $0,2 I_{5}$ & 7,98 \\
\hline $\mathrm{Na}$ plasma ......... & $g /$ litre & $\ldots$ & $3, \mathrm{I}$ I I & 2,879 & 3,343 & 3,73 \\
\hline Ca sérique $\ldots \ldots \ldots$ & $111 \mathrm{~g} / 100 \mathrm{ml}$ & - & 10,031 & 8,277 & I I, 785 & 8,74 \\
\hline$P$ total sérique $\ldots \ldots$ & $\mathrm{mg} / \mathrm{roo} \mathrm{ml}$ & - & I 3,178 & 8,840 & 17,516 & 16,46 \\
\hline $\mathrm{P}$ minéral sang..... & $\mathrm{mg} / \mathrm{I} O \mathrm{\textrm {ml }} \mathrm{\textrm {ml }}$ & - & 5,693 & 3,574 & 7,819 & I 8,67 \\
\hline Ca urinaire $\left({ }^{2}\right) \ldots \ldots$ & g/litre & $\begin{array}{l}\text { racine } \\
\text { quatrieme }\end{array}$ & 0,0426 & 0,0064 & 0,3153 & $\mathrm{I} 43,3^{8}$ \\
\hline$P$ urinaire $(2) \ldots$ & $g /$ litre & $\begin{array}{l}\text { racine } \\
\text { quatrieme }\end{array}$ & 0,1297 & 0,0034 & $\mathrm{I}, 2 \mathrm{So} 5$ & I77,57 \\
\hline Ca fécal. & P. то0о (M.S.) & - & 24,868 & 9,370 & 40,366 & $3 I, I 6$ \\
\hline$P$ fécal. & p. 1000 (M.S.) & - & 10,217 & $3,59 \mathrm{I}$ & 16,843 & 32,43 \\
\hline $\mathrm{K}$ poil & p. J000 & $\log r$ & 0,0989 & 0,0394 & 0,2486 & 47,78 \\
\hline $\mathrm{Na}^{+}$poil..... & 1). 1000 & $\log$ & 0,1152 & $0,0,397$ & 0,3343 & $5^{6,86}$ \\
\hline$P$ poil $\ldots \ldots \ldots \ldots$ & 1). 1000 & $\log$ & $0,17 \mathrm{I} 4$ & 0,1317 & $0,223 \mathrm{I}$ & I 3,2 I \\
\hline Ca poil ..... & 1. 1000 & $\log$ & 0,3537 & 0,2114 & 0,5917 & 26,01 \\
\hline Mg poil. & 1). 1000 & $\log$ & $0,04 \mathrm{I} 7$ & 0, orI 7 & 0,1488 & 67,87 \\
\hline
\end{tabular}

(1) Ce coefficient de variation a été obtenu en rapportant la moitié de l'intervalle de confiance correspondant à un seuil de probabilité de $67 \%$ à la valeur centrale de la distribution figurant à la $4^{\mathrm{e}}$ colonne.

$\left({ }^{2}\right)$ Étant domé la très forte dissymétrie de la répartition de Ca et $\mathrm{P}$ urinaire (voir fig. 3 et 4), dissymétrie qui n'est que partiellement anéliorée par la transformation racine quatrième, il ne faut évidemment considérer les chiffres donnés pour ces variables que comme des indications générales.

La plupart des variables envisagées présentaient une courbe de répartition des fréquences différant nettement d'une courbe normale. Nous avons utilisé les transformations suivantes qui nous ont paru justifiées :

a) $\log x$ (courbe $\log$ normale ou logarithmico-normale (fig. 2), dans le cas $\mathrm{du}$ potassium alimentaire, du calcium alimentaire, du rapport $\mathrm{Ca} / \mathrm{P}$ fécal et de tous les dosages des minéraux des poils. 
b) $\sqrt{x}$ (courbe de répartition des fréquences caractéristiques d'une 1oi de Poisson $=$ fig. 3 ) dans le cas des rapports $\mathrm{Ca} \mathrm{P}$ alimentaire et urinaire, du calcium et du phosphore urinaires.

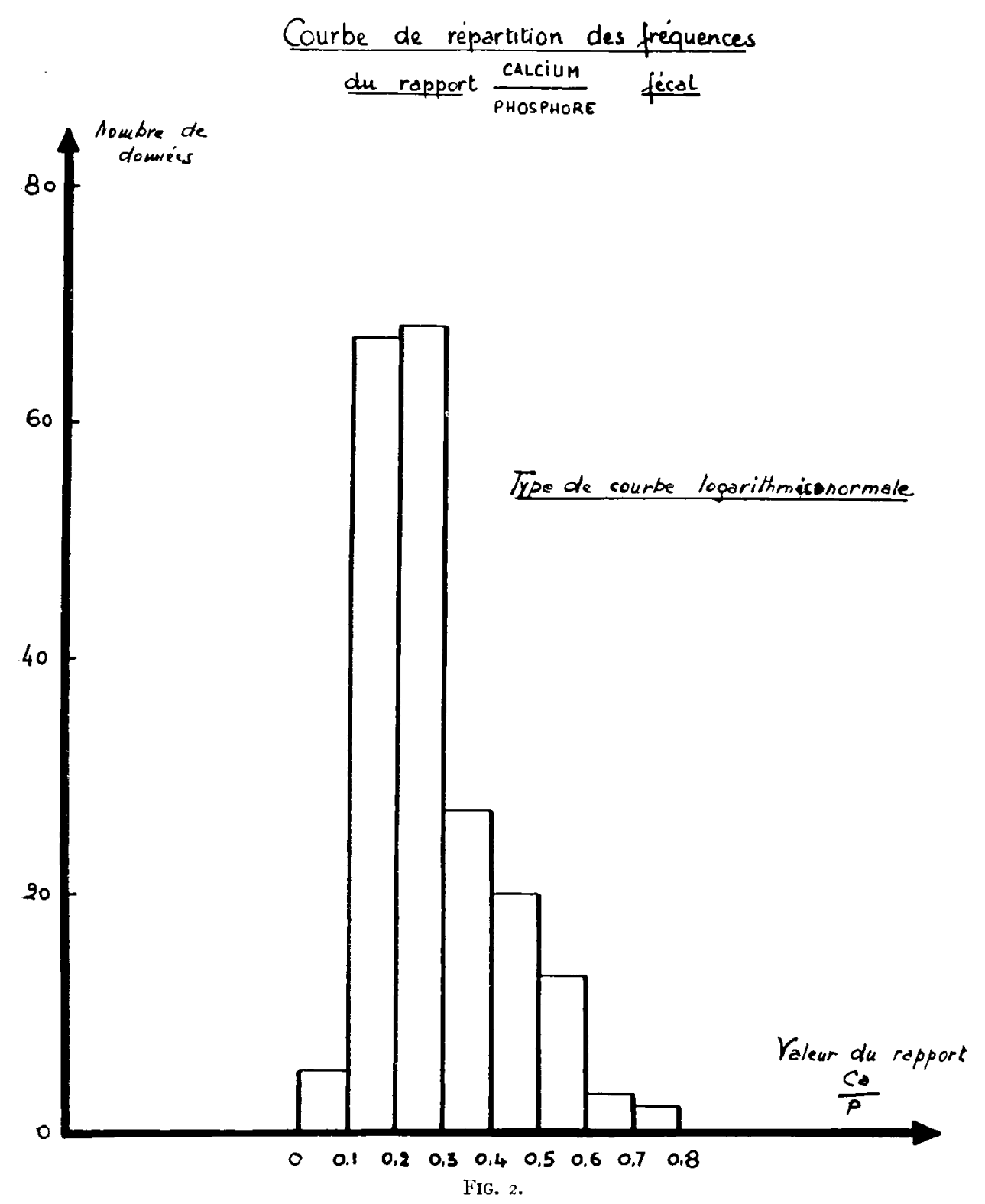

Dans ce dernier cas, toutefois, la transformation n'est que très approximative. L'examen de la courbe de répartition des fréquences du taux de phosphore urinaire (fig. 4) nous permet en effet de remarquer 


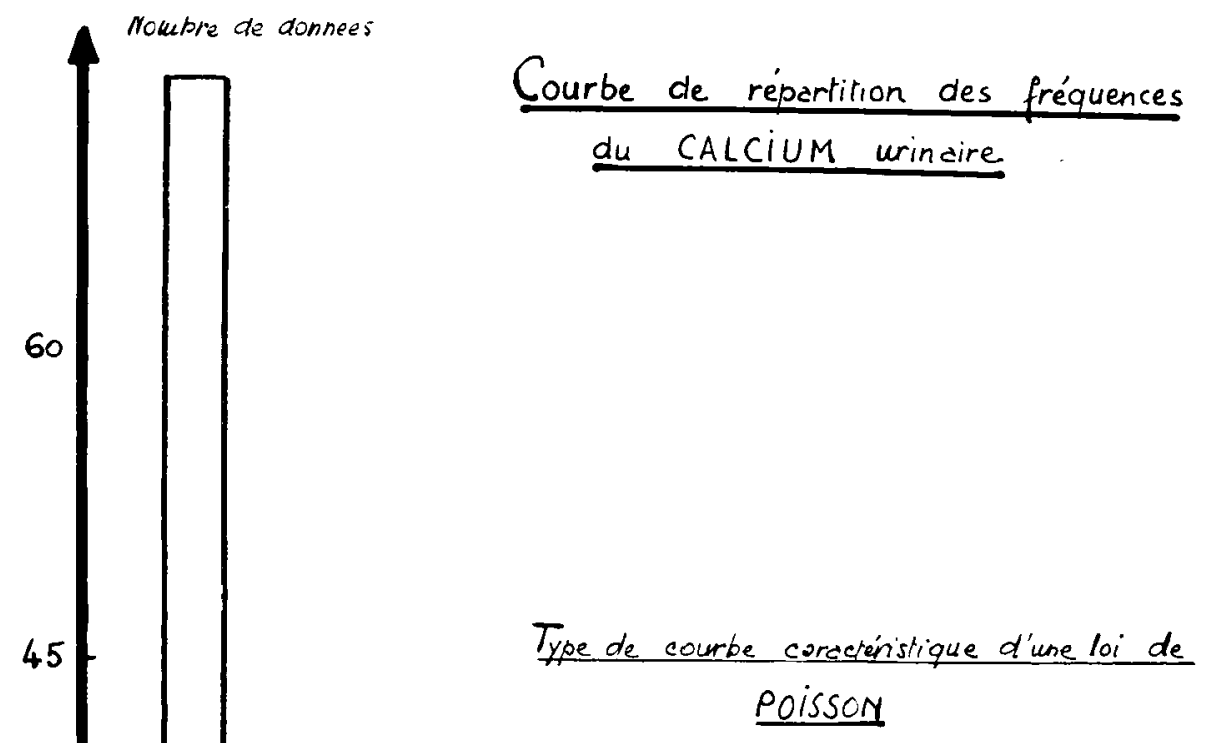




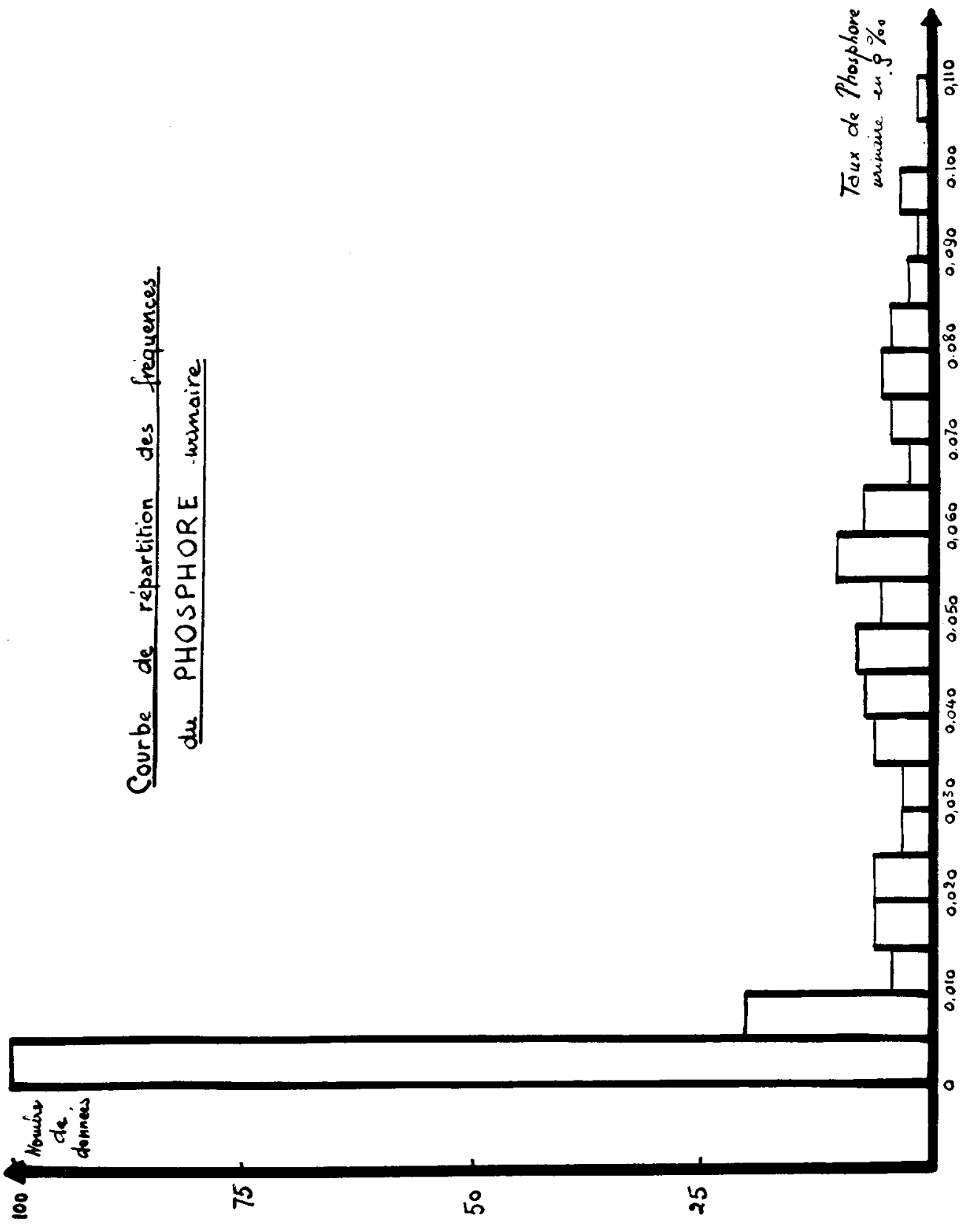

FIG. 4 . 
- un ensemble d'effets nombreux, dont les actions s'additionneraient comme dans le cas d'une variable normale, au-delà de ce seuil.

Le simple examen des courbes po répartition des fréquences peut,

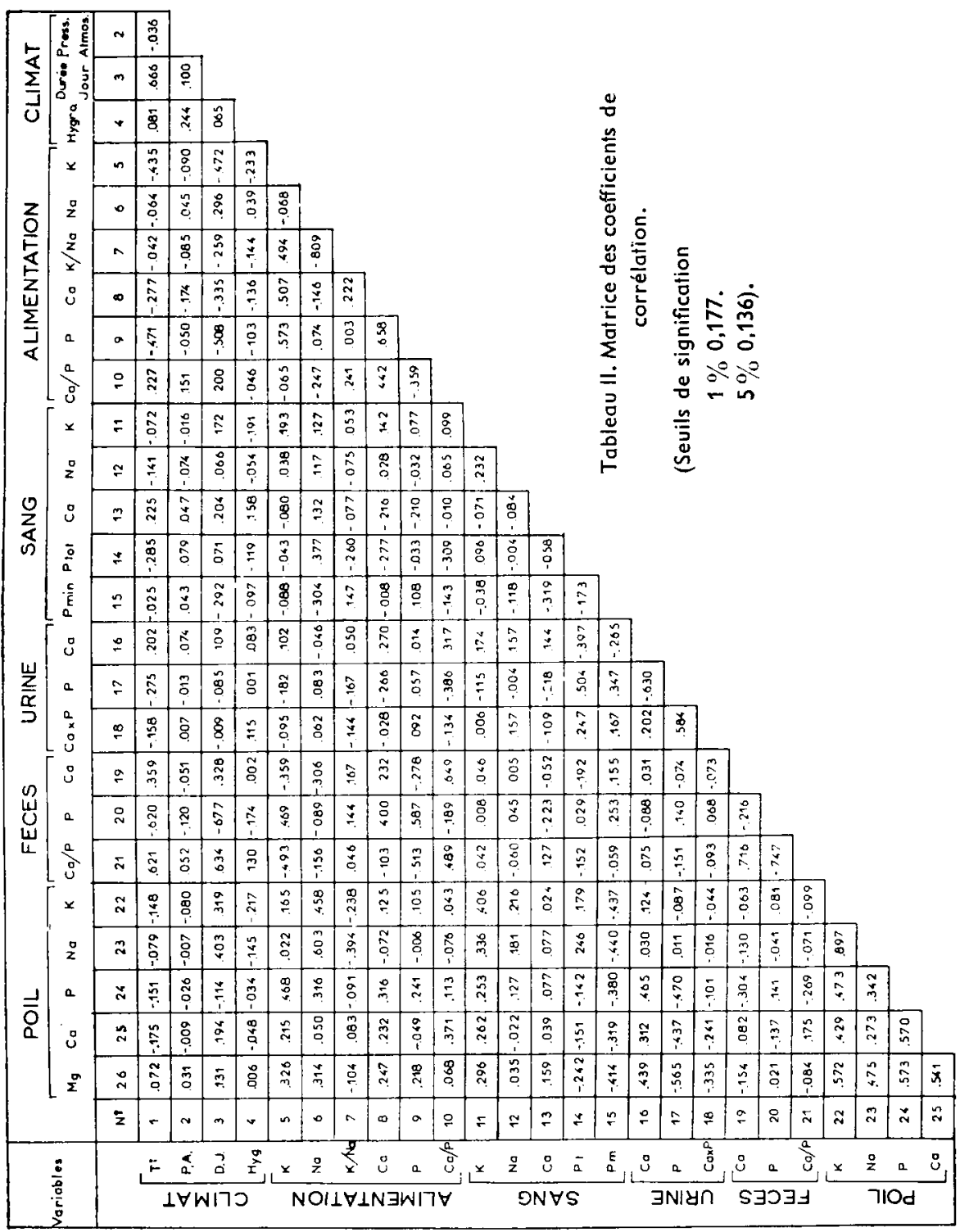

ainsi fournir un indice sur les modalités d'action des mécanismes qui régissent les variations des paramètres étudiés. On sait qu'une variable soumise à l'action d'un grand nombre de facteurs qui agissent indépendamment, dont les actions individuelles s'additionnent, et sont faibles, 

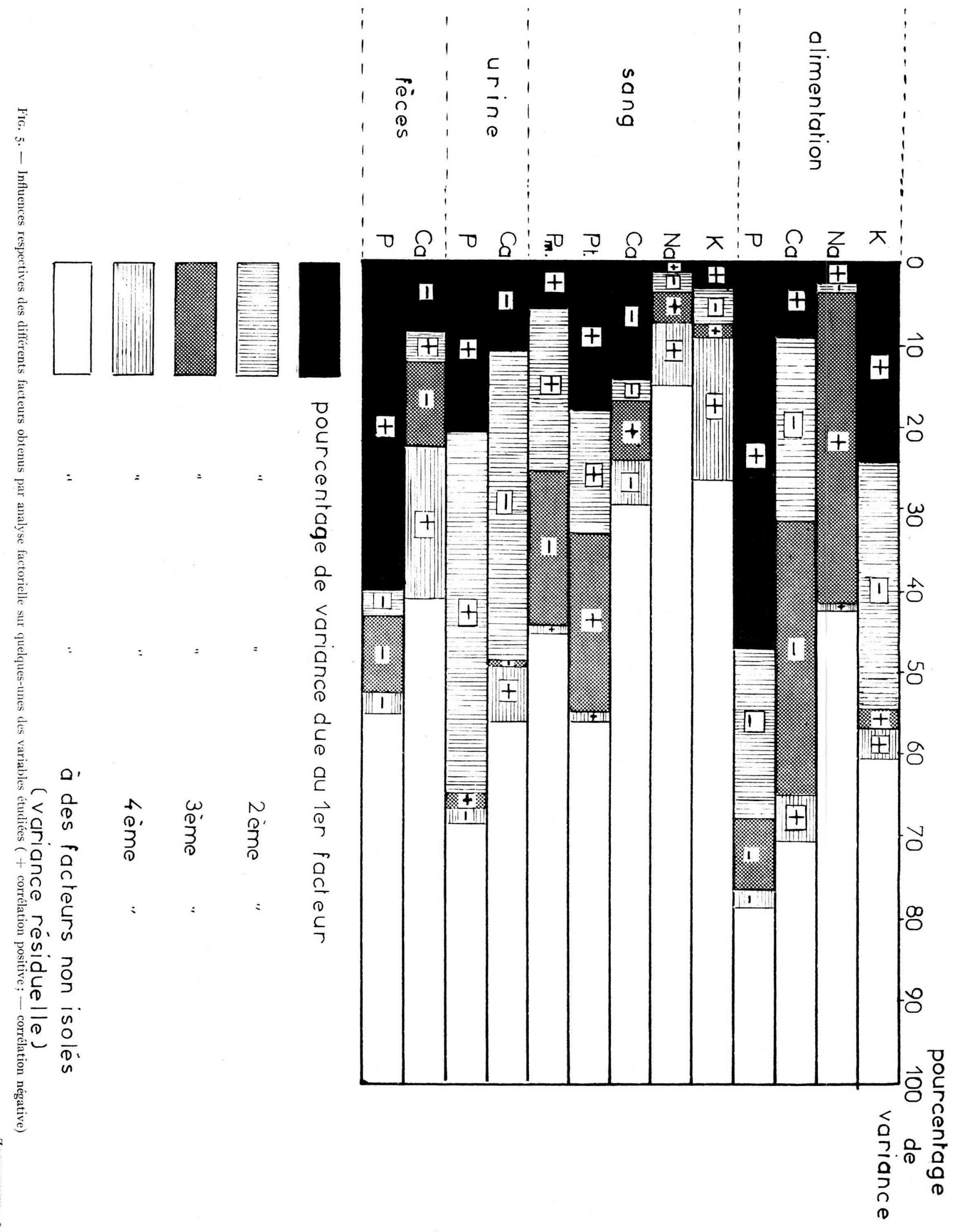
mise à l'analyse factorielle et chaque facteur extrait par cette analyse permet :

a) de calculer la part de variance due à chaque facteur dans la variance totale d'une variable;

\section{'TABLEAU III}

\section{Résultats de l'analyse factorielle.}

\begin{tabular}{|c|c|c|c|c|c|}
\hline $\begin{array}{l}\text { Numéro } \\
\text { de la } \\
\text { variable }\end{array}$ & $\begin{array}{c}\text { Facteur } \\
\text { I } \\
\text { (j)hosphore } \\
\text { alimentaire) }\end{array}$ & $\begin{array}{c}\text { Facteur } \\
2 \\
\text { (Activite } \\
\text { thyroidieme) }\end{array}$ & $\begin{array}{c}\text { Facteur } \\
3 \\
\text { (Catiacité } \\
\text { dassimilation) }\end{array}$ & $\begin{array}{c}\text { Facteur } \\
4 \\
\text { (Photopériode) }\end{array}$ & $\begin{array}{l}\text { Facteurs } \\
\text { non identifies }\end{array}$ \\
\hline K Alimentaire & $\begin{array}{r}+0,+96 \\
(24,60)\end{array}$ & $\begin{array}{r}-0,551 \\
(30,36)\end{array}$ & $\begin{array}{r}0, \mathrm{I}+\mathrm{I} \\
(\mathrm{I}, 99)\end{array}$ & $\begin{array}{r}0,195 \\
(3,80)\end{array}$ & $(.39,25)$ \\
\hline $\mathrm{Na} \stackrel{2}{2}$ Alimentaire & $+\underset{(2,72)}{0,165}$ & $\begin{array}{r}-0,098 \\
(0,96)\end{array}$ & $\begin{array}{r}0,616 \\
(37,95)\end{array}$ & $+\underset{(0,0,1)}{0,0-8}$ & $(57,76)$ \\
\hline Ca Alinientaire & $\begin{array}{r}0,302 \\
(9,10)\end{array}$ & $\begin{array}{r}-0,47,3 \\
(22,37)\end{array}$ & $\begin{array}{r}-0,580 \\
(3,3,64)\end{array}$ & $\begin{array}{r}0,2,34 \\
(5,48)\end{array}$ & $(29,41)$ \\
\hline P. Alimentaire & $\begin{array}{r}+0,687 \\
(47,20)\end{array}$ & $\begin{array}{r}0,454 \\
(20,6 \mathrm{I})\end{array}$ & $\begin{array}{c}0,290 \\
(8,+1)\end{array}$ & $\begin{array}{r}-0,1,32 \\
(1,74)\end{array}$ & $(22,04)$ \\
\hline K Plasma & $\begin{array}{r}+0,172 \\
(2,96)\end{array}$ & $\begin{array}{r}-0,21 \text { I } \\
(4,75)\end{array}$ & $\begin{array}{r}+0,125 \\
(1,56)\end{array}$ & $\begin{array}{r}+0,+17 \\
(17,39)\end{array}$ & $(7,3,64)$ \\
\hline $\begin{array}{c}6 \\
\text { Na Plasma }\end{array}$ & $\begin{array}{c}c, 098 \\
(0,06)\end{array}$ & $\begin{array}{r}0,16 \mathrm{I} \\
(2,59)\end{array}$ & $\begin{array}{r}0,191 \\
(3,65)\end{array}$ & $\begin{array}{r}+0,277 \\
(7,67)\end{array}$ & $(85,1,3)$ \\
\hline Ca Plasma & $\begin{array}{l}0,377 \\
(14,21)\end{array}$ & $\begin{array}{r}0,172 \\
\left(2,0 f^{6}\right)\end{array}$ & $\begin{array}{r}+0,267 \\
(7,1,3)\end{array}$ & $\begin{array}{r}-0,2,34 \\
(5,48)\end{array}$ & $(70,22)$ \\
\hline Pt sérique & $\begin{array}{r}-\quad 0,424 \\
(12,08)\end{array}$ & $\begin{array}{r}+\quad 0,391 \\
(15,29)\end{array}$ & $\begin{array}{r}+\quad 0,472 \\
(22,28)\end{array}$ & $\begin{array}{r}0,101 \\
(1,02)\end{array}$ & $(43,4,3)$ \\
\hline l'm Sang & $\begin{array}{c}+0,2,36 \\
(5,57)\end{array}$ & $\begin{array}{c}+0,+52 \\
(20,+3)\end{array}$ & $\begin{array}{c}0,+333 \\
(18,75)\end{array}$ & $\begin{array}{c}0,066 \\
(0,+3)\end{array}$ & $(54,82)$ \\
\hline Ca Lrine & $\begin{array}{l}-0,325 \\
(10,56)\end{array}$ & $\begin{array}{r}\cdots, 0,1227 \\
(39,31)\end{array}$ & $\begin{array}{r}0,0,57 \\
(0,32)\end{array}$ & $\begin{array}{c}0,278 \\
(7,7,3)\end{array}$ & $(42,06)$ \\
\hline $\mathrm{P} \stackrel{\mathrm{I} \mathbf{1}}{\mathrm{urine}}$ & $\begin{array}{c}+\quad 0,4,54 \\
(20,6) 1 \mathrm{I})\end{array}$ & $\begin{array}{r}+0,661 \\
(4,3,70)\end{array}$ & $\begin{array}{c}+0,1,50 \\
(2,2,5)\end{array}$ & $\begin{array}{r}-0,1,35 \\
(1,82)\end{array}$ & $(.31,62)$ \\
\hline Ca Fices & $\begin{array}{r}-0,284 \\
(8,07)\end{array}$ & $\begin{array}{r}0,192 \\
(3,60)\end{array}$ & $\begin{array}{r}-\quad 0,327 \\
(10,(x))\end{array}$ & $\begin{array}{r}+0,424 \\
(17,98)\end{array}$ & $(59,57)$ \\
\hline Prees & $\begin{array}{r}+0,6,35 \\
(40,32)\end{array}$ & $\begin{array}{r}-0,19,3 \\
(3,72)\end{array}$ & $\begin{array}{r}0,3 \mathrm{II} \\
\left(0, f_{7}\right)\end{array}$ & $\begin{array}{c}-0,158 \\
(2,50)\end{array}$ & $(+3,79$ \\
\hline $\begin{array}{l}\text { Rôle de chaque fat: } \\
\text { teur dans la va } \\
\text { riation totale (et } \\
\text { p. 100) } \ldots \ldots\end{array}$ & $\mathrm{I} 5, \mathrm{I}$ & ] $6,2 " 0$ & $12,2 \%$ & $5,7 \%$ & 50,8 \\
\hline
\end{tabular}

- Le chiffre supérieur indique la corrélation entre la variable et chaque facteur. Le chiffre inférieur entre parenthés is indique $l$ pourcentase de variance attribuable à chaque facteur dans la variance totale de thaque variable; ces pourcentages de variance et le signe de la corrélation sont représentés schématiquement sur la figure 5 . 
est répartie suivant une loi normale (phosphore minéral du sang par exemple). I-orsque ces facteurs de variation cumulent leurs effets de façon multiplicative, et non additive, la loi de variation est au contraire du type logarithmico-normale (rapport $\mathrm{Ca} / \mathrm{P}$ par exemple). On trouvera rassemblées sur le tableau I les caractéristiques principales de la distribution des diverses variables.

$2^{\circ}$ Calcul de l'importance respective des liaisons entre les teneurs minérales des divers éléments étudiés, et entre ces teneurs, d'une part, et les caractéristiques climatiques et alimentaires d'autre part.

La matrice des coefficients de corrélation entre les variables prises 2 à 2 est représentée sur le tableau II.

Afin d'obtenir une appréciation plus exacte des vraies relations directes entre deux variables, nous avons dî̀, dans certains cas, éliminer l'influence d'une variable dont l'action sur la fluctuation des deux variables étudiées était prépondérante, et pouvait induire indirectement une relation entre elles. Le coefficient de corrélation partielle entre deux variables $x, y$, une troisième variable $z$ étant maintenue constante, a été calculé par la formule :

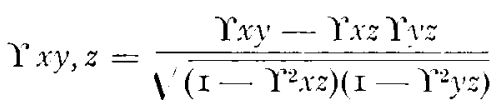

$\Upsilon x y, z=$ coefficient de corrélation partielle entre $x$ et $y$, à $z$ constant.

$\Upsilon^{2} x y, I^{2} x z, \quad Y y z=$ coefficients de corrélation entre $x$ et $y, x$ et $z$, $y$ et $z$.

Dans d'autres cas, nous avons caractérisé l'importance des fluctuations d'une variable donnée en fonction de celles de 2,3 ou, en général, plusieurs variables, par le coefficient de corrélation multiple.

$3^{\circ}$ Analyse factorielle. - Celle-ci constitue une voie d'approche permettant de déceler d'une façon globale les mécanismes qui commandent les relations entre les variables, telles qu'elles sont analysées par la matrice du tableau II (SEWALL WRIGHT, CATTELI).

La difficulté d'interprétation des liaisons existant entre des grandeurs de même nature (dosages de minéraux, par exemple) vient du fait que l'on a affaire à des variables qui sont toutes plus ou moins liées entre elles, sous l'influence de mécanisnes organiques dont elles constituent un reflet, mais qu'on ne peut pas contrôler directement. I'analyse factorielle permet justement de passer d'un système de variables contrôlables et dépendantes en un système de variables indépendantes mais hypothétiques, ou "facteurs", que l'on assimile aux mécanismes " sousjacents " qui commandent les relations entre les rariables. Le calcul et la comparaison des coefficients de corrélation entre chaque variable sou- 
b) de déterminer l'importance globale de chaque facteur dans la fluctuation d'ensemble de toutes les variables étudiées.

Le physiologiste peut, à l'examen de ces résultats, émettre des hypothèses sur la nature même des facteurs : action alimentaire, climatique, mécanisme endocrinien, etc...

L'extraction des divers facteurs de l'analyse factorielle a été effectuée sur ordinateur I. B. M. 704, par la méthode centroïde de Thurstone.

$4^{\circ}$ Identification des facteurs. - Parmi les 26 variables qui ont été envisagées pour établir la matrice des coefficients de corrélation, nous avons sélectionné I3 grandeurs de même nature, qui ont été soumises à l'analyse factorielle (résultats de dosages de minéraux). Nous avons notamment éliminé de ce calcul les rapports $\mathrm{Ca} / \mathrm{P}$ et $\mathrm{K} / \mathrm{Na}$, les caractéristiques climatiques, et les dosages minéraux des poils, qui n'avaient été effectués qu'avec une périodicité bi-mensuelle.

Nous avons représenté sur le tableau III les coefficients de corrélation entre chaque variable et chacun des 4 premiers facteurs extraits par l'analyse factorielle. (Six facteurs ont été extraits, mais quatre seulement ont pu être identifiés.) Les pourcentages de variance attribuables à chaque facteur dans la variance totale de chaque variable, d'une part, et de l'ensemble des variables, d'autre part, sont également représentés sur ce tableau, et schématisés sur la figure 5 .

Après avoir essayé, dans un but de synthèse, d'identifier les facteurs obtenus par l'analyse factorielle, nous analyserons dans le détail leurs influences, ainsi que les relations existant entre les diverses variables, telles qu'elles apparaissent à l'examen de la matrice des coefficients de corrélation. On voit que, sur l'ensemble des données (tableau III), le facteur d'ordre I intervient pour I5,I p. Ioo dans la variation totale, le facteur d'ordre 2 pour I6,2 p. IOO, le facteur d'ordre 3 pour I2,2 p. Ioo, et le facteur d'ordre 4 pour 5,7 p. Ioo. Nous laisserons de côté les facteurs d'ordre 5 et 6 que nous n'avons pas pu interpréter valablement, et qui ne représentent que 3,5 et 2,7 p. Ioo de la variation totale. Ces chiffres permettent d'ores et déjà de penser qu'un grand nombre de mécanismes et d'influences doivent être invoqués pour expliquer les fluctuations de nos variables, et qu'une part importante de celles-ci échappera à l'analyse. I es 4 premiers facteurs ne rendent compte en effet que de $50 \mathrm{p}$. Ioo de la variation totale que l'on caractériserait de façon complète avec $\mathrm{I}_{3}$ facteurs. Il n'existe pas, en outre, contrairement à ce qui est souvent le cas dans de telles analyses, de facteur général ou primaire prédominant, les trois premiers facteurs ayant une influence sensiblement équivalente.

Nous allons, en premier lieu, essayer d'identifier les 4 premiers facteurs à des influences extérieures (nutritionnelles ou climatiques) ou 
aux nécanismes physiologiques responsables de la variation des teneurs en minéraux.

$I^{\circ}$ FACTEUR $\mathrm{N}^{0} \mathrm{I}$.

Le facteur $n^{\circ}$ I présente les coefficients de corrélation les plus élevés en valeur absolue avec le $P$ alimentaire et le $P$ fécal ; il exerce une influence notable sur le $P$ total sérique, le $P$ urinaire. Il est en corrélation positive avec $\mathrm{K}$ alimentaire. I1 est à noter également qu'il exerce une influcuce négative sur tous les témoins du métabolisme calcique (plasma, urine, fèces). Il est vraisemblable que ce facteur pourrait être le $\mathrm{P}$ alimentaire lui-même, tant en raison de la corrélation très élevée qu'il présente avec ce dernier, que de sa variation concomitante avec $\mathrm{K}$ alimentaire, et de l'influence négative qu'il exerce, à tous les niveaux, sur le métabolisme calcique. I a relation négative entre $\mathrm{Ca}$ et $\mathrm{P}$ sériques correspond à la donnée classique de la constance du produit $\mathrm{Ca} \times \mathrm{P}$ sériques ; nous avons démontré (I,ARVOR et BROCHART, I959) que cette relation a sa traduction au niveau urinaire. La réduction du $\mathrm{Ca}$ fécal ne peut résulter d'une absorption accrue du $\mathrm{Ca}$ alimentaire, car, dans ce cas, on devrait observer une augmentation du Ca sérique; cette baisse du Ca fécal provient plus vraisemblablement de la réduction du Ca fécal endogène, qui résulte logiquement de la baisse du Ca sérique. Ainsi, en présence d'un apport phosphorique et calcique supérieur aux besoins, on observe une assimilation préférentielle du phosphore, entrainant la réduction du Ca sérique et urinaire.

$2^{\circ}$ FACTEUR $\mathrm{N}^{\mathrm{O}} 2$.

I,e deuxiène facteur se caractérise tout d'abord par une forte relation négative avec trois minéraux alimentaires $(\mathrm{Ca}-\mathrm{P}-\mathrm{K})$ sur quatre. On verra que les apports alimentaires en $\mathrm{Ca}, \mathrm{P}, \mathrm{K}$ ont varié au cours de notre expérience selon un cycle apparemment annuel (fig. 6), avec un maximum d'apports au cours de l'hiver et en début de printemps. L,e facteur 2 pourrait donc être soit un facteur alimentaire en corrélation négative simultanée avec $\mathrm{Ca}, \mathrm{P}, \mathrm{K}$ alimentaires, soit un facteur saisonnier tel que la température, dont le cycle d'évolution est en corrélation négative avec le cycle des apports alimentaires. Par ailleurs, le niveau des apports alimentaires en $\mathrm{Ca}, \mathrm{P}, \mathrm{K}$ a été presque constamment plus élevé pour le couple I-III que pour le couple E-S. I es corrélations observées entre le facteur 2 et les apports en $\mathrm{Ca}, \mathrm{P}, \mathrm{K}$ pourraient donc traduire un comportenient différent des deux couples de vaches utilisés; cette dernière hypothèse est la plus vraisemblable. En effet, le couple E.-S a présenté presque constamment au cours de l'expérience un phosphore sérique total et un $\mathrm{P}$ urinaire supérieurs à ceux du couple I-III (fig. 6 bis) alors que ce dernier couple a présenté une calciurie toujours supérieure 
à celle du couple E-S. Or le facteur 2 est en corrélation fortement positive avec $\mathrm{P}$ total sérique et $\mathrm{P}$ urinaire, et fortement négative avec la calciurie. Le facteur 2 est donc un facteur apparemment lié au couple,
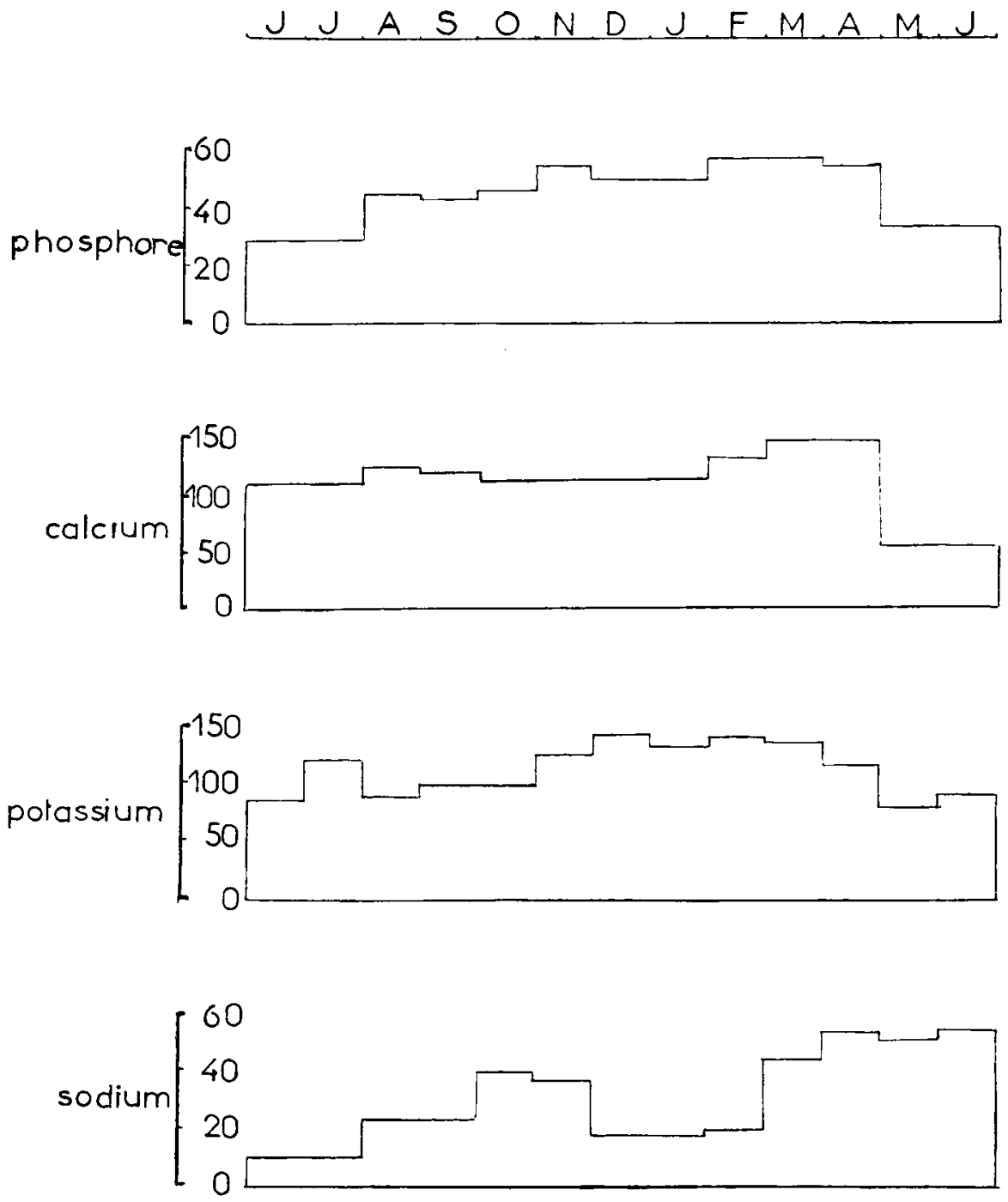

Fig. 6. - Evolution des apports alimentaires (en grammes) au cours de la période expérimentale (moyennes mensuelles).

et ayant une puissante action au niveau du $\mathrm{P}$ total sérique et de $\mathrm{P}$ et $\mathrm{Ca}$ urinaires.

L'identification du facteur 2 nous a été facilitée lorsque nous avons examiné l'évolution du $\mathrm{P}$ sérique total et du $\mathrm{P}$ urinaire pour chaque couple de jumelles, et en poursuivant cet examen au delà de la période 
expérimentale d'un an ayant fait l'objet du présent travail, soit jusqu'en décembre I958, la phase de croissance (couple E-S), ou le cycle de production laitière (couple I-III), étant achevés à cette date (fig. 6 bis).

On observe que pour le couple E-S le phosphore sérique total et le $\mathrm{P}$ urinaire ont été élevés tant que ces génisses ont augmenté de poids,

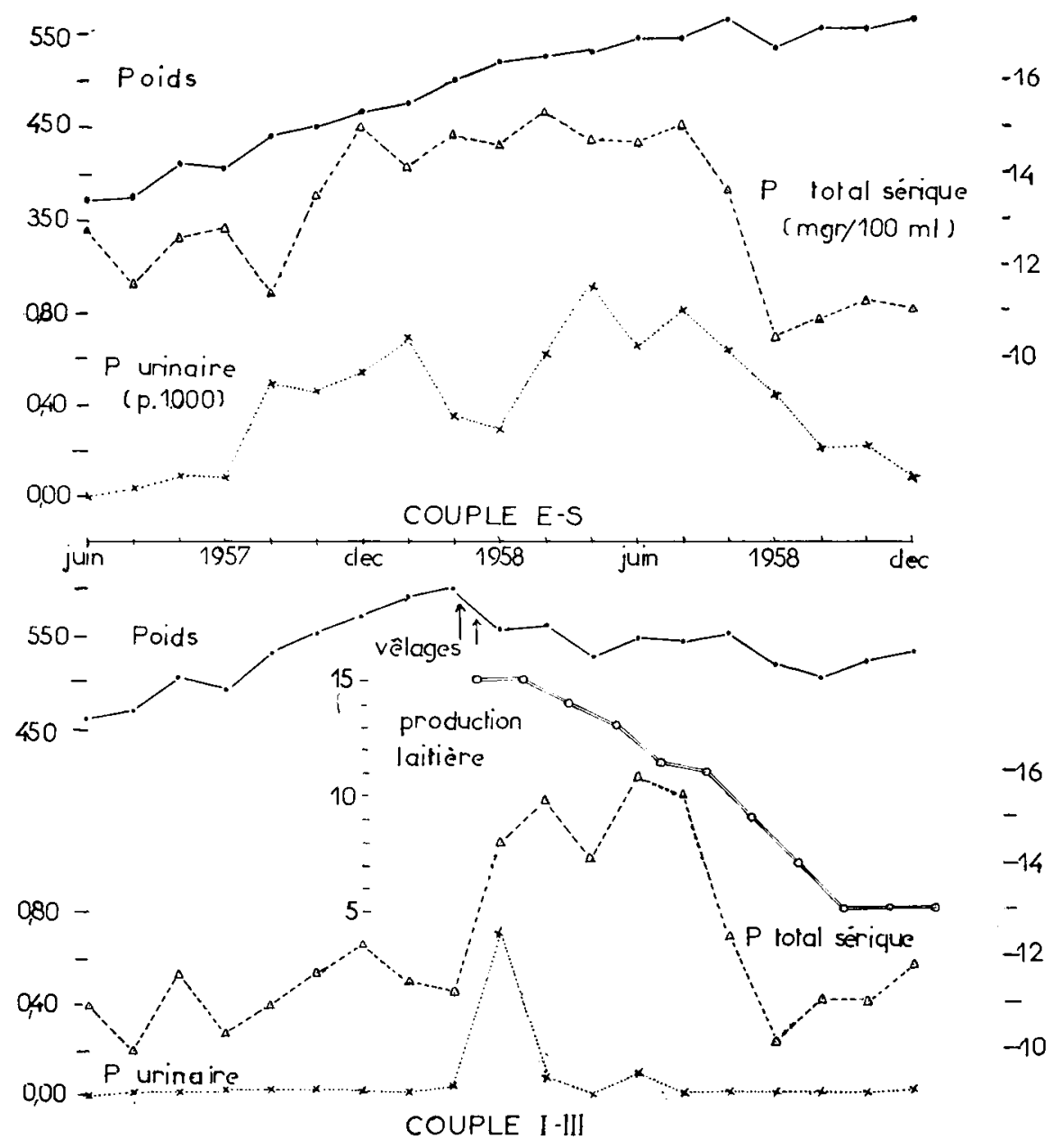

FIG. 6 bis.

et que ces deux variables ont baissé rapidement dès que la croissance a été achevée. Le couple I-III n'a présenté une augmentation notable du P sérique total qu'au cours des quatre premiers mois de lactation, le $\mathrm{P}$ urinaire ne présentant qu'une courte période de fortes valeurs (la compétition de la mamelle pour le $\mathrm{P}$ explique sans doute la briéveté de la phosphaturie élevée observée). Il apparait ainsi que l'évolution 
du $\mathrm{P}$ sérique total, et, secondairement, du $\mathrm{P}$ urinaire, est fonction pour une part de l'activité métabolique. Par ailleurs, le synchronisme de la chute du $\mathrm{P}$ sérique total en août 1958 et de la remontée de celui-ci à partir d'octobre, observées chez les deux couples, suggère une influence saisonnière. Il nous paraît donc licite d'identifier le facteur 2, qui est lié à l'activité métabolique et à la saison, à l'activité thyroïdienne. A 1'appui de cette hypothèse, nous citerons les travaux d'OWEN (I948) qui a démontré chez la vache que la thyroxine améliore le bilan phosphorique tout en augmentant la phosphaturie.

\section{$3^{\circ}$ FACTEUR N $N^{0} 3$.}

Ce facteur est en corrélation positive avec $\mathrm{Na}$ alimentaire, et négative avec $\mathrm{Ca}$ et $\mathrm{P}$ alimentaires. Au niveau sanguin, son action tend à augmenter le $\mathrm{P}$ total sérique et, dans une moindre mesure, le Ca sérique et le Na plasmatique, et à diminuer le $\mathrm{P}$ minéral. Son action au niveau urinaire est négligeable; au niveau fécal, il exerce une action négative sur $\mathrm{Ca}$ et $\mathrm{P}$. On se trouve donc en présence d'un facteur dont l'action prépondérante

\section{TABLEAU IV}

\section{Influence des apports alimentaires en $\mathrm{Na}$ et $\mathrm{K}$ sur quelques constantes sanguines.}

\begin{tabular}{|c|c|c|c|c|c|c|c|c|c|}
\hline \multirow{2}{*}{ Auteurs } & \multirow{2}{*}{ Date } & \multirow{2}{*}{$\begin{array}{c}\text { Minéral } \\
\text { Alimentaire } \\
\text { Considéré }\end{array}$} & \multirow{2}{*}{ Espèces } & \multicolumn{6}{|c|}{ Effets plasmatiques } \\
\hline & & & & $\mathrm{Na}$ & $\mathrm{Cl}$ & $\mathrm{K}$ & $\mathrm{Ca}$ & $\mathrm{P}$ & $\mathrm{Mg}$ \\
\hline BERndT \& Coll. . & I934 & $\mathrm{K}+$ & vache & & & & & & \\
\hline Dennis $\&$ Coll.......... & 1948 & $\mathrm{KCl} 300 \mathrm{~g} / \mathrm{j}$ & vache & & & $=$ & $=$ & & \\
\hline PEARson \& Coll. ...... & 1949 & $\mathrm{~K} 5 \%$ de ration & mouton & & & + & $=$ & & $=$ \\
\hline Curme \& Coll. ........ & I949 & $\mathrm{K}_{4} \%$ de ration & mouton & & & $=$ & $=$ & & \\
\hline PISTOR \& Coll. ......... & $195^{\circ}$ & $\mathrm{SaCl}+45^{\circ} \mathrm{g} / \mathrm{j}$ & vache & & $=$ & $=$ & & & \\
\hline MeYjer \& Coll. . . & $195^{\circ}$ & $\mathrm{Na}+5 \%$ & rat & $=$ & & & & & \\
\hline MeYer \& Coll. . & I950 & $\mathrm{K}+5 \%$ & rat & $\overline{=}$ & - & $=$ & & & \\
\hline NELSON \& Coll. . & I95 I & $\mathrm{NaCl}+400 \mathrm{~g} / \mathrm{j}$ & vache & $=$ & $\bar{t}$ & $=$ & & & \\
\hline EАTоN \& Coll. ........ & $195^{2}$ & $\mathrm{~K}_{3,2} \%$ de ration & mouton & & & $=$ & - ou $=$ & & \\
\hline DANIEL \& Coll......... & 1952 & $\mathrm{KCl} 7,7 \%$ de ration & mouton & $=$ & & + & $=$ & $=$ & $=$ \\
\hline Kunkel \& Coll. ....... & $\mathrm{I} 953$ & $\mathrm{~K} 5 \%$ de ration & mouton & $=$ & & $=$ & $+\mathrm{ou}=$ & & - \\
\hline Toussaint \& Coll..... & I 953 & $\begin{array}{l}\mathrm{NaCl}+.5 \% \\
\text { de ration }\end{array}$ & rat & + & & $=$ & & & \\
\hline Meyer \& Coll. . & I 954 & $\begin{array}{l}\mathrm{NaCl} 13 \% \\
\text { de ration }\end{array}$ & mouton & $=$ & + & $\overline{=}$ & & & \\
\hline
\end{tabular}


tend à augmenter $\mathrm{P}$ total et $\mathrm{Ca}$ sérique, en dépit d'une réduction des apports alimentaires phosphocalciques, ce qui suggère que ce pourrait être un facteur efficace d'assimilation. Divers auteurs ont signalé un effet positif général du sodium sur les mécanismes d'assimilation (RIGGs et coll. I95I ; AINLS et SMI'H, I957), ce qui expliquerait la corrélation positive entre ce facteur et l'apport alimentaire sodique. Par ailleurs, il a été observé chez de nombreuses espèces de laboratoire (NICOLAyssen et coll. I953), et chez les bovins (BODA et CoLE. I956), que la réduction des apports calciques et phosphoriques accroit le coefficient d'utilisation de ces éléments, ce qui expliquerait les corrélations négatives entre le facteur 3 et les apports alimentaires phospho-calciques. Nous pensons donc qu'il est licite d'assimiler ce facteur à la capacité d'assimilation intestinale, elle-même fonction des apports sodiques et phospho-calciques.

I a corrélation négative entre le facteur 3 et le $\mathrm{P}$ minéral sanguin est plus difficile à expliquer. I'apport sodique a été le plus souvent associé à un apport de chlore (sous forme de $\mathrm{Cl} \mathrm{Na}$ ) ; il est possible que la réduction du $\mathrm{P}$ minéral sanguin soit le fait de l'ion chlore. Plusieurs auteurs (tableau IV) ont en effet observé que l'apport de sel ne modifiait pas sensiblement le sodium plasmatique, ce que nos observations confirment, mais augmentait le chlore plasmatique. On peut penser que l'augmentation du taux d'ions $\mathrm{Cl}^{-}$a pour effet, par un mécanisme de régulation acidobasique du sang, de réduire la quantité d'ions $\mathrm{PO}_{4}^{--}$. Un telantagonisme entre $\mathrm{Cl}^{-}$et $\mathrm{PO}^{---}$a été observé au niveau urinaire par IARVOR et BROCHART ( I959), qui ont observé une corrélation négative entre le chlore et le phosphore urinaire, corrigé en fonction de la matière sèche $(r=-0,72$; significatif à 5 p. Ioo - seuil à I p. IOO : - 0,73 ).

\section{$4^{\circ}$ FACTEUR No 4 .}

Le facteur 4 intervient pour une part nettement plus faible que les trois facteurs précédents dans la variation générale $(5.7 \mathrm{p}$. Ioo) ; il présente une corrélation positive élevée avec le $\mathrm{K}$ et le $\mathrm{Na}$ plasmatiques, ainsi qu'avec le Ca fécal et le Ca urinaire, et est en corrélation négative avec le Ca sérique. L'examen des courbes d'évolution saisonnière de $\mathrm{K}$, $\mathrm{Na}$ du sang, confrontées avec l'évolution des différents facteurs saisonniers (fig. 7), montre que la photopériode (que nous avons ici chiffrée comme étant l'allongement ou la diminution de la durée du jour au cours de chaque mois) est bien liée à ces teneurs minérales du plasma. Nous verrons, lors de la discussion sur l'influence de la température, que les modifications de $\mathrm{Na}$ et $\mathrm{K}$ du plasma sont en relation avec le volume circulant, lui-même modifié par la secrétion de 1'A. D. H. SJosTRAND (I953) a observé l'augmentation du volume sanguin chez quatre femmes pendant le passage de l'hiver au printemps, mais il signale que ces variations 
n'ont suivi que de très loin les variations de température, et il en conclut que la durée du jour est l'agent causal. Cependant Bass et Henscher (1956) font remarquer que l'examen des domées de SJostravi montre que les volumes sanguins les plus élevés surviennent 4 mois avant la
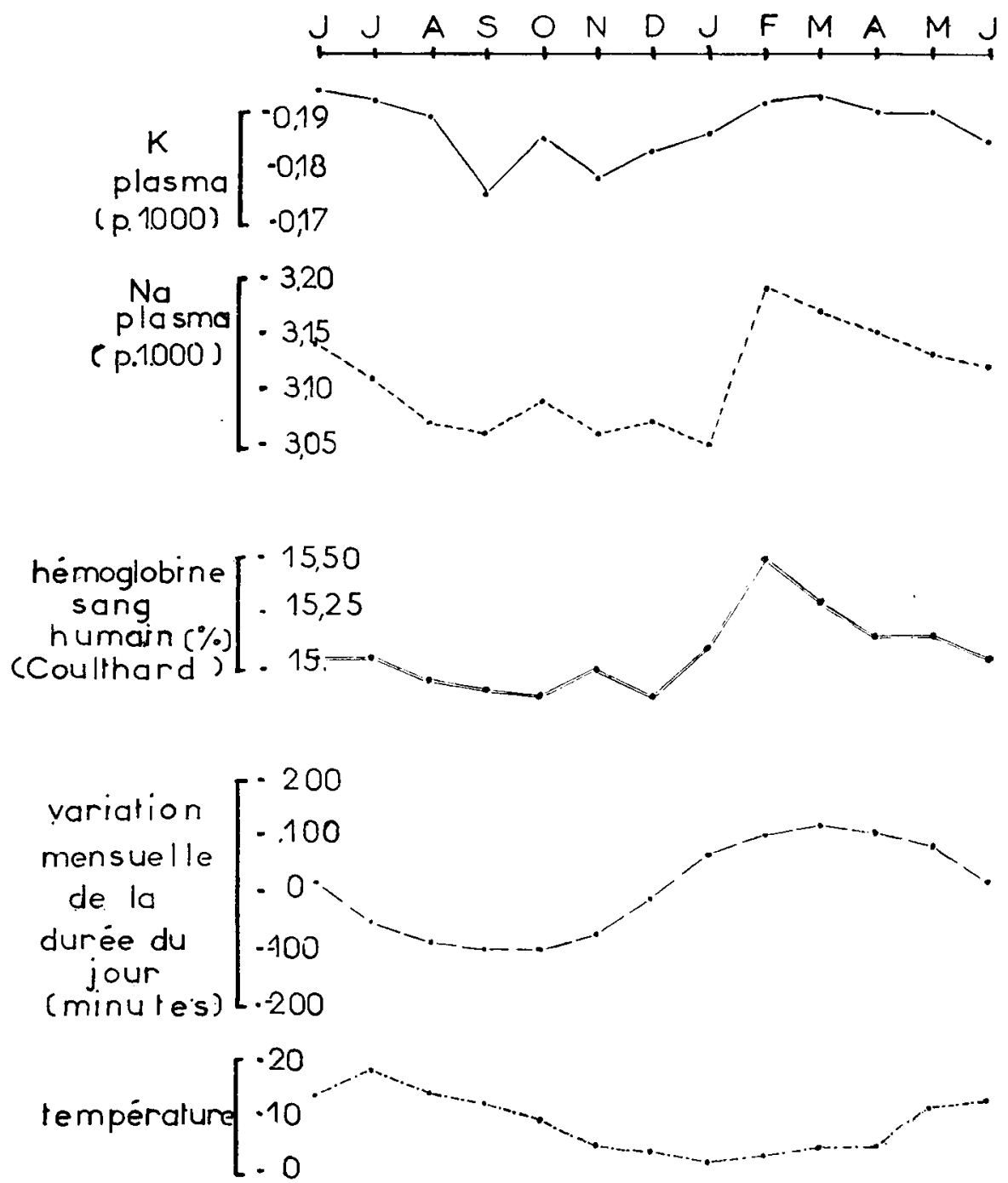

Fig. 7.- Evolution saisonnière de $\mathrm{Na}$ et $\mathrm{K}$ plasmatique.

Relation avec la photopériode.

durée du jour maximum. Il est tout à fait remarquable que cette période, qui correspond également aux valeurs maximum du Na et du $\mathrm{K}$ plasmatiques dans nos recherches, est celle où le taux d'accroissement de la durée du jour est le plus élevé. De même, le taux d'hémoglobine du sang humain 
tel que CoulthaRD (I948) 1'a calculé sur des milliers de dosages effectués, par lui ou d'autres auteurs, présente une courbe de variation tout à fait similaire. Ia figure 7 permet de comparer ces différentes données, et la coïncidence étroite entre des travaux d'ordre aussi divers ne permet pas de douter du rôle décisif de la photopériode.

Nous avons également remarqué que, chez nos bovins, la mue débutait en février, donc en même temps que d'importantes variations plasmatiques. Or, il est parfaitement établi, chez la jument (BurkHardT, I947), et chez la vache (IAING, I948), que la mue est en relation étroite avec la photopériode. Cet ensemble de résultats nous amène à identifier le facteur $n^{\circ} 4$ (qui intervient pour 8 p. Ioo de la variation du $\mathrm{Na}$ plasmatique et pour I7 p. roo de la variation du $\mathrm{K}$ ) à un phénomène saisonnier de nature endocrinienne, probablement la sécrétion d'A. D. H. post hypophysaire, elle-même très étroitement sous la dépendance de la photopériode (et peut-être, dans une moindre mesure, de la température).

Par ailleurs, Brown et Coll. (I943) chez l'homme, et Crarg et GADD chez le cheval, ont noté une variation saisonnière de la concentration des protéines du plasma, qui semble se faire presque exactement en sens inverse de la variation de $\mathrm{Na}$ et de l'hémoglobine.

L'influence du facteur 4 sur le métabolisme calcique tend à augmenter l'élimination calcique urinaire et fécale et à réduire le calcium sérique. $\mathrm{Il} \mathrm{y}$ a donc une influence saisonnière qui au moment de l'augmentation de la photopériode tend à réduire l'assimilation du calcium ; il est possible que l'activité thyroïdienne soit en cause, puisque la thyroxine a pour effet de rendre négatif le bilan calcique (OWE,N, I948).

\section{B. - Influence des facteurs saisonniers.}

Nous avions étudié primitivement l'influence de quatre facteurs saisonniers : température, pression atmosphérique, durée du jour et hygrométrie. Par la suite, nous avons été amenés à envisager également la photopériode, dont le rôle semble réellement primordial.

Ces facteurs ont été étudiés sans transformation, les trois premiers parce qu'ils ont une répartition normale (suivant une courbe de Gauss), et l'hygrométrie parce que nous n'avons pas pu trouver une transformation satisfaisante. Pour la température, la pression atmosphérique et l'hygrométrie, il s'agit d'observations hebdomadaires faites à l'Observatoire Géophysique du Parc Saint Maur, à 6 heures G.M.T.

Il y a évidemment une corrélation très élevée entre la durée du jour et la température $(+0,666)$, ce qui va rendre délicate l'interprétation de certaines corrélations, et, notamment, 1'attribution d'une action précise à l'un ou l'autre de ces deux facteurs. Par contre, la corrélation 
positive significative hygrométrie-pression atmosphérique ne compliquera pas l'interprétation, car ces deux variables semblent avoir une influence minime sur la composition minérale.

\section{I0 Corrélations entre les facteurs saisonniers et l'alimentation.}

Nous avons été surpris de constater qu'il existait une corrélation souvent hautement significative entre les facteurs saisonniers et I'alimen-

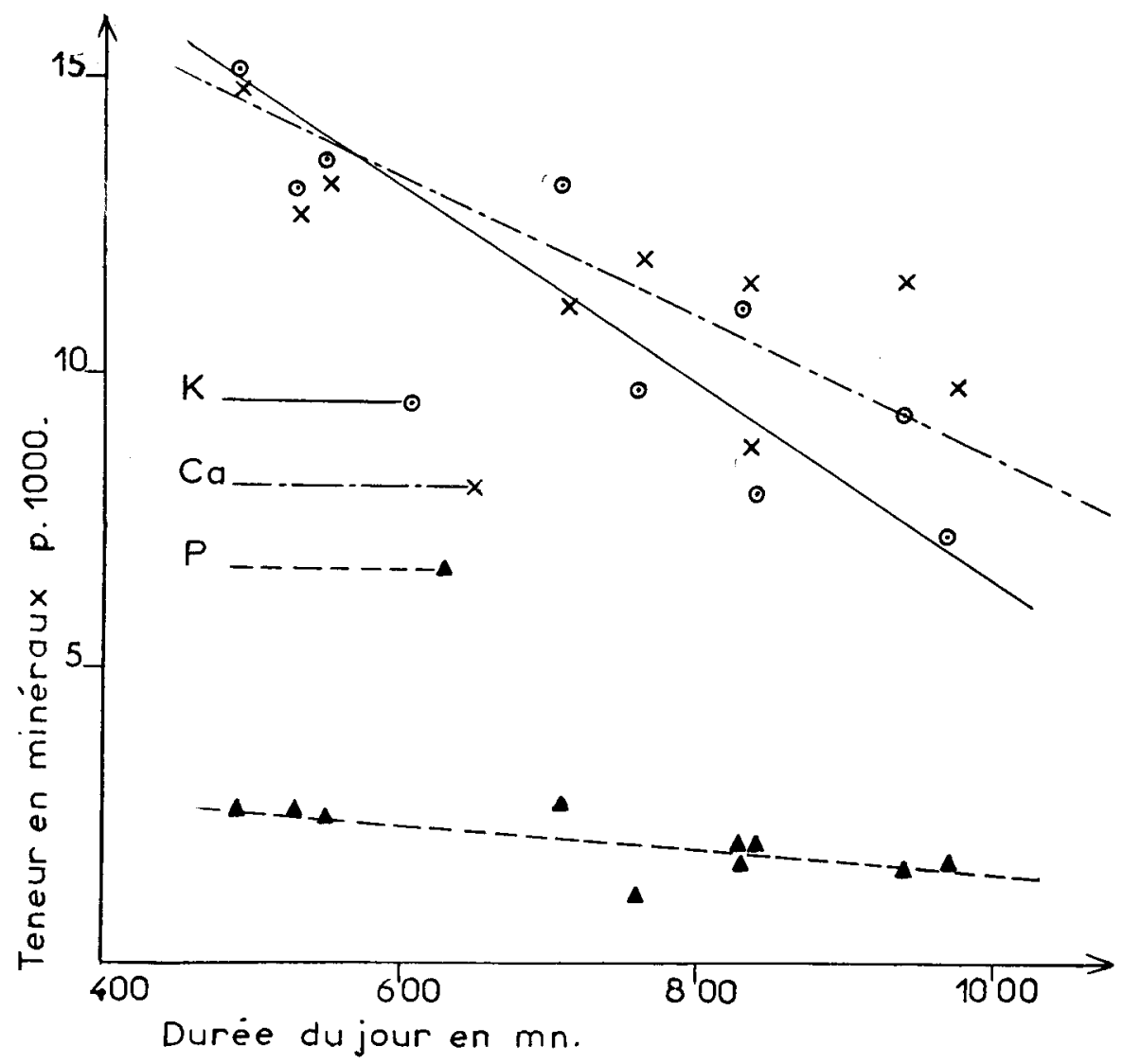

FIG. 8. - Corrélation entre la teneur en Ca, $\mathrm{P}$ et $\mathrm{K}$ des foins de luzerne et la durée du jour au moment de leur livraison.

tation minérale (tableau II) ; 1'examen des causes possibles de ces liaisons statistiques nous a montré qu'elles étaient dues, pour une large part, à la composition minérale des différents foins de luzerne qui nous furent fournis. La figure 8 montre la relation négative étroite qui lie la teneur en calcium, phosphore et potassium, des fourrages consommés avec la durée du jour au moment de l'arrivage, donc de la consommation, (notre fourrage étant renouvelé presque tous les mois). Les durées du jour courtes 
correspondent à des fourrages stockés depuis plusieurs mois, alors que les durées du jour longues correspondent à des fourrages récoltés depuis peu ; la durée du jour n'est donc en fait qu'une manière d'exprimer le temps de stockage de ces fourrages. I'explication de cette relation nous semble devoir être trouvée dans la perte de poids que subissent les four-

TABLEAU V

Influence de la température sur le volume des liquides biologiques et leur concentration

\begin{tabular}{|c|c|c|c|c|c|}
\hline Auteurs & Année & Espèce & $\begin{array}{l}\text { Conditions } \\
\text { expérimentales }\end{array}$ & $\begin{array}{l}\text { Modifications } \\
\text { de volume }\end{array}$ & $\begin{array}{l}\text { Modifications } \\
\text { de concentration }\end{array}$ \\
\hline $\begin{array}{l}\text { LEHMANN } \\
\text { et coll. }\end{array}$ & 1938 & Homme & $\begin{array}{l}\text { Travail en atmo- } \\
\text { sphère chaude. }\end{array}$ & & $\begin{array}{l}\text { Baisse de la chloré- } \\
\text { mie. }\end{array}$ \\
\hline BAZETT & I94I & $"$ & $\begin{array}{l}\text { Acclimatation : } \\
\text { I }^{\mathbf{0}} \text { à la chaleur } \\
2^{0} \text { au froid. }\end{array}$ & $\begin{array}{l}\text { I }^{\circ} \text { Augmentation vo- } \\
\text { Iume plasma. } \\
2^{0} \text { Diminution. }\end{array}$ & $\begin{array}{l}\mathrm{I}^{0} \text { Baisse proténé- } \\
\text { mie, puis normale ou } \\
\text { même supérieure. }\end{array}$ \\
\hline $\begin{array}{l}\text { BAZETT } \\
\text { et coll. }\end{array}$ & I 940 & $n$ & $\begin{array}{l}\text { Exposition à } 32^{\circ} \mathrm{C}, \\
\text { en hiver. }\end{array}$ & $\begin{array}{l}\text { Masse sanguine }+8 \\
\text { à } 23 \% .\end{array}$ & \\
\hline $\begin{array}{l}\text { CoNLEY } \\
\text { et coll. }\end{array}$ & I945 & " & $\begin{array}{l}\text { Exposition prolongée? } \\
\text { au froid. }\end{array}$ & $\begin{array}{l}\text { Volume extracellu- } \\
\text { laire sans changement. }\end{array}$ & $\begin{array}{l}\text { Xa, Cl, hématocrite } \\
\text { sans changement. }\end{array}$ \\
\hline $\begin{array}{l}\text { SPEALMAN } \\
\text { et coll. }\end{array}$ & 1947 & " & $\begin{array}{l}\text { I }^{\circ} \text { Exposition à tem- } \\
\text { pérature élevée en été. } \\
2^{\circ} \text { Température basse } \\
\text { en été. }\end{array}$ & & $\begin{array}{l}\text { I }^{\circ} \text { Protéinémic et } \\
\text { hémoglobine varient } \\
\text { peu. } \\
2^{\circ} \text { Augmentation. } \\
\text { Vice versa en hiver. }\end{array}$ \\
\hline $\begin{array}{l}\text { BASS } \\
\text { et coll. }\end{array}$ & 1955 & $"$ & $\begin{array}{l}\text { Exposition } 14 \text { jours } \\
\text { à } 38 \text { à } 49^{\circ} \mathrm{C} \text {. }\end{array}$ & $\begin{array}{l}\text { Volume plasmatique } \\
\text { et extracellulaire aug- } \\
\text { mentent. } \\
\text { Naximum le } 5^{\mathrm{e}} \text { jour. }\end{array}$ & \\
\hline $\begin{array}{l}\text { WALSH } \\
\text { et coll. }\end{array}$ & I956 & $n$ & $\begin{array}{l}\text { Refroidissement de } \\
29^{\circ} 5 \text { à } 14^{\circ} 5 .\end{array}$ & & $\begin{array}{l}\text { Augmentation de la } \\
\text { concentration de l'hé- } \\
\text { moglobine. }\end{array}$ \\
\hline DASS & $195^{8}$ & " & Brèves périodes à & Volume plasma et & \\
\hline et coll. & & & & sang identiques. & \\
\hline $\begin{array}{l}\text { BARBOUR } \\
\text { et coll. }\end{array}$ & 1943 & Singe & $\begin{array}{l}\text { Baisse temp. centrale } \\
\text { à } 23^{\circ} \text {. }\end{array}$ & & $\begin{array}{l}\text { Hémoconcentration, } \\
\text { augmentation de } \mathrm{Cl} \text {. }\end{array}$ \\
\hline $\begin{array}{l}\text { STEDMAN } \\
\text { et coll. }\end{array}$ & I94I & Lapin & $\begin{array}{l}\text { Refroidissement va- } \\
\text { riable. }\end{array}$ & & $\begin{array}{l}\text { Pas de variations } \\
\text { cohérentes de } \mathrm{Na} \text { ou } \\
\text { de concentration. }\end{array}$ \\
\hline $\begin{array}{l}\text { SQUiBB } \\
\text { et coll. }\end{array}$ & I954 & Rat & $\begin{array}{rlll}7^{\circ} & \text { heures à } 25 & \text { ou } \\
35^{\circ} \mathrm{C} & \end{array}$ & & Hémoconcentration. \\
\hline $\begin{array}{l}\text { DEB } \\
\text { et coll. }\end{array}$ & I.956 & $n$ & 5 semaines à $6^{\circ}$. & $\begin{array}{l}\text { Augmentation } 30 \% \\
\text { volume sanguin. }\end{array}$ & \\
\hline $\begin{array}{l}\text { BAKER } \\
\text { et coll. }\end{array}$ & I957 & $b$ & 45 jours à $2^{\circ} \mathrm{C}$. & $\begin{array}{l}\text { Augmentation vo- } \\
\text { lume sang et plasma. }\end{array}$ & $\begin{array}{l}\text { Na et } \mathrm{K} \text { plus élevés } \\
\text { pendant } 8 \text { à Io jours. }\end{array}$ \\
\hline $\begin{array}{l}\text { HANNON } \\
\text { et coll. }\end{array}$ & $195^{8}$ & Chien & $\begin{array}{l}\text { Baisse temp. cen- } \\
\text { trale à } 22^{\circ} \text {. }\end{array}$ & & $\begin{array}{l}\text { K, Ca, P, Cl sans } \\
\text { changement, élévation } \\
\text { de Na douteuse et de } \\
\text { Mg significative. } \\
\text { Hémoconcentration. }\end{array}$ \\
\hline $\begin{array}{l}\text { APPLEMAN } \\
\text { et coll. }\end{array}$ & 1958 & Chèvre & $\begin{array}{l}\text { Exposition à tempé- } \\
\text { ratures de o à } 40^{\circ} \text {. }\end{array}$ & & $\begin{array}{l}\text { Densité sang const. } \\
\mathrm{Cl} \text { plasma maximum à } \\
20^{\circ} \text { baisse si tempéra- } \\
\text { ture augmente ou di- } \\
\text { minue. }\end{array}$ \\
\hline $\begin{array}{l}\text { DALE } \\
\text { et coll. }\end{array}$ & 1956 & Vache & $\begin{array}{l}\text { Augmentation de } \\
\text { température. }\end{array}$ & $\begin{array}{l}\text { Augmentation vo- } \\
\text { lume sanguin. }\end{array}$ & \\
\hline BiANCA & I957 & $n$ & $\begin{array}{r}45^{\circ} 5 \text { heures p/jour } \\
\text { pendant } 3 \text { semaines. }\end{array}$ & $\begin{array}{l}\text { Augmentation vo- } \\
\text { lume plasma. }\end{array}$ & $\begin{array}{l}\text { Concentration plas- } \\
\text { ma constante. }\end{array}$ \\
\hline
\end{tabular}


rages entre le moment où ils sont emmagasinés (mai-juin), et le moment où ils sont livrés. Bien que non physiologiqnes, nous sommes obligés de prendre ces relations en considération parce qu'elles compliquent l'interprétation. L’influence personnelle a joué également, les apports minéraux ayant été modifiés à plusieurs reprises au cours de l'expérience, et notamment de façon importante en période terminale.

\section{TABLEAU VI}

Influences saisonnières sur le volume ou la concentration des liquides biologiques

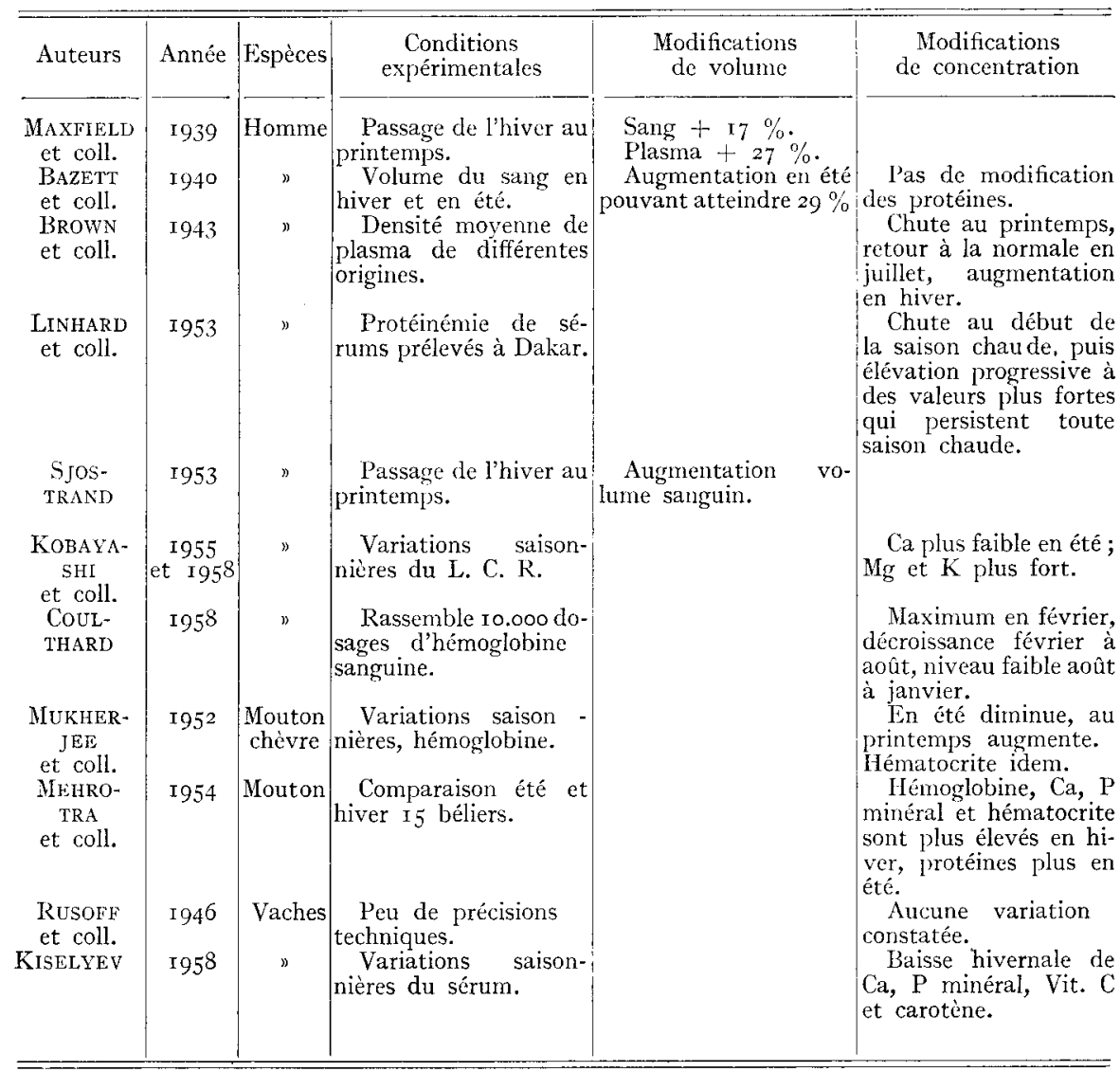

\section{$2^{\circ}$ Corrélations entre les facteurs saisonniers et la composition du sang.}

L'analyse factorielle nous a montré 1'existence d'un facteur saisonnier essentiel, le facteur $n^{\circ} 4$, qui représente peut-être les modifications de la sécrétion de 1'A. D. H. ; commandées essentiellement par la photo- 
période et, éventuellement par la température. Ce facteur intervient pour I7 $\mathrm{p}$. Ioo dans la variation du $\mathrm{K}$ plasmatique, et pour 8 p. Ioo dans la variation de $\mathrm{Na}$.

On a vu (voir page $2 \mathrm{I}$ ) que le facteur 2 paraît soumis dans une certaine mesure aux influences saisonnières.

La pression atmosphérique n'offre à considérer aucune corrélation significative avec aucun composant minéral, non seulement du plasma, mais aussi des différents produits dosés.

Il est difficile d'apprécier les influences de la durée du jour et de la température, mais il est probable qu'elles sont relativement minimes, une fois les corrélations précédentes écartées. En effet, les influences de la durée du jour ne semblent s'exercer que par 1'intermédiaire de ses rapports avec la photopériode.

\section{$3^{\circ}$ Corrélations entre les facteurs saisonniers et la concentration urinaire en minéraux.}

La photopériode (facteur $n^{\circ} 4$ ) augmente légèrement la concentration du Ca urinaire ( $8 \mathrm{p}$. Ioo de la variation totale du Ca urinaire).

\section{$4^{\circ}$ Corrélations entre les facteurs saisonniers et la composition minérale des fèces.}

La photopériode (facteur no 4) a eu une influence notable sur les variations $\mathrm{du}$ calcium fécal ( 8 p. Ioo de ses variations).

\section{$5^{\circ}$ Discussion :}

Parmi les facteurs climatiques et saisonniers, l'influence de la température a certainement été la mieux étudiée. Dès I795, JAckson notait chez 1'homme l'expansion des fluides et la réplétion des vaisseaux lors de l'acclimatation à la chaleur ; en I888, TREILLE signalait la plus grande fluidité du sang des sujets exposés aux climats tropicaux, tandis qu'en Igog Gibson montrait l'existence de la diurèse au froid, et que BARBour (I92I) établissait que, dans tout phénomène de régulation thermique, il se produit des échanges d'eau entre les différents compartiments liquidiens de l'organisme. Nous nous bornerons à citer quelques références récentes ou particulièrement importantes ; pour la bibliographie d'ensemble on pourra consulter BINET (I929), THAUER (I939), BONVALIET et DFiL (I949) et BAss et Henschel (I956).

En I948, Bonval, İT et Coll. montraient qu'après section du faisceau supraopticoposthypophysaire les variations de la diurèse avec la température n'apparaissent plus, donc que 1'A.D.H. est en cause dans ce phénomène. 
Le tableau $\mathrm{V}$ rassemble, sous une forme abrégée, quelques références sur la question de l'influence de la température sur le volume des liquides biologiques et leur concentration minérale ou globale. Il est difficile de tirer des conclusions nettes de cet ensemble d'expériences réalisées dans des conditions très variées, et qui donnent des résultats parfois contra-

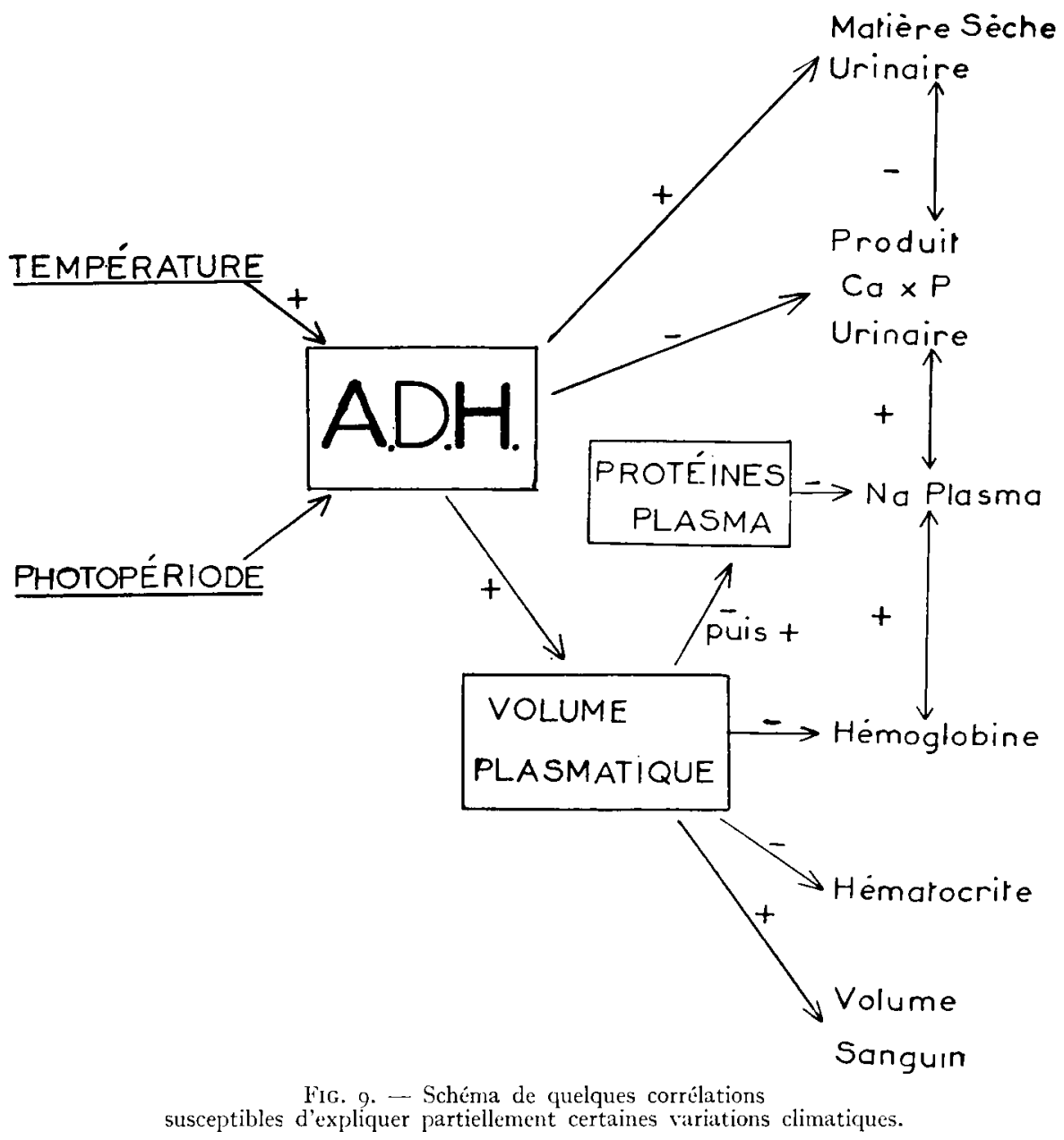

dictoires. Il s'en dégage cependant les phénomènes généraux suivants :

a) Les volumes plasmatiques et sanguins varient parallèlement entre eux en fonction de la température; ils augmentent quand elle s'élève, et semblent également augmenter quand elle baisse, encore que ce dernier point soit controversé. Les variations du volume extracellulaire sont beancoup moins cohérentes encore.

b) I a concentration des protéines du plasma subit une phase de di- 
minution transitoire quand le volume plasmatique augmente, mais il y a rapidement compensation, (et même hypercompensation) de longue durée. La compensation peut être assez rapide pour que le premier phénomène de dilution plasmatique passe inaperçu.

c) I a concentration du plasma en $\mathrm{Cl}$ semble suivre celle des protéines.

d) I a concentration en Na semble varier de façon à pallier la dilution temporaire des protéines plasmatiques.

e) Dans l'exposition prolongée au froid, il ne semble pas y avoir de modifications de la concentration en protéines, $\mathrm{Cl}, \mathrm{K}$, Ca et $\mathrm{P}$. L'élévation de Mg est significative chez le rat (Hannon et Coll. : I958) ; il semble par contre que chez les bovins il y ait une baisse de Mg (BARKER).

Le tableau VI groupe quelques résultats concernant l'influence de la saison sur le volume ou la concentration des liquides biologiques (sang, plasma, sérum, liquide extra-cellulaire); il apparaît que ces liquides prennent une extension considérable au printemps, les données concernant les autres facteurs étant beaucoup moins régulières.

Ces données cadrent assez mal avec la notion de l'influence de la température ; par contre, elles s'accordent bien à l'hypothèse d'une intervention de la photopériode dans la libération de 1'A.D.H., phénomène qui commande manifestement les variations de $\mathrm{Na}$ et $\mathrm{K}$ plasmatiques que nous avons enregistrées. I1 semble donc que, dans les variations saisonnières des volumes liquidiens et des concentrations minérales du sang, le rôle essentiel soit joué par la photopériode, la température n’intervenant que d'une façon minime et dans le cadre de phénomènes de régulation à court terme.

Les résultats obtenus en milieu tropical semblent être beaucoup plus liés aux variations de température. Et ceci semble logique, puisque les variations de la photopériode sont minimes aux faibles latitudes. Petut-être faut-il voir là une des raisons pout lesquelles RUSOFF et PIERCY (I946) n'ont pas observé de variations saisonnières dans la composition du sang des bovins (climat de Louisiane); peut-être aussi le nombre de leurs observations était-il trop réduit, et surtout la répartition de leurs prélèvements laissait-elle des " trous " aux moments des changements de saison, lorsque les modifications plasmatiques sont les plus importantes.

Nous envisagerons dans la discussion générale le mécanisme d'action de la photopériode.

Ia figure 9 essaie de rendre compte d'une partie des faits observés. Il ne faut pas néanmoins se dissimuler que cette interprétation est loin de tout éclaircir. On ne saurait manifestement, par exemple, attribuer toutes les modifications des électrolytes plasmatiques à une action exclusive de 1'hormone antidiurétique; il semble bien également qu'il y ait une périodicité annuelle des surrénales, non seulement d'un point de vue morphologique, mais aussi d'un point de vue secrétoire. Holc OMBE 
(I957) constate que l'excrétion urinaire des " corticoïdes réducteurs" chez le taureau, passe par un minimum en janvier, s'élève rapidement entre février et juin, et diminue ensuite progressivement de juin à janvier, semblant suivre une courbe parallèle à la durée du jour.

En ce qui concerne le $\mathrm{P}$ et le $\mathrm{Ca}$, nos résultats sont beaucoup moins nets. KISEI,YEV (I958) a constaté une baisse hivernale du calcium et du phosphore minéral, baisse qu'il attribue à la stabulation et au régime. Nos résultats concordent en ce qui concerne le calcium, mais non le phosphore ; par ailleurs les modifications que nous enregistrons sont manifestement saisonnières, puisqu'elles subsistent, même calculées à alimentation minérale constante.

La pression atmosphérique n'a pas joué de rôle dans les variations de la composition minérale sanguine, bien que BERG et coll. (I940) aient constaté une corrélation significative entre le $\mathrm{pH}$ sanguin de l'homme et du chien et la pression atmosphérique, et que, par ailleurs, HuEy et Holmes (I950), ainsi que ELLIS (1953), aient constaté que l'acclimatation à l'altitude s'accompagne d'une réduction du volume plasmatique.

\section{C. - Influenee des facteurs alimentaires.}

\section{$I^{\circ}$ Apports alimentaires au cours de la période expérimentale.}

A l'exception d'une courte période (mai-juin I958) intéressant un seul couple de vaches (couple I-III), le rationnement a peu varié au cours de 1'expérience, et à comporté, selon le poids et la production des animaux : de 5 à $9 \mathrm{~kg}$ de foin de luzerne, $0,75 \mathrm{~kg}$ de son, 0,5 à $2 \mathrm{~kg}$ de pulpes sèches, de I à $6 \mathrm{~kg}$ de recoupe de blé. Cette ration a assuré pour le couple $\mathrm{S}-\mathrm{E}$ un gain de poids quotidien moyen de $0,465 \mathrm{~kg}$, de l'âge de 27 mois $(370 \mathrm{~kg}$ ) à l'âge de 39 mois $(540 \mathrm{~kg})$, et pour le couple I-III de o,69o kg, de l'âge de 26 mois (46o kg), au vélage à 34 mois (6r5 kg). Divers compléments minéraux ont été distribués, (phosphate dicalcique, phosphate disodique, carbonate de chaux) pendant des périodes de durée diverse, afin de faire varier les apports phospho-calciques dans d'assez larges limites ; toutefois, en dehors de la période précitée, n'intéressant que le couple I-III, et en dépit du fait que le rapport $\mathrm{Ca} / \mathrm{P}$ ait varié dans de larges limites (de I,5 à 4,5), les apports phospho-calciques ont été égaux ou supérieurs aux besoins théoriques calculés selon les normes suivantes: $\mathrm{Ca}=5 \mathrm{~g}, \mathrm{P}=3 \mathrm{~g}$ par Ioo $\mathrm{kg}$ de poids ; $\mathrm{Ca}=2,5 \mathrm{~g}, \mathrm{P}=2 \mathrm{~g}$ par litre de lait. (Chaque vache a reçu quotidiennement 5000 U.I. de vit. D et 25 ooo U. I. de vit. A pure $\left({ }^{1}\right)$.

I a période mai-juin I958 intéressant le couple I-III a été caractérisée par une réduction considérable des apports phospho-calciques, tendant à

(1) Nous tenons à remercier la Société VetEGric qui nous a fourni gracieusement la vit. A pour cette expérience. 
provoquer une carence associée en Ca et $\mathrm{P}$; dans ce but, nous avons réduit à I $\mathrm{kg}$ l'apport du foin de luzerne, supprimé le son et la recoupe, qui ont été remplacés par de la pulpe sèche, de la paille mélassée et des tourteaux de lin et d'arachide. Cette ration a assuré les apports théoriques énergétiques et protéiques. I a réduction des apports phospho-calciques pour un couple au cours de la période terminale de l'expérience a eu pour effet d'accuser l'évolution cyclique artificielle des apports moyens phosphocalciques pour l'ensemble des 4 vaches au cours de la période expérimentale, évolution qui est due, pour une part, ainsi que nous l'avons mentionné, à la variation de la composition des foins de luzerne au cours de l'expérience (fig. 8).

Le caractère cyclique des apports potassiques a été également très net au cours de notre expérience.

Les apports sodiques n'ont pas varié d'une façon cyclique comme $\mathrm{P}, \mathrm{K}$ et $\mathrm{Ca}$, du fait que le Na distribué sous forme de complément minéral (sel surtout, et, pour une courte période, phosphate disodique) a souvent égalé ou dépassé le $\mathrm{Na}$ des fourrages ; or, la distribution de ces compléments n'a été ni régulière ni cyclique au cours de l'expérience. Les apports en $\mathrm{Na}$ et $\mathrm{K}$ n'ont jamais été inférieurs aux besoins, calculés selon les normes de IU ToIT et Coll. (I934, I940) et THEILER et Co11. (I927), soit, pour $\mathrm{Na}: 4 \mathrm{~g}$ pour l'entretien et $\mathrm{I} \mathrm{g}$ par litre de lait; et pour $\mathrm{K}: 25 \mathrm{~g}$ pour l'entretien, et $3 \mathrm{~g}$ par litre de lait.

\section{$2^{0}$ Corrélations entre les apports alimentaires.}

Les moyennes et écarts types des distributions des variables alimentaires sont figurées au tableau I.

On notera que $\mathrm{Ca}, \mathrm{P}$ et $\mathrm{K}$ alimentaires sont associés deux à deux par des corrélations positives hautement significatives. Ces corrélations découlent pour une large part de la variation parallèle de $\mathrm{Ca}, \mathrm{P}$ et $\mathrm{K}$ dans les foins.

Le $\mathrm{Na}$ alimentaire n'est pas en corrélation avec $\mathrm{P}$ et $\mathrm{K}$, pour les raisons précédenment énoncées. Il est en corrélation négative avec le $\mathrm{Ca}$ alimentaire. Il est à noter que son coefficient de variation est très supérieur à ceux des autres minéraux. Nous serons naturellement amenés à tenir compte de l'association entre $\mathrm{Ca}, \mathrm{P}$ et $\mathrm{K}$ dans l'interprétation des influences alimentaires.

\section{$3^{\circ}$ Influence des facteurs alimentaires sur la composition plasmatique ou sérique.}

L'analyse factorielle (tableau VIII) indique une influence importante du $\mathrm{P}$ alimentaire ( $\mathrm{r}^{\mathrm{er}}$ facteur) sur le Ca sérique puisque, sur 1'ensemble des 6 facteurs de variation envisagée, près de 18 p. Ioo de la 
variation du Ca sérique lui est imputable. Alors que le $\mathrm{P}$ alimentaire est en liaison négative avec le $\mathrm{Ca}$ sérique, il tend au contraire à varier dans le même sens que le $P$ total sérique; cet antagonisme peut être expliqué par le balancement existant au niveau plasmatique entre $\mathrm{Ca}$ et $\mathrm{P}$. On remarquera que l'influence du $\mathrm{P}$ alimentaire sur le $\mathrm{P}$ minéral est faible, mais on se rappellera que nos animaux, sauf pour une faible période, et uniquement pour un couple, n'ont jamais été carencés en phosphore.

\section{TABLEAU VII}

\section{Influence de l'apport alimentaire sodique sur la variabilité de la natrémie.}

\begin{tabular}{|c|c|c|c|c|c|c|}
\hline $\begin{array}{l}\text { Na flimentaire } \\
\text { quotidien. }\end{array}$ & $10-15 \mathrm{~s}$ & $\mathrm{I} 6-22 \mathrm{~g}$. & 23 à $42 \mathrm{~g}$. & +3 à $54 \mathrm{~g}$. & 55 à $70 \mathrm{~g}$. & \\
\hline $\begin{array}{l}\text { Nombre de dosages } \\
\text { de plasma........ }\end{array}$ & 32 & 55 & 50 & 50 & 30 & \\
\hline $\begin{array}{c}\mathrm{Na} \text { plasmatique } \\
\text { moyen............ }\end{array}$ & $.3,089$ & $3, \mathrm{I} I 8$ & 3,079 & 3,122 & 3,150 & non significatif \\
\hline $\begin{array}{r}\text { Coëfficient de varia- } \\
\text { tion du Xa plas- } \\
\text { matique......... }\end{array}$ & $4,4.3 \%$ & $+10 \%$ & $3,-35 \%$ & $2,85 \%$ & $2,69 \%$ & significatif $\mathbf{\%} \%$. \\
\hline
\end{tabular}

Étant donné les relations qui unissent le Ca alimentaire (tableau II) avec la durée du jour, le $\mathrm{P}$ et le $\mathrm{Na}$ alimentaires, ainsi qu'avec le $\mathrm{P}$ et le $\mathrm{Ca}$ sanguin, urinaire ou fécal, toutes les corrélations entre $\mathrm{Ca}$ alimentaire et ces dernières variables ont été exprimées en coefficients de corrélation partiels, à durée du jour, sodium alimentaire et phosphore alimentaire constants (fig. Io). Dans ces conditions, on note que le Ca alimentaire n'exerce plus qu'une action négative significative à I p. Ioo sur le phosphore total sérique. La corrélation positive entre $\mathrm{Ca}$ alimentaire et $\mathrm{K}$ plasmatique devient non significative lorsqu'elle est recalculée à $\mathrm{K}$ alimentaire constant.

I'analyse factorielle indique que le $\mathrm{Na}$ alimentaire n'exerce qu'une faible action non significative, sur le Na plasmatique; il a cependant une action manifeste sur les variations du $\mathrm{Na}$ plasmatique autour de sa moyenne, ainsi que le montre l'étude des fluctuations de la dispersion des valeurs plasmatiques en fonction de la quantité de Na ingérée quotidiennement.

Le tableau VII met en évidence le fait qu'une alimentation riche e: $\mathrm{Na}$, sans élever le niveau plasmatique (ou très faiblement), dininue significativement l'amplitude des écarts observés d'une semaine à l'autre. 
Les limites des classes de $\mathrm{Na}$ alimentaire ont été choisies d'amplitude variable, de façon à obtenir une répartition du nombre de dosages qui ne soit pas trop disproportionnée.

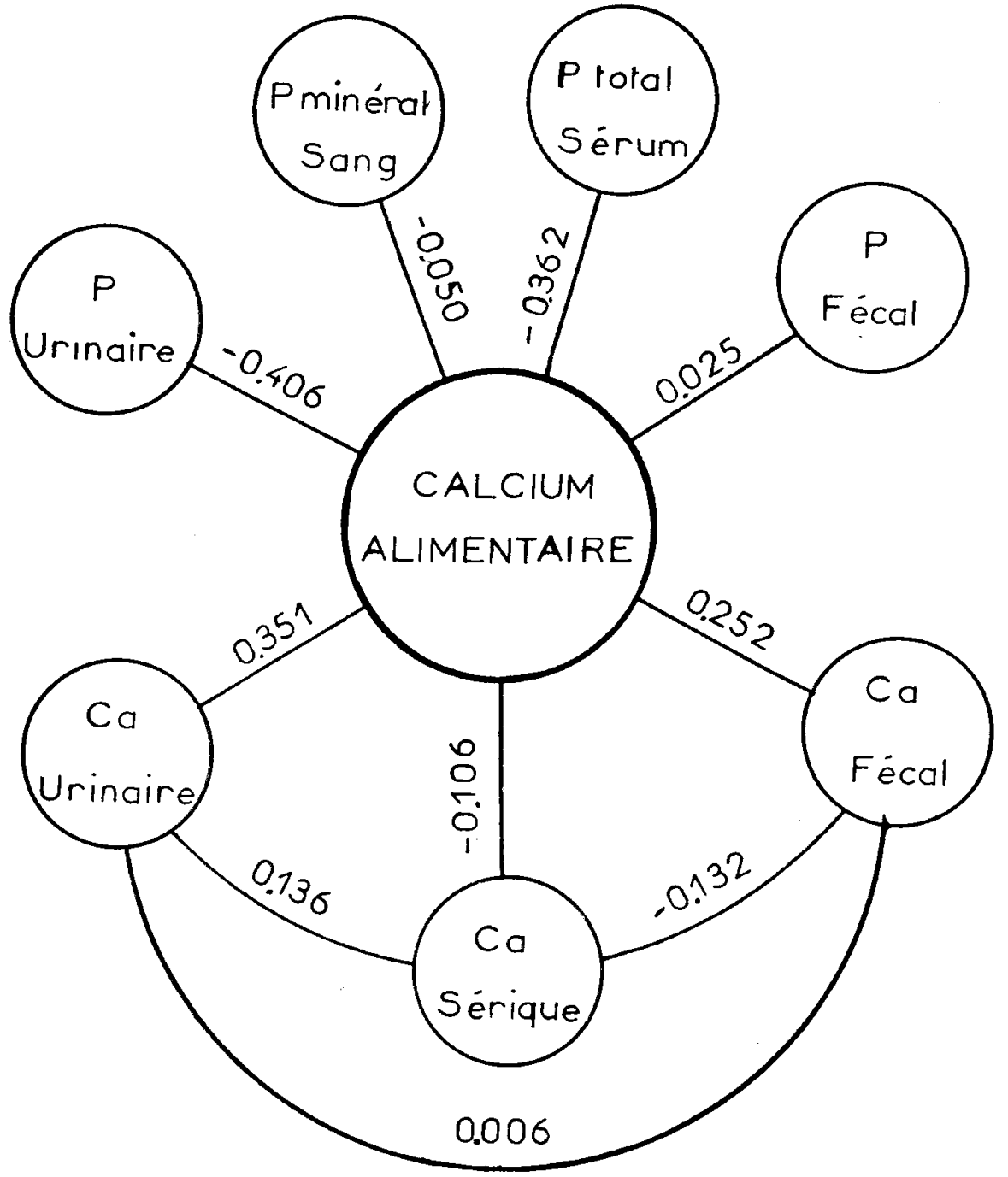

FIG. I0. - Corrélations entre le calcium alimentaire et quelques autres variables, à phosphore alimentaire, sodium alimentaire et durée du jour constants. Seuils de signification $1 \%: 0, \mathbf{I} 77.5 \%$ $0, \mathrm{I} 36$.

L'analyse factorielle ne fait pas apparaître le $\mathrm{K}$ alimentaire comme un élément décisif de variation; néanmoins, il exerce une action positive significative (tableau II), sur le $\mathrm{K}$ plasmatique $(r=+0, \mathrm{I} 93)$, action qui subsiste après l'élimination statistique de l'action des facteurs interférants. 
$\mathrm{La}$ liaison positive intense de $\mathrm{K}$ alimentaire avec le premier facteur ( $\mathrm{P}$ alimentaire) tient vraisemblablement à la corrélation élevée $\mathrm{K}$ alimentaire- $\mathrm{P}$ alimentaire $(+0,573$; tableau II). La liaison négative intense de $\mathrm{K}$ alimentaire avec le $2^{\mathrm{e}}$ facteur (activité thyroïdienne) provient vraisemblablement du fait que le couple E-S ayant présenté l'activité thyroïdienne la plus élevée est celui qui a constamment reçu des apports potassiques inférieurs à ceux du couple I-III.

\section{$4^{\circ}$ Influence des facteurs alimentaires sur la concentration urinaire en $\mathbf{C a}$ et $\mathbf{P}$.}

L'analyse factorielle montre que le phosphore alimentaire ( $\mathrm{I}^{\mathrm{er}}$ facteur) varie dans le même sens que le $P$ urinaire, mais en sens contraire par rapport aux fluctuations du Ca urinaire, son action intervenant dans le même sens aux niveaux urinaire et sérique. Il est à remarquer que l'influence du $\mathrm{I}^{\mathrm{er}}$ facteur ( $\mathrm{P}$ alimentaire) sur l'élimination urinaire de $\mathrm{Ca}$ et $\mathrm{P}$ est faible par rapport à celle exercée par le $2^{\mathrm{e}}$ facteur (1'activité thyroïdienne) (tableau III) (respectivement II et $39 \mathrm{p}$. Ioo pour $\mathrm{Ca}$, 2I et 44 p. Ioo pour P).

Par contre, le calcium alimentaire (fig. Io) est en corrélation positive avec le calcium urinaire et négative avec la phosphaturie ; cette action peut s'expliquer par l'effet dépressif du $\mathrm{Ca}$ alimentaire sur le phosphore sérique total, avec diminution consécutive de l'élimination urinaire du phosphore, ainsi que par une inhibition thyroïdienne entrainant la réduction de la phosphaturie, ces deux phénomènes pouvant jotter concuremment.

Etant donné 1'action en sens contraire exercée par Ca et $\mathrm{P}$ alimentaires sur la calciurie et la phosphaturie, il est prévisible que le rapport $\mathrm{Ca} / \mathbf{P}$ agira sur ces deux variables dans le même sens que $\mathrm{Ca}$, et avec une influence renforcée.

corrélation $\mathrm{Ca} / \mathrm{P}-\mathrm{Ca}$ urinaire $r=+0,3 \mathrm{r} 7$.

- P urinaire $r=-0,386$.

L'influence négative du $\mathrm{K}$ alimentaire sur le $\mathrm{P}$ urinaire résulte des corrélations positives $\mathrm{Ca}-\mathrm{P}-\mathrm{K}$ alimentaires.

\section{$5^{\circ}$ Influence des facteurs alimentaires sur la composition fécale.}

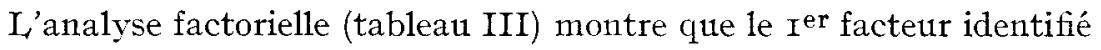
au phosphore alimentaire, influence positivement de façon très importante le phosphore fécal, et négativement, mais dans une faible mesure, le calcium fécal.

Le calcinm alimentaire (fig. Io) est en relation positive avec le cal- 
ciun fécal; son action sur le $\mathrm{P}$ fécal est nulle, et il ne semble donc pas que le Ca alimentaire puisse influencer l'absorption de $\mathrm{P}$.

Le $\mathrm{K}$ alimentaire exerce sur $\mathrm{Ca}$ et $\mathrm{P}$ fécal une action identique à celle de $\mathrm{P}$; les corrélations $\mathrm{K}$ alimentaire - Ca fécal, à Ca fécal constant, et $\mathrm{K}$ alimentaire $-\mathrm{P}$ fécal, à $\mathrm{P}$ alimentaire constant, deviennent non significatives.

I,e sodium alimentaire, selon l'analyse factorielle, exerce une action négative sur le $\mathrm{Ca}$ fécal. $\mathrm{I}_{\text {a }}$ corrélation négative $\mathrm{Na}$ alimentaire - $\mathrm{Ca}$ fécal (tableau II), derient à Ca alimentaire constant, significative.

\section{$6^{\circ}$ Discussion.}

On notera, après examen du tableau VIII, résumant les données de la littérature concernant les relations entre les apports alimentaires phosphocalciques et les valeurs de $\mathrm{Ca}$ et $\mathrm{P}$ du sang et des fèces, que nos résultats concordent, dans la majorité des cas, avec ces données.

Nous n'observons toutefois pas d'influence du P alimentaire sur la phosphatémie ( $\mathrm{P}$ inorganique ou minéral), alors que la majorité des auteurs observent des variations parallèles entre apport phosphorique et $\mathrm{P}$ minéral sanguin, mais ceci surtout lorsque les apports sont faibles, ce qui n'a pas été le cas dans notre expérience, sauf pour une faible durée, n'intéressant qu'un couple de vaches.

I,e $\mathrm{P}$ alimentaire diminue la calcémie, augnente le $\mathrm{P}$ fécal, et tend à diminuer le Ca fécal, cette dernière influence étant toutefois assez faible.

I'apport calcique est sans influence sur la calcémie; seul parmi divers auteurs, SAARINEN (I950) a signalé une légère augmentation de la calcémie lors d'apport calcique accru. I.e Ca alimentaire augmente le Ca fécal; il n'exerce pas d'action sur la phosphatémie, les indications bibliographiques montrant une action faible et contradictoire selon les auteurs. I,e $\mathrm{Ca}$ alimentaire exerce par contre une nette action négative sur le phosphore sérique total (fig. 5).

$P$ et $\mathrm{Ca}$ alimentaires ont donc une action antagoniste sur le $\mathrm{P}$ sérique total, le calcium sérique ne dépendant que de l'apport phosphorique. Au niveau fécal, si le $\mathrm{P}$ ' alimentaire parait exercer une action faible sur l'assimilation calcique, le calcium alimentaire n'influence pas l'assimilation du phosphore.

Au niveau urinaire, l'action du phosphore alimentaire est faible, comparée à celle de l'activité thyroïdienne. L'action du calcium alimentaire est par contre importante, et se manifeste par une augmentation de la calciurie et une réduction de la phosphaturie.

I, 'influence négligeable du $\mathrm{Na}$ alimentaire sur le $\mathrm{Na}$ plasmatique est en accord avec les données bibliographiques (tableau IV). La technique, assez répandue dans certaines régions des Etats-Unis, qui consiste à 
donner au bétail, sans restriction, des tourteaux fortement salés, le sel étant le facteur limitant de la consommation spontanée, a en effet entraîné plusieurs études sur l'influence de quantités importantes de sels sur la physiologie des ruminants; on constate qu'il faut atteindre les limites de l'intoxication saline pour observer une influence sur le Na plasmatique.

\section{TABLEAT VIII}

\section{Influence des apports alimentaires phospho-calciques sur $C a$ et $P$ sanguins et Ca et $P$ fécal.}

\begin{tabular}{|c|c|c|c|c|c|c|c|}
\hline Auteurs & & $\begin{array}{l}\text { Apport } \\
\text { calcique }\end{array}$ & $\begin{array}{c}\mathrm{Ca} \\
\text { liéral }\end{array}$ & Calcénie & $\begin{array}{c}\text { Apport } \\
\text { thospho- } \\
\text { rique }\end{array}$ & $\begin{array}{l}\text { P'́cal } \\
\text { Fécal }\end{array}$ & $\begin{array}{l}\text { Phosphat- } \\
\text { témie }\end{array}$ \\
\hline MeIas \& Coll. & $\begin{array}{l}\text { r } 1917 \\
\text { r } 1926\end{array}$ & \pm & & & $\ldots$ & $\rightarrow+$ & \\
\hline ECKLES \& Coll. & I935 & -- & -- & $\rightarrow=$ & $-\cdots$ & & $\rightarrow-$ \\
\hline GROENEWALI & 1935 & - & & $=$ & & & \\
\hline WESTERLUNI) & 1937 & +- & $\rightarrow \pm$ & & -+ & & \\
\hline Oтto & 1938 & $\overline{+}$ 二 & - & $\bar{\square}$ & $+=$ & & $\Rightarrow-$ \\
\hline Palmer \& Coll. & $194 \mathrm{I}$ & & & & - & & - \\
\hline Hansson & 1942 & + & & $\rightarrow=$ & $+\cdots$ & - & $\rightarrow=$ \\
\hline WEBB \& Coll. & $19+8$ & + & & & & & $=$ \\
\hline WATKINS \& KNOX & $\bar{x} 1948$ & & & & - & & - \\
\hline RUSHOFF & 1950 & - & & $=$ & 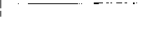 & & \\
\hline LEWIS \& Coll. & 1951 & & & $\begin{array}{l}= \\
=\end{array}$ & $\square+\cdots$ & & $\rightarrow+$ \\
\hline SAARINEX & $195^{\circ}$ & + & & + & & & \\
\hline JARL & r953 & & & $\overline{=}$ & - & & - \\
\hline BODA \& COLE & 1956 & $\ldots$ & & $=$ & & & \\
\hline Dowe \& Coll. & 1957 & $+=$ & $=$ & $\rightarrow=$ & $\square$ & 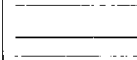 & $\rightarrow-$ \\
\hline ENDER \& Coll. & I957 & & & - & + & & \\
\hline
\end{tabular}

Cependant, nous avons observé qu'à un niveau de sodium alimentaire élevé correspond une stabilité plus grande des valeurs de $\mathrm{Na}$ (tableau VII), ce que l'on peut tenter d'interpréter comme résultant de la mise au repos progessive de la fonction minérale du cortex surrénal. Il est en effet vraisemblable que lorsque des apports faibles en $\mathrm{Na}$ amènent l'organisme à faire intervenir des mécanismes de rétention sodique (sécrétion d'aldostérone), le constant réajustement de la sécrétion peut entraîner des varia- 
tions assez grandes de la natrémie, soit par élimination rénale, soit par échanges actifs cellules-plasma (REINBERG et STOLKOWSKI, I957).

L'influence importante du $\mathrm{Na}$ alimentaire, qui s'exerce de façon indirecte par l'intermédiaire des mécanismes d'assinilation intestinale sur le métabolisme phospho-calcique, est assez inattendue, et n'a pas encore été signalée à notre connaissance ; cette action est décisive sur le $\mathrm{P}$ total sérique et le $\mathrm{P}$ ninéral du sang, le premier étant augmenté et le second abaissé sous l'influence de l'apport sodique.

La question de l'influence du potassium alimentaire sur les minéraux plasmatiques a fait l'objet de quelques travaux chez les ruminants, en relation arec 1'étiologie de la tétanie d'herbage (tableau IV). On voit que les auteurs sont loin d'être unanimes ; nos résultats semblent cependant nettement indiquer que dans les conditions d'une expérimentation de longue durée on observe une variation concomitante de $\mathrm{K}$ alimentaire et de $\mathrm{K}$ plasmatique, bien que les quantités absorbées soient toujours restées dans les limites physiologiques habituelles. Il semble qu'il faille faire intervenir des quantités de $\mathrm{K}$ beaucoup plus élevées pour observer une interférence avec les autres minéraux du plasma.

\section{D. - Relations entre les variables sanguines, urinaires et lécales.}

\section{I $^{0}$ Relations entre les variables sanguines.}

On trouvera résumées au tableau IX les observations d'un certain nombre d'auteurs sur les variables sanguines, ainsi que la moyenne et les caractéristiques de dispersion des 216 déterminations effectuées par nous sur chacune des variables. Nos résultats sont dans l'ensemble très comparables à ceux de ces auteurs.

On observe (tableau II) une corrélation négative hautement significative entre le calcium sérique et le phosphore minéral, relation qui traduit la loi très générale de la constance du produit $\left(\mathrm{PO}_{4}^{--}\right) \times\left(\mathrm{Ca}^{++}\right)$.

On note une relation négative entre le phosphore sérique total et le phosphore minéral, due, selon toute vraisemblance, à l'influence du $\mathrm{Cl} \mathrm{Na}$ alimentaire, qui s'exerce en sens contraire sur ces deux variables.

On n'observe aucune relation entre $\mathrm{Ca}$ sérique, $\mathrm{P}$ sérique total, $\mathrm{P}$ minéral, d'une part, et $\mathrm{K}$ et $\mathrm{Na}$ plasmatiques d'autre part. Il semble donc bien qu'au niveau sérique les régulations de ces deux groupes de métabolites soient indépendantes.

$\mathrm{K}$ et Na plasmatique sont liés par une corrélation positive hautement significative due essentiellement à leur variation parallèle sous l'iufluence de la photopériode (facteur $\mathbf{n}^{\circ} 4$ ). 


\section{TABLEAU IX}

Valeurs des variables sanguines observées par quelques auteurs. Comparaison avec les résultats du présent travail. $(\mathrm{P}=$ plasma $\mathrm{S}=$ sérum ; valeurs exprimées en $\mathrm{g}$ par litre $)$.

\begin{tabular}{|c|c|c|c|c|c|c|c|}
\hline \multicolumn{2}{|l|}{ Auteurs } & & $\mathrm{Na}$ & K & $\mathrm{Ca}$ & $P$ minéral & $\mathrm{P}$ total \\
\hline ABDERHALDEN & 1906 & $s$ & 3,120 & $0,2 \mathrm{I} 2$ & & & \\
\hline MARXer & 1929 & $s$ & & & & 0,051 à 0,058 & \\
\hline Paluifr \& Coll. & 1929 & $1^{\prime}$ & & & & 0,021 à 0,089 & \\
\hline HAAG \& Coll. & 19.35 & $s$ & & & $\left(0,0805\right.$ a $\left.0, \mathrm{I}_{4}\right)$ & $0,0,52$ & \\
\hline AILCROFT \& GREEN & 19.38 & $\dot{s}$ & & & & 0,040 à 0,060 & \\
\hline SAIGLES & $193^{8}$ & $\mathrm{~S}$ & & & & $0,05+$ à 0,066 & \\
\hline Dukes & $\begin{array}{l}\mathbf{1} 94.3 \\
1955\end{array}$ & $s$ & 3,199 & $0,2 \mathrm{I} 2$ & 0,09 ì 0,12 & 0,03 à 0,08 & \\
\hline LIEGEOIS \& Coll. & $19+5$ & $s$ & & & $\begin{array}{c}0,11+ \\
(0,100 \text { à } 0,120)\end{array}$ & $\mid \begin{array}{c}0,049 \\
(0,045 \text { à } 0,058)\end{array}$ & \\
\hline Rusolf \& Coll. & $19+6$ & P & & & 0,1089 à $0,1+56$ & $0,0,502$ à 0,0577 & \\
\hline PAYNE \& Coll. & $19+6$ & $s$ & & & $(0,09$ à $0,1, j 0)$ & $(0,047$ à $0,0,3)$ & \\
\hline KoHL & 1950 & $1^{2}$ & $3,5.3^{\circ}$ & 0,180 & 0,095 & 0,0808 & \\
\hline EATON \& Coll. & 1952 & $\mathrm{~s}$ & & 0,206 & 0,1021 & & \\
\hline Long \& Coll. & 1952 & $s$ & & & 0,101 à 0,122 & $0,0,3.5$ à 0,075 & \\
\hline Hutten \& Coll. & 1952 & $S$ & & & $\left(\begin{array}{l}0,098 \\
a 0,172)\end{array}\right.$ & $0,0.43$ & \\
\hline HANSARI \& Coll. & 1954 & $s$ & & & 0,089 à $0,1.32$ & & \\
\hline $\begin{array}{c}\text { MagNaNI } \\
"\end{array}$ & $\underset{7}{1955}$ & $s$ & & & $\left|\begin{array}{lll}0,109 & \therefore- & 0,004 \\
0,100 & = & 0,005\end{array}\right|$ & $\left|\begin{array}{ll}0,0,378 & 0,0096 \\
0,0,307 & =0,004^{6}\end{array}\right|$ & \\
\hline DE FRANCISCIS & 1957 & s & $\left(2,3_{7}^{3,20}\right.$ à $\left., 3,6,3\right)$ & $(0,109 \dot{a} \quad 0,226)$ & $\begin{array}{c}0,099 \\
(0,07 \dot{a} 0,16)\end{array}$ & & \\
\hline $\begin{array}{l}\text { Résultats duprésent } \\
\text { Moyenne : } \\
\text { Écart type : }\end{array}$ & ravail: & & $\begin{array}{l}p \\
3,1107 \\
0,116\end{array}$ & $\begin{array}{c}\mathrm{P} \\
0,1854 \\
0,0148\end{array}$ & $\begin{array}{c}S \\
0,100,31 \\
0,00877\end{array}$ & $\begin{array}{l}\text { Sitngr } \\
0,0,693 \\
0,01063\end{array}$ & $\begin{array}{c}S \\
0,131,8 \\
0,02169\end{array}$ \\
\hline $\begin{array}{l}\text { Soit écart maximu } \\
\text { une sécurité de }\end{array}$ & $\begin{array}{l}n \text { avec } \\
9 \%:\end{array}$ & & $2,8 \mathrm{I}$ à $, 3,4 \mathrm{I}$ & 0,147 à 0,224 & 0,077 à $0, \mathrm{I} 2,3$ & $0,0,30$ à 0,084 & $\begin{array}{l}0,076 \\
\text { à } 0,188\end{array}$ \\
\hline
\end{tabular}

( $\mathrm{P}=$ plasma $; \mathrm{S}=$ sérum, valeurs exprimées en $\mathrm{g}$ par litre). 


\section{$2^{\circ}$ Relations entre les variables urinaires et sanguines.}

I.es données bibliographiques sur la calciurie et la phosphaturie sont rares, reposent généralement sur un faible nombre de mesures, et ne tiennent pas compte des variations nycthémérales. Même lorsqu'on cherche, comme nous l'avons fait, à réduire l'importance de ces dernières en effectuant les prélèvements toujours à la même heure, on observe une dispersion très importante; les courbes de fréquence (fig. 3 et 4) présentent une dissymétrie très nette. I'analy̧se mathématique indique que de telles courbes résultent souvent de l'influence d'un effet de seuil, qui pourrait être, dans le cas de l'élimination urinaire du phosphore, celui de l'action phosphaturique de la thyroxine. Dans le cas ou apparaissent de tels effets de seuil pour une variable donnée ( $P$ urinaire), il est intéressant de comparer, pour chacune des autres variables, les valeurs obtenues avant seuil à celles obtenues après ce seuil. Nous arons dans ce but calculé les tests de différence entre les moyennes de quelques variables correspondant aux valeurs de $\mathrm{P}$ urinaire groupées avant et après le seuil de o,or (fig. 4). En ce qui concerne les deux variables indépendantes envisagées, on observe que la différence n'est significative que pour la température, les valeurs élevées de celle-ci étant associées aux faibles valeurs de $\mathrm{P}$ urinaire, et les températures les plus fortes aux fortes valeurs de $\mathrm{P}$ urinaire ; or, il résulte de la confrontation des figures 6 bis et 7 qu'il y a eu coïncidence, au cours de l'expérience, entre les périodes d'activité métabolique faible et les températures relativement élevées, et inversement.

I,es relations entre les variables plasmatiques et urinaires peuvent être envisagées, chez les bovins, principalement dans le sens plasmaurine. En effet, l'élimination urinaire de Ca et $\mathrm{P}$ chez les bovins est très faible, puisqu'elle représente, selon KLEIBER et I, ICK (I956), respectivement I p. Ioo et $0,6 \mathrm{p}$. Ioo de l'élimination fécale totale, et 2,6 et I p. Ioo de l'excrétion fécale endogène. On peut donc penser que les variations de l'élimination urinaire influenceront peu, tout au moins dans les conditions normales, le niveau plasmatique de $\mathrm{Ca}$ et $\mathrm{P}$, et que c'est plutôt ce dernier qui influence le niveau urinaire de $\mathrm{Ca}$ et $\mathrm{P}$.

On observe effectivement (tableau II) que le phosphore minéral sanguin et le phosphore sérique total sont tous deux en corrélation positive avec la phosphaturie. I, ealcium sérique est également en corrélation positive avec le $\mathrm{Ca}$ urinaire. I,e phosphore total sérique et le $\mathrm{P}$ minéral d'une part, le Ca sérique d'autre part, exercent une influence négative, les premiers sur le calcium urinaire, le second sur la phosphaturie, ce qui résulte de leur relation inverse au niveau sanguin.

On observe, par ailleurs, une corrélation négative hautement signi- 
ficative entre $\mathrm{Ca}$ et $\mathrm{P}$ urinaires, ce qui est en accord avec la relative constance $\mathrm{du}$ produit $\mathrm{Ca} \times \mathrm{P}$ urinaire, phénomène signalé par IARVor et BROCHART (I959). On remarquera de plus que le coefficient de variation du produit $\mathrm{Ca} \times \mathrm{P}$ est de I29,2 p. Ioo alors que celui de $\mathrm{Ca}$ urinaire est de I43,4 p. Ioo et celui de $\mathrm{P}$ I77, 6 p. Ioo.

TABLEAU X

Comparaison des valeurs moyennes avant seuil et après seuil pour quelques variables

(en unités des variables réelles ou transformées).

\begin{tabular}{|c|c|c|c|c|c|}
\hline \multirow{2}{*}{ Variables } & \multicolumn{2}{|c|}{$\begin{array}{c}\text { Avant seuil } \\
\text { (faibles valeurs) }\end{array}$} & \multicolumn{2}{|c|}{$\begin{array}{c}\text { Après seuil } \\
\text { (fortes valeurs) }\end{array}$} & \multirow{2}{*}{$\begin{array}{l}\text { Test de différence } \\
\text { entre les } 2 \text { groupes }\end{array}$} \\
\hline & $\mu$ & $=$ & $\because$ & $=$ & \\
\hline Température ........... & 9,4 & 5,58 & 6,6 & 4,36 & $4,05++$ \\
\hline$P$ alimentaire $\ldots \ldots \ldots \ldots$ & 4,6 & 1,87 & $4,+$ & 1,24 & $0,9,39 \mathrm{NS}$ \\
\hline$P$ sérique total $\ldots \ldots \ldots$ & 12,6 & 2,18 & $\mathrm{I} 4,5$ & 1,68 & $7, \mathrm{I} \mathbf{I}++$ \\
\hline $\mathrm{P}$ minéral sang........... & 5,4 & 1,09 & 6,3 & $0,9 \mathbf{I}$ & $6,4+T$ \\
\hline Ca sérique........ & 10,2 & 0,93 & 9,8 & 0,88 & $3, \mathrm{I}++$ \\
\hline $\mathrm{Ca}$ urinaire $\ldots \ldots \ldots \ldots$ & 9,3 & 6,77 & 2,6 & 2,72 & $10,3++$ \\
\hline $\mathrm{Ca} \times \mathrm{P}$ urinaire $\ldots \ldots \ldots$ & 3,9 & 4,29 & $\mathrm{r} r, 7$ & 10,05 & $6,3+\div$ \\
\hline P fécal .................. & 9,2 & 3,77 & 9.6 & 2,67 & $0,38,3 \mathrm{NS}$ \\
\hline Ca fécal.............. & 2,5 & 0,88 & 2,4 & 0,7 & $0,909 \mathrm{NSS}$ \\
\hline a $/ P$ fécal............ & 2,9 & 2,14 & 2,5 & $\mathbf{1}, 26$ & $1,724+$ \\
\hline
\end{tabular}

L'influence positive de $\mathrm{K}$ et $\mathrm{Na}$ plasmatiques sur $\mathrm{Ca}$ urinaire résulte, pour le premier, de la corrélation $\mathrm{K}-\mathrm{Ca}-\mathrm{P}$ alimentaire, et pour le second, de son action positive sur la calcémie (tableau III).

\section{$3^{\circ}$ Relations entre les variables sanguines et fécales.}

La répartition normale des valeurs fécales de $\mathrm{Ca}$ et $\mathrm{P}$ suggère que l'élimination fécale dépend de l'influence d'un grand nombre de facteurs à action additive, ce que paraît confirmer la pluralité des facteurs influençant 1'élimination fécale, alors que la concentration urinaire dépend de façon prépondérante de l'activité thyroïdienne.

I e sens des relations entre les variables sanguines et fécales est plus délicat à interpréter que dans le cas précédent. En effet, il ne nous est pas possible de différencier, dans notre expérience, ce qui revient, dans l'élimination fécale, au $\mathrm{Ca}$ et $\mathrm{P}$ endogènes et au $\mathrm{Ca}$ et $\mathrm{P}$ exogènes. I.e nii- 


\begin{tabular}{|c|c|c|c|c|}
\hline & & $=4$ & 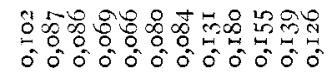 & $\ddot{\Xi}$ \\
\hline & $\widehat{8}$ & $\ddot{z}$ & 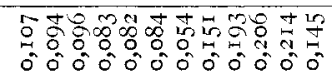 & . \\
\hline & $\dot{\xi}$ & $\stackrel{50}{z}$ & 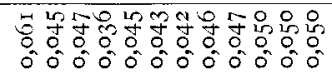 & 言 \\
\hline & $\frac{n}{a}$ & $\ddot{3}$ & 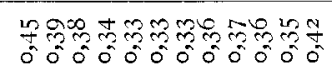 & 芯 \\
\hline & & $=$ & 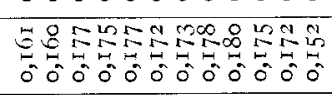 & 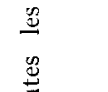 \\
\hline & 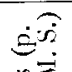 & i & 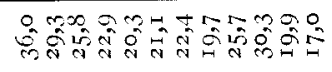 & $\stackrel{\overrightarrow{0}}{=}$ \\
\hline & 焉员 & 2 & 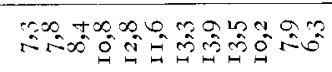 & $\exists$ \\
\hline$\dot{8}$ & $\hat{g}$ & 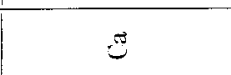 & 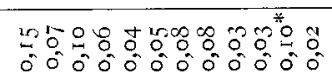 & \\
\hline$\sqrt{\frac{\pi}{3}}$ & 苛富 & 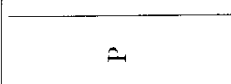 & 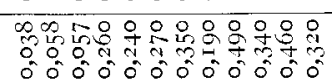 & שֶّ \\
\hline$\frac{\sqrt{3}}{3}$ & & $(\partial x ! 1 \cdot d)$ Y & 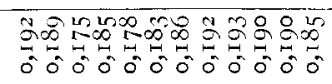 & 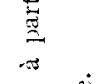 \\
\hline$\underset{\infty}{\infty}$ & & 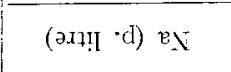 & 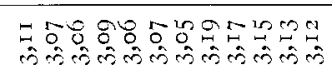 & 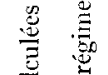 \\
\hline$\overline{4} \stackrel{0}{\mathbb{E}}$ & 站 & ( & 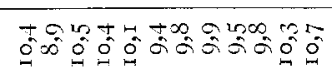 & 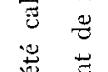 \\
\hline 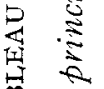 & & 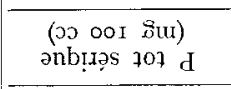 & 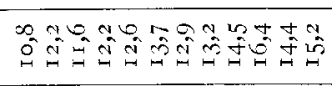 & 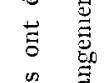 \\
\hline$\stackrel{3}{5}$ & & 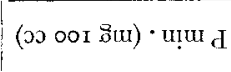 & 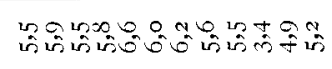 & \\
\hline$\frac{2}{\sqrt[3]{2}}$ & 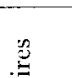 & 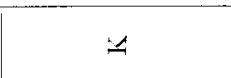 & 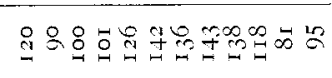 & 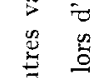 \\
\hline$\underset{\Xi}{\Xi}$ & 悉 & $\ddot{z}$ & 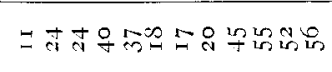 & \\
\hline$\approx$ & 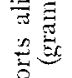 & $\mathbb{3}$ & 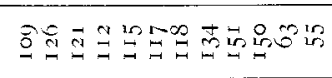 & 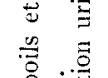 \\
\hline$\frac{3}{3}$ & $\overline{\bar{\lambda}}$ & $=$ & 我 & \\
\hline$\Xi$ & 苛 & 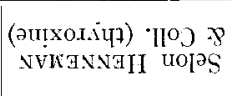 & 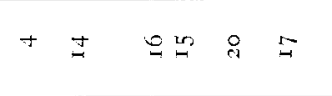 & $\stackrel{2}{2}$ \\
\hline & 至焉 & $\begin{array}{l}\text { (IgA) } \\
\text { NASNGYOS UOPJ }\end{array}$ & 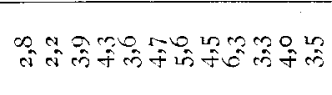 & 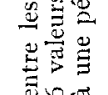 \\
\hline & ยІ әр & 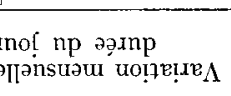 & 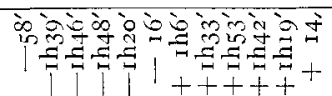 & 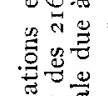 \\
\hline & әичว & 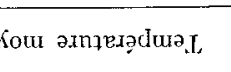 & 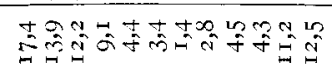 & \\
\hline & & $\stackrel{2}{2}$ & 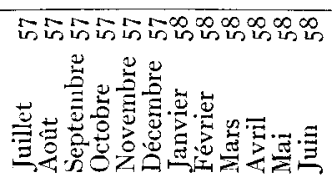 & 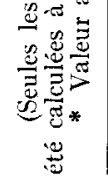 \\
\hline
\end{tabular}


veau plasmatique de $\mathrm{Ca}$ et $\mathrm{P}$ peut être le reflet de l'absorption intestinale, avec, dans ce cas, une relation négative prévisible entre les valeurs fécale et plasmatique ; le niveau fécal peut être le reflet de la sécrétion endogène avec, dans ce cas, une relation positive prévisible, les deux phénomènes jouant concuremment et avec des proportions variables selon les apports alimentaires et la saison.

I,e sens de ces relations peut toutefois, dans une certaine mesure, être prévu en fonction de la répartition des fractions endogène et exogène, telle qu'elle a été étudiée par KLEIBER et I, CICK (I956) à 1'aide des radioéléments : selon ces auteurs, le $\mathrm{Ca}$ et le $\mathrm{P}$ endogène représentent respectivement $4 \mathrm{I}$ et $66 \mathrm{p}$. Ioo de l'élimination fécale totale.

Nous observons une corrélation positive phosphore minéral sanguin- P fécal, ce qui tendrait à confirmer la nature surtout endogène du $P$ fécal. Ira corrélation négative $C a$ sérique - Ca fécal (fig. Io) n'est pas significative, ce qui tendrait à montrer que l'excrétion fécale de Ca ne dépend pas de façon prépondérante d'une sécrétion endogène ou de l'apport exogène, mais d'une combinaison de ces deux influences.

I a relation négative entre $C a$ sérique et $P$ fécal semble due à la corrélation négative $\mathrm{Ca}$ sérique $-\mathrm{P}$ ninéral. I a relation négative phosphore total sérique - Ca fécal est due à l'action du $\mathrm{P}$ alimentaire, qui est en corrélation positive avec le $\mathrm{P}$ sérique total et négative avec le Ca fécal (tableau III).

\section{E. - Relations entre la composition des poils en Ca, $\mathbf{P}$, Ya, $K$ et les autres variables.}

Io Corrélations générales. - I es corrélations significatives suivantes ont été fournies par la matrice générale des corrélations (tableau II ; les senils de signification à I $\mathrm{p}$. IOO $(\mathrm{xx})$ et 5 p. IOO $(\mathrm{x})$ sont respectivement de 0,487 et $0,38 I$, compte tenu du fait qu'il $y$ a eu sept déterminations de la composition minérale des poils pour chaque vache, soit 27 degrés de liberté) :

a) corrélation avec les facteurs climatiques : durée du jour-sodium des poils $+0,403(\mathrm{x})$;

b) corrélations avec les facteurs alimentaires :

$\mathrm{K}$ alimentaire- $\mathrm{P}$ des poils $+0,468(\mathrm{x})$;

$\mathrm{Na}$ alimentaire-Na des poils $+0,603(\mathrm{xx})$;

$\mathrm{Na}$ alimentaire-K des poils $+0,45^{8}(\mathrm{x})$;

c) corrélations avec les facteurs sanguins :

$\mathrm{K}$ plasmatique- $\mathrm{K}$ des poils $+0,406(\mathrm{x})$;

$\mathrm{P}$ minéral sanguin - $\mathrm{Mg}$ des poils - o,4If $(\mathrm{x})$

$\begin{array}{llll}" & \mathrm{Ca} & " & -0,3 \mathrm{I} 9 \\ " & \mathrm{P} & " & -0,380(\mathrm{x}) \\ & \mathrm{Na} & " & -0,440(\mathrm{x})\end{array}$


$\mathrm{P}$ minéral sanguin $-\mathrm{K} \quad$ " $-0,437(\mathrm{x})$;

d) corrélations avec les facteurs urinaires :

$\mathrm{P}$ urinaire $-\mathrm{P}$ des poils $-0,470(\mathrm{x})$

" Ca $\quad-0,437(\mathrm{x})$

" $\quad \mathrm{Ig} \quad-0,5^{6} 5(\mathrm{xx})$

Ca urinaire $-\mathrm{P}$ des poils $+0,465(\mathrm{x})$

$\mathrm{Ca} \quad+0,3 \mathrm{I} 2$

$\mathrm{MIg} \quad+0,439(\mathrm{x})$;

e) corrélations entre les minéraux des poils : tous les minéraux des poils sont liés par des corrélations positives, pour la plupart hautement significatives.

L es phénomènes essentiels que révèlent ces corrélations sont de detux ordres :

$I^{0} \mathrm{~L}$ a minéralisation des poils est un phénomène global, intéressant tous les minéraux du poil.

$2^{\circ}$ Le degré de minéralisation global est en relation négative avec le phosphore minéral du sang, la concentration en $\mathrm{P}$, Ca et $\mathrm{Mg}$ étant, de plus, en corrélation négative avec le phosphore urinaire, et positive avec le calcium urinaire.

Nous retrouvons dans ces dernières corrélations les corrélations liées aı couple de vaches déjà observées lors de l'identification du facteur 2 . En effet, le niveau de minéralisation global des poils du couple E-S a été constamment inférieur à celui du couple I-III ; nous rappellerons que le premier couple a présenté des valeurs de $\mathrm{P}$ total sérique, de $\mathrm{P}$ minéral et de $\mathrm{P}$ urinaire constamment supérieures à celles du deuxième couple (fig. 6 bis). Il y a donc une relation inverse entre l'activité métabolique, telle qu'elle s'exprime par le niveau du métabolisme du phosphore, et la minéralisation des poils, qui apparaissent done comme un tissu non prioritaire dont la minéralisation ne s'opère à un haut niveau que s'il n'y a pas compétition de la part d'autres tissus. Dans la mesure où la relation négative activité métabolique-degré de minéralisation des poils exprime la relation activité thyroïdienne-degré de minéralisation des poils, on peut ainsi expliquer de façon satisfaisante les relations négatives antérieurement observées par nous (BrocharT, I957; BrocharT, COLEOU et LARVOR, I959) dans divers élevages entre la teneur minérale des poils. en $\mathrm{Ca}$ ou $\mathrm{P}$ et la production laitière ou la fertilité, toutes deux dépendantes dans une large mesure de l'activité thyroïdienne.

On notera enfin que les apports alimentaires ou les minéraux plasmatiques autres que le phosphore minéral sanguin influencent peu les minéraux des poils (à l'exception du sodium alimentaire et du potassium plasmatique). Ces constatations sont en opposition avec des résultats antérieurs publiés par l'un de nous (BROCHART, I957); ce problème sera discuté plus loin. 
$2^{\mathrm{o}}$ Évolution saisonnière. - Nous avons utilisé pour cette étude les moyemes des quatre valeurs individuelles des sept prélèvements de poils effectués au cours de la période expérimentale d'un an, en y ajoutant la moyenne des valeurs d'un prélèvement effectué après la fin de

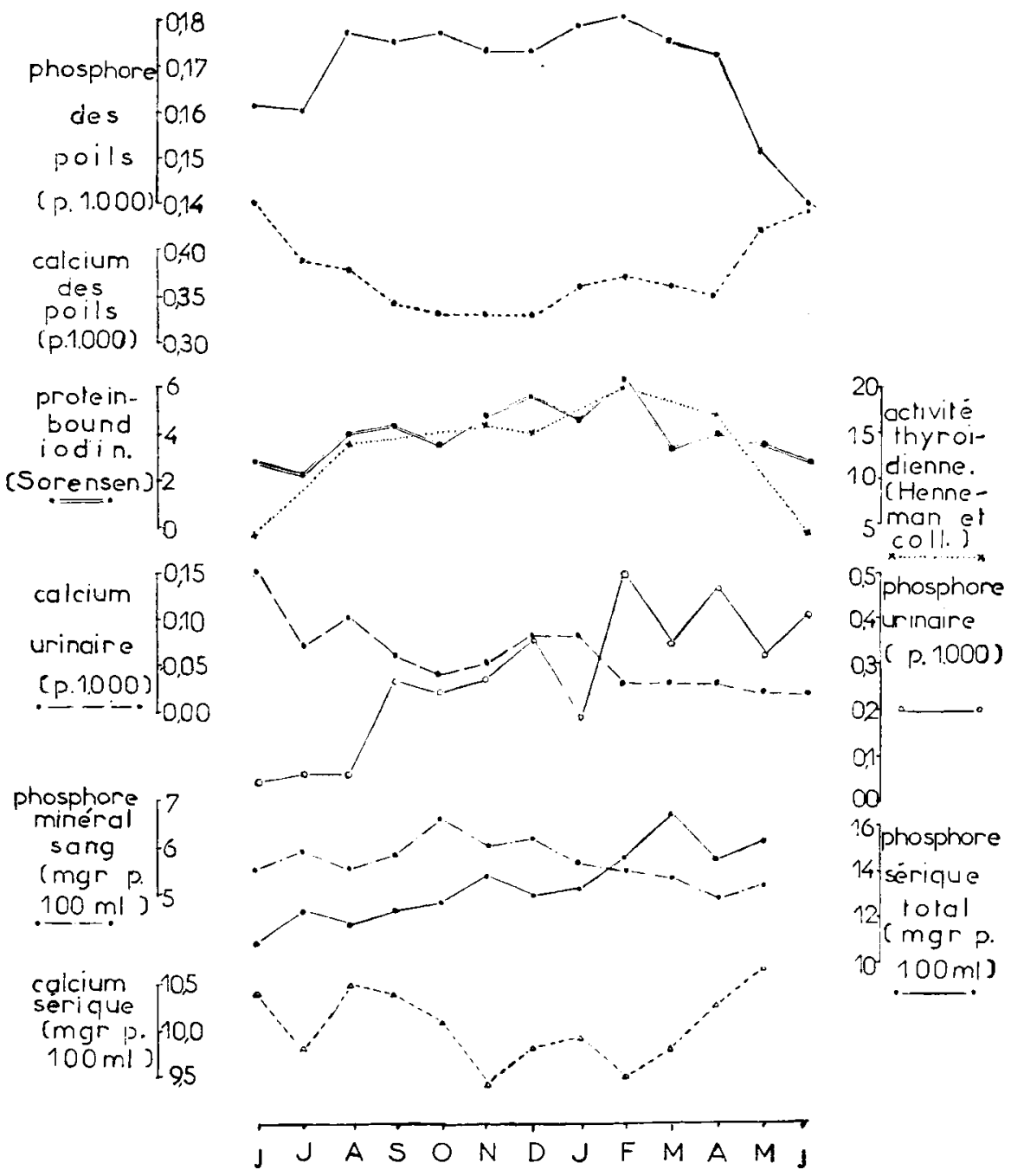

Fıc. ı. - Relations entre la teneur des poils en Ca et $\mathrm{P}$ et l'activité throijdiemne.

cette période expérimentale, afin de compléter le cycle annuel d'évolution de la composition des poils.

On observe (fig. II) qu'il existe tant pour $\mathrm{P}$ que $\mathrm{Ca}$ un cycle annuel très net, indépendant des variations sanguines (moyennes mensuelles pour les quatre vaches), et que $\mathrm{P}$ et Ca des poils sont liés par une corré- 
lation négative hautement significative $(r=-0,706$; setil à I p. Ioo pour II degrés de liberté $=0,683)$. Cette corrélation n'est pas en contradiction avec les corrélations fournies par la matrice globale : elle exprime le fait qu'il existe un cycle annuel des valeurs de $\mathrm{P}$ des poils inverse de celui de $\mathrm{Ca}$, les valeurs de chaque individu restant toutefois liées
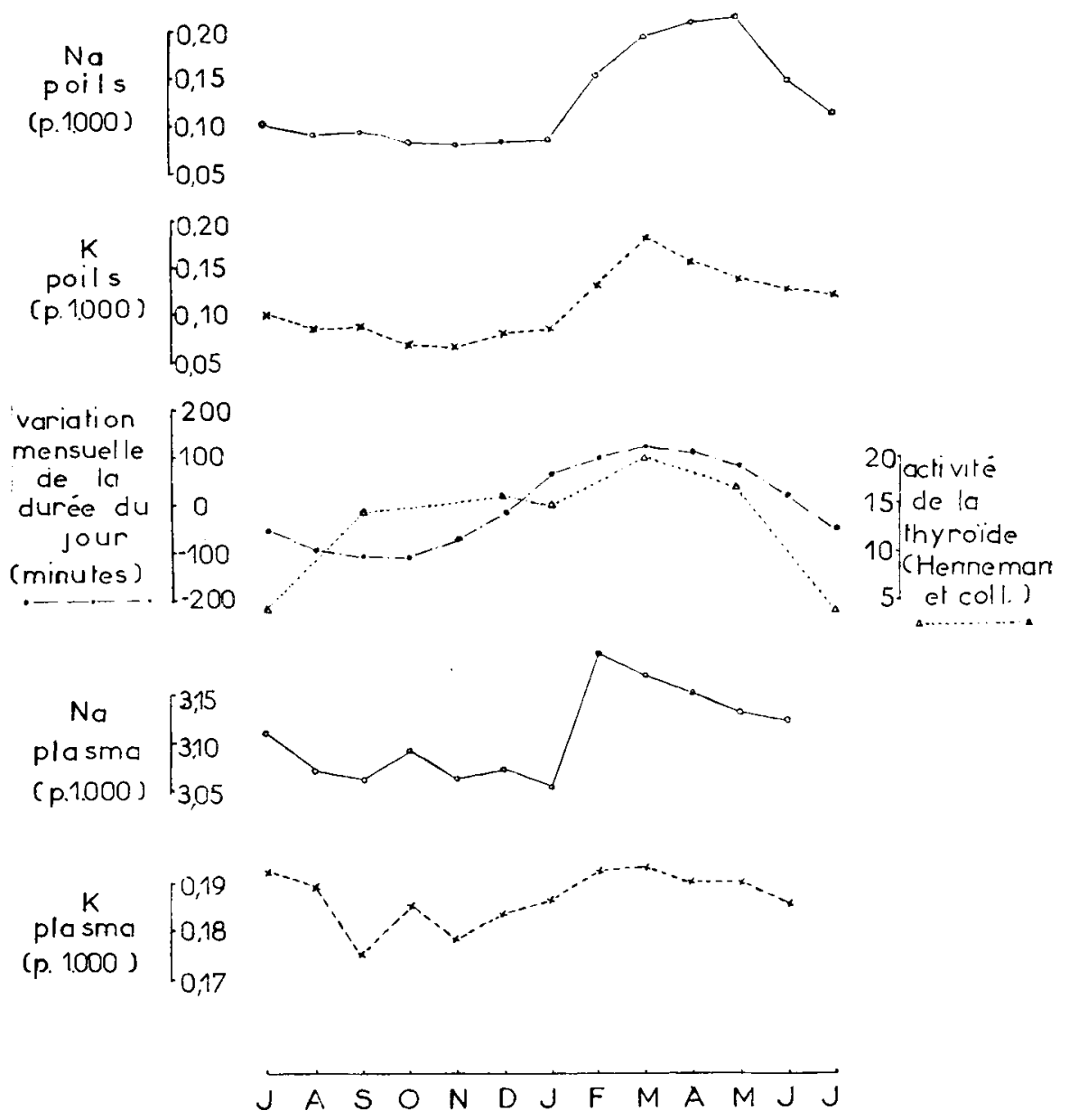

FIG. 12, - Relation entre la teneur en $\mathrm{Na}$ et $\mathrm{K}$ des poils et la photopériode.

négativement au $\mathrm{P}$ minéral sanguin et au $\mathrm{P}$ urinaire. En d'autres termes, les valeurs de $\mathrm{P}$ et $\mathrm{Ca}$ des poils de chaque individu (et de chaque couple) oscillent selon un cycle anuuel autour d'un niveau général qui, lui, est conditionné par l'activité métabolique individuelle, et donc, en dernière analyse, probablement par l'activité thyroïdienne.

Le déterminisme de ce cycle saisonnier des valeurs de $\mathrm{P}$ et $\mathrm{Ca}$ des 
poils est probablement fonction du cycle annuel d'activité thyroïdienne ; en utilisant les données de Sorensen (1958) établies chez les bovins, et de Henneman et coll. (I955), obtenues chez les ovins, on observe les corrélations suivantes entre l'activité thyroïdienne saisonnière et le $\mathrm{P}$ des poils :

$\mathrm{P}$ des poils - activité thyroïdienne selon Sorensen :

$$
r=+0,907 \text { (sign. I p. IOO) }
$$

$\mathrm{P}$ des poils - activité thyroïdienne selon HENNEMAN et coll. :

$$
r=+0,532 \text { (sign. } 5 \text { p. IOo). }
$$

Toutefois, ce ne peut être l'action de la thyroïde sur le métabolisme du phosphore qui détermine le cycle des valeurs de $P$ des poils, car les valeurs de $\mathrm{P}$ des poils devraient être minimum au maximum d'activité thyroïdienne, et inversement, alors que nous observons le phénomène opposé. Il est possible que l'influence de la thyroïde sur le métabolisme du phosphore soit masquée, au niveau des poils, par la puissante action exercée sur la croissance de ceux-ci, à moins que l'on admette que les poils constituent en hiver un tissu prioritaire (chez les sujets très jeunes, on constate également que la phosphatémie et le $\mathrm{P}$ des poils sont tous deux très élevés).

I'évolution cyclique inverse du calcium est par contre en accord avec l'action de la thyroxine sur le métabolisme calcique, puisque les valeurs minimum du $\mathrm{Ca}$ des poils sont atteintes en hiver, donc au maximum d'activité thyroïdienne. C'est également en hiver que le taux de mélanine, qui contrôle en partie le taux calcique des poils, est minimum.

Alors que $\mathrm{Ca}$ et $\mathrm{P}$ des poils suivent fidèlement les variations de l'activité thyroïdienne, $\mathrm{Na}$ et $\mathrm{K}$ des poils sont en relation beaucoup plus nette avec la photopériode (fig. I2). Il est vraisemblable que $\mathrm{Na}$ et $\mathrm{K}$ des poils sont toutefois également influencés par la thyroïde, mais ne répondent à la stimulation de cette glande qu'à partir d'un certain seuil, qui est peut-être le seuil d'activité susceptible de provoquer la mue. On observe en effet que la brusque augmentation de Na et $\mathrm{K}$ des poils entre janvier et février correspond à un taux d'accroissement important de l'activité thyroïdienne.

Alors que $\mathrm{Ca}$ et $\mathrm{P}$ des poils sont manifestement indépendants des variations sanguines de $\mathrm{P}$ minéral, de $\mathrm{P}$ total sérique ou de Ca sérique, les variations de $\mathrm{Na}$ et $\mathrm{K}$ des poils paraissent être plus en rapport avec $\mathrm{Na}$ et $\mathrm{K}$ plasmatiques (fig. I2).

Les corrélations entre $\mathrm{Na}-\mathrm{K}$ des poils, Na-K plasmatiques et la photopériode sont les suivantes :

$\mathrm{Na}$ poils-photopériode : $+0,766$ (Significatif I p. Ioo).

$\mathrm{K}$ poils-photopériode : $+0,753$ (Significatif I p. I00).

$\mathrm{Na}$ poils-Na plasmatique : $+0,839$ (Signi at p. Ioo).

$\mathrm{K}$ poils- $\mathrm{K}$ plasmatique : $+0,685$ (Sig! a p. IOO). 


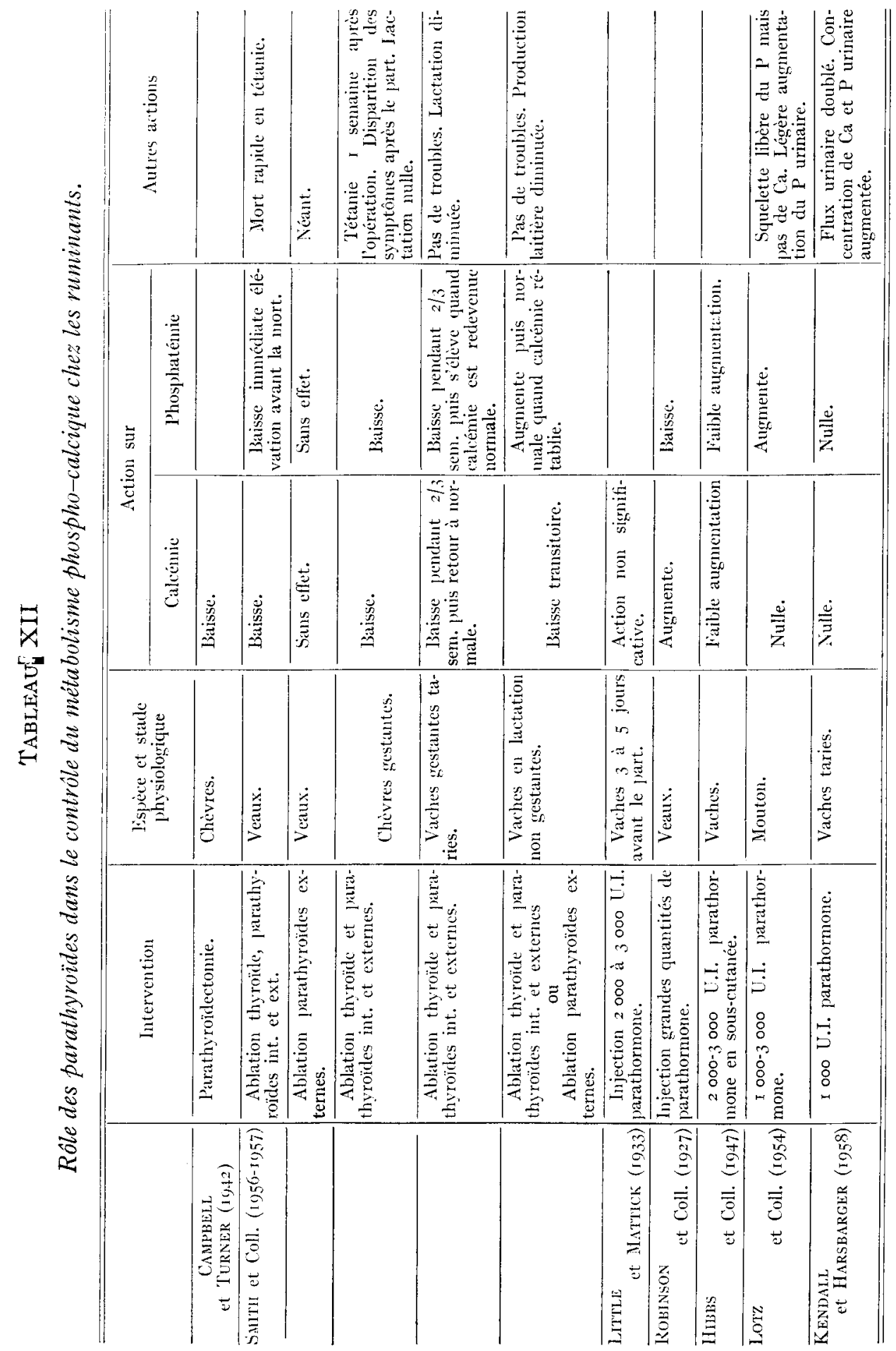


Na-plasma-photopériode : + o,708 (Significatif I p. Ioo).

$\mathrm{K}$ plasma-photopériode : + o,6ro (Significatif 5 p. Ioo).

Dans ces conditions, il est vraisemblable que les variations mensuelles de $\mathrm{Na}$ et $\mathrm{K}$ des poils sont dues principalement aux phénomènes de mue et de croissance $d \mathbf{u}$ poil, et, pour une part plus restreinte, aux modifications du métabolisme de $\mathrm{Na}$ et $\mathrm{K}$, ces deux groupes de phénomènes étant eux-mêmes sous la dépendance de la photopériode.

\section{IV. - DISCUSSION GÉNÉRALE}

\section{A. - Conditions expérimentales.}

Io Bien que nous ayons utilisé 2 couples de jumelles univitellines, on pourra s'étonner du fait que nous n'avons pas analysé la variabilité intra-couple des diverses variables étudiées. Cette recherche doit faire l'objet d'une publication ultérieure.

$2^{\circ}$ Nos animaux ayant été entretenus pendant un an en stabulation, et ayant reçu une alimentation qualitativement constante (à 1'exception d'une courte période, et pour un seul couple), ceci a sans doute permis une mise en évidence des facteurs saisonniers plus facilement que dans les conditions normales, où le changement important de régime alimentaire, lors du passage de la stabulation à l'herbage, vient ajouter ses effets à ceux des variations climatiques. Toutefois, si les apports alimentaires en Ca-P-K ont peu varié qualitativement au cours de la période expérimentale, ils ont cependant présenté une évolution cyclique, apparemment annuelle, sur le plan quantitatif; cette évolution n'était pas prévue initialement, et a parfois gêné l'interprétation des résultats. On a vu, néanmoins, que l'infuence de cette évolution cyclique des apports minéraux du point de vue quantitatif pouvait être nettement différenciée de l'influence saisonnière.

$3^{\circ}$ La signification de la mesure hebdomadaire de la concentration minérale d'un échantillon de fèces ou d'urine peut être contestée. En ce qui concerne les fèces, et dans nos conditions expérimentales, nous pensons que cette mesure est valable, et indique réellement le niveau d'élimination fécale, étant donné : a) la stabilité de la concentration fécale en minéraux au cours du nycthémère (IARVor et BROCHART, I959), b) le fait que la quantité de matière sèche ingérée ayant peu varié au cours de l'expérience, le poids de fèces éliminé a été relativement constant. Etant donné que 98 à $99 \mathrm{p}$. roo de l'élimination totale de $\mathrm{Ca}$ et $\mathrm{P}$ s'opère par voie fécale, on peut donc considérer qu'un dosage hebdomadaire de la concentration fécale de $\mathrm{Ca}$ et $\mathrm{P}$ a de fortes chances de représenter assez fidèlement le niveau d'élimination phospho-calcique. Si, par ailleurs, on souscrit à la thèse très convaincante de DUNCAN (1958) sur le peu de validité 
des mesures de bilan à long terme, on en arrive à la conclusion qu'un échantillonnage de fèces, prélevé avec une périodicité à définir selon les conditions expétimentales, permet de se faire une idée de l'évolution de l'élimination phospho-calcique au cours d'une durée de plusieurs mois.

La validité d'un échantillon hebdomadaire d'urine, même prélevé à l'heure où la variabilité est la plus faible, est plus contestable, étant donné les variations importantes de la concentration minérale et du flux urinaire en fonction du nycthémère et de la température; néanmoins, à condition d'effectuer les prélèvements à heure fixe, et lorsque la variabilité est minimum, la mesure de $\mathrm{Ca}$ et $\mathrm{P}$ urinaires peut contribuer à l'estimation du niveau d'élimination de ces éléments. Il ne saurait, par contre, être question d'apprécier par ce moyen le niveau d'élimination de $\mathrm{K}$ et $\mathrm{Na}$, étant donné la part importante que joue l'élimination urinaire dans l'excrétion de ces minéraux (respectivement, selon VAN DER HORS'T et HENDRIKS (I958), go et 75 p. Ioo, non compris l'excrétion par le lait).

$4^{\circ}$ Le grand nombre de facteurs envisagés dans cette étude a nécessité une interprétation statistique parfois délicate. Il nous a semblé cependant utile d'étudier notamment le rôle des facteurs climatiques sur le métabolisme de Ca-P et de K-Na d'une part, et des interférences pouvant exister entre ces 2 groupes de métabolites d'autre part, ces divers problèmes ne semblant pas avoir été approfondis dans le passé. Jugeant que nous avions suffisamment de facteurs en cause dans cette étude, nous avons volontairement négligé le rôle de la vitamine $\mathrm{D}$, en nous assurant de la constance relative de ce facteur par une distribution quotidienne de cette vitamine, à une dose devant assurer les besoins minima.

Cette constance du facteur vitaminique $D$ a peut-être permis une mise en évidence plus facile de l'action des autres facteurs, alors que dans les conditions naturelles le taux de vitamine D subit des oscillations importantes.

\section{B. - Le métabolisme phospho-calcique des bovins.}

Celui-ci présente des caractères spécifiques qu'il convient de souligner avant d'interpréter des résultats obtenus dans cette espèce, ou d'extrapoler aux bovins les résultats obtenus avec d'autres espèces : I) étant donné la composition des fourrages ingérés par les bovins, la carence calcique paraît être rare; la carence phosphorique est, par contre, beaucoup plus fréquente, 2) le contrôle parathyroïdien du métabolisme phospho-calcique, peut-être biologiquement adapté à ce type particulier d'apport, paraît assez différent de celui observé chez les carnivores, les rongeurs et 1'homme. En effet, chez ces espèces, il est démontré que la parathormone entraîne $a$ ) l'ostéolyse, b) l'élimination accrue de phos- 
phore par voie urinaire, du fait d'un abaissement du seuil rénal d'élimination des phosphates, $c$ ) l'hypophosphatémie.

Chez les bovins (tableau XII), la parathormone parait n'influencer la phosphatémie qu'à des doses extra-physiologiques (RoBINson et Coll, 1927), ou uniquement chez la vache en lactation (STOTт et SмIтн, 1957). De toute façon, la perte de $\mathrm{P}$ par voie urinaire provoquée par la parathormone ne peut représenter en général qu'une faible fraction de l'élimination totale de $\mathrm{P}$ qui, chez les bovins, s'effectue essentiellement par voie fécale (KLEIBER et $\mathrm{L}_{\text {UICK, }}$ 1956). L'élimination urinaire de $\mathrm{P}$ représente donc un témoin du niveau des apports alimentaires ou de l'activité métabolique et endocrinienne, mais ne peut contribuer de façon importante au métabolisme de cet élément, tout au moins dans les conditions normales. A l'appui de l'hypothèse d'une adaptation biologique du rôle de la parathormone au type d'apport phospho-calcique propre aux ruminants, on peut noter que LoTz et coll. (1954) ont démontré, à l'aide des radio-éléments, que, chez le mouton, la parathormone provoque au niveau de l'os uniquement la libération de phosphore.

La réaction hyper parathyroïdienne " classique " n'est observée, chez les bovins qu'après une longue période de carence calcique et phosphorique associée. On observe alors de l'hypercalcémie, de l'hyperphosphaturie (en dépit de la carence phosphorique) et de l'hypophosphatémie ; ces réactions d'ailleurs fugaces ont été obtenues par nous postérieurement à la période expérimentale faisant l'objet du présent travail, et seront décrites ultérieurement.

Dans le cas d'apports phospho-calcique et vitaminique D suffisants, les facteurs principaux agissant sur le métabolisme phospho-calcique paraissent être donc, par ordre d'importance décroissants : a) l'apport phosphorique alimentaire, $b$ ) l'activité thyroïdienne, $c$ ) la capacité d'assimilation intestinale, $d$ ) la photopériode.

L'assimilation du phosphore alimentaire parait s'exercer préférentiellement à celle de $\mathrm{Ca}$; en effet, on note que lors d'apport phosphorique et calcique suffisant ou élevé, il y a un déplacement vers les valeurs élevées $\mathrm{du} \mathrm{P}$ sérique, avec réduction corrélative du $\mathrm{Ca}$ sérique, mécanisme qui est sans doute régi par la loi de constance du produit $\mathrm{Ca} \times \mathrm{P}$ sérique. $\mathrm{Au}$ niveau rénal, l'excrétion de $\mathrm{Ca}$ et $\mathrm{P}$ paraît dépendre d'un simple phénomène de filtrationi-réabsorption, et peut-être d'une action phosphaturique des hormones thyroïdiennes.

Il semble bien qu'il faille accorder un rôle décisif dans le contrôle endocrinien du métabolisme phospho-calcique à la thyroïde, et non, comme nous l'avions estimé précédemment (BrocharT, I957), à la parathyroïde. En effet, dans la mesure où le phosphore des poils paraît être un témoin indirect de l'activité métabolique, et donc, en dernière analyse, de l'activité thyroïdienne, il apparaît que la capacité de production 
laitière dépend de ce niveau d'activité thyroïdienne individuelle (BroCHAR'T, COLEOU et LARVOR, I959). Les besoins alimentaires et les possibilités de carences éventuelles dépendent évidemment de ce niveau d'activité thyroïdienne. Chez une vache à faible activité métabolique, la carence phospho-calcique paraît être un hasard assez improbable avec la plupart des rations classiques. Par contre, chez les grandes laitières, dont les besoins sont élevés, et dont l'excrétion de $\mathrm{P}$ et $\mathrm{Ca}$ par voie urinaire et fécale est importante, la carence phospho-calcique présente une probabilité beaucoup plus élevée, qui pourrait même avoir un caractère obligatoire chez les hyperthyrö̈diennes (cas des vaches à bilan négatif " obligatoire " dans les premiers mois de lactation, et qui ne peuvent réajuster leur production au niveau des apports alimentaires). Chez de tels individus, la contribution des réserves squelettiques devient sans doute indispensable, et le mécanisme parathyroïdien doit entrer en jeu.

Nous nous proposons dans un prochain travail de vérifier ces hypothèses par la mesure simultanée de l'activité thyroïdienne, de la composition sanguine, de la teneur minérale des poils et de la production laitière.

L'influence du sodium alimentaire, et probablement du chlore qui lui est associé dans le sel, sur le métabolisme phospho-calcique est importante. Le sodium paraît exercer une action favorable sur l'assimilation phospho-calcique, car il réduit de façon sensible le $\mathrm{Ca}$ et $\mathrm{P}$ fécal, et augmente le $\mathrm{Ca}$ et $\mathrm{P}$ total sérique. Cette action s'inscrit sans doute dans le cadre général de l'influence positive du chlorure de sodium sur l'appétit, l'assimilation des protéines et des glucides.

I a corrélation positive élevée du Ca fécal avec le facteur 4, qui contrôle 1'activité de l'hormone antidiurétique, est plus difficile à expliquer. I1 est possible qu'elle soit due au cycle saisonnier de l'activité thyroïdienne.

\section{C. - Métabolisme du sodium et du potassium.}

Rien ne semble indiquer que le métabolisme de ces minéraux, notamment vu sous l'angle du contrôle endocrinien, soit fondamentalement différent chez les ruminants de celui des animaux de laboratoire ou de 1'homme.

La surrénalectomie (STRAND et Coll I934; Hol,Combe, I957 ; GoDING et Denton, I957 ; MC Donald et Coll. 1958 ; Cowie et Tindal, I958) entraine les modifications classiques de la composition sanguine : diminution de $\mathrm{Na}$ et du glucose, acidose, augmentation de $\mathrm{K}$ et du $\mathrm{P}$ minéral, ainsi que de l'excrétion urinaire de $\mathrm{Na}$, et rétention de $\mathrm{K}$. La cortisone et la DOC (Holcombe, I957 ; Goding et Denton, I957), ou l'implantation surrénalienne (Mc DoNaLD et Coll. I958), permettent 
une survie prolongée ; l'excès de DOCA (Godrng et Denton, I957) produit les mêmes effets que sur les autres espèces, sauf peut être 1'augmentation de la diurèse, qui ne semble pas se manifester. L'analyse des surrénales de bovins (KAnNT et Coll. I955; WETTSTEIN et Coll. I955) a montré la présence d'aldostérone en quantités appréciables; de même, on en trouve dans les produits de perfusion de la surrénale de bœuf invitro (UNGaR et Coll. I954). On trouve également de l'aldostérone dans le sang des bovins (NEHER et WETTSTEIN, I955) ; l'aldostéronémie des bovins semble d'ailleurs être assez élevée, ce qui est peut-être en relation avec le rapport $\mathrm{K} / \mathrm{Na}$ habituellement très fort dans leur alimentation. On peut également penser que le contrôle hypothalamique de la secrétion d'aldostérone, démontré chez le chien par Ratschkoi,B et I'ARreli (I956), est également valable chez les bovins, puisque des extraits bruts de diencéphale de bœuf stimulent de façon marquée la secrétion d'aldostérone (RACschkol B et Coll. 1957).

Fin ce qui concerne l'effet de l'alimentation minérale sur le taux de $\mathrm{Na}$ du plasma des bovins, nos résultats sont conformes à ceux de la plupart des auteurs, (tableau IV) ; le Na n'a pas d'influence, aux taux habituellement trouvés dans l'alimentation, sur le Na du plasma. Il n'en reste pas moins qu'en cas de carence ou d'excès caractérisé (même avant d'avoir atteint les premiers symptômes de toxicité), on peut observer des modifications plasmatiques de $\mathrm{Na}$. De plus nous avons noté une nette influence du sodium alimentaire sur la plus ou moins grande stabilité du sodium plasmatique. Nous pensons que ce phénomène est dû au fait que dans le cas d'apports faibles en $\mathrm{Na}$, l'équilibre hydrosodique de 1'organisme est plus sujet à des remaniements constants.

Par contre, l'influence du $\mathrm{K}$ alimentaire sur le $\mathrm{K}$ plasmatique se révèle significative, même si elle est calculée de façon à annuler l'action des autres facteurs.

Il n'en demeure pas moins que les divers facteurs identifiés et susceptibles d'influencer le niveau plasmatique de $\mathrm{K}$ et $\mathrm{Na}$ ne représentent respectivement que ${ }_{5} \mathrm{p}$. Ioo et $24 \mathrm{p}$. Ioo de la variation globale de ces deux minéraux. La distribution normale des valeurs de $\mathrm{K}$ et Na plasmatiques permet de penser qu'ils sont soumis à des influences diverses à actions additives. Il a été démontré par PALMFr et Coll. (I929) qu'une autre variable sanguine, le phosphore minéral, varie en fonction des influences les plus diverses : difficulté à réaliser la saignée, ingestion d'ean froide, déplacements au dehors, durée de l'intervalle après le repas, etc... Nous avons effectué une vérification de cette variabilité des teneurs minérales du sang en effectuant 4 prélèvements de sang espacés de quelques heures au cours d'une même journée. Les résultats figurant au tableau XIII montrent que la variabilité de $\mathrm{Na}, \mathrm{K}$ plasmatique, $\mathrm{P}$ minéral et $\mathrm{P}$ total sérique est presque aussi élevée pour 4 mesures effectuées au cours d'un 
intervalle de 4 heures que pour l'ensemble des données obtenues au cours d'un an. L'imperfection des techniques utilisées ne rend compte que d'une fraction de cette variabilité (moins de $25 \mathrm{p}$. Ioo). I'essentiel de la variation des minéraux sanguins paraît donc dû̀ à des influences aléatoires que nous n'avons pu contrôler.

TABLEAU XIII

Variabilité des minéraux du sang

\begin{tabular}{|c|c|c|c|c|}
\hline & \multicolumn{4}{|c|}{ Coefficients de variation des minéraux du sang } \\
\hline & Au cours d'un an & $\stackrel{2}{2}$ au cours de 4 h. & $\begin{array}{c}\text { Pour } 8 \text { échantillons } \\
\text { identiques }\end{array}$ & $\begin{array}{l}\text { \% de la variance } \\
\text { expérimentalepar } \\
\text { rapportà la variance } \\
\text { au cours de } 4 \mathrm{~h} \text {, }\end{array}$ \\
\hline 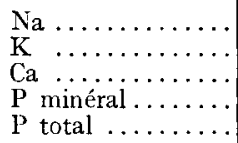 & $\begin{array}{r}3 \cdot 73 \\
7,93 \\
8,74 \\
18,67 \\
16,46\end{array}$ & $\begin{array}{r}3,34 \\
6,50 \\
3,23 \\
\mathbf{1 6 , 8 5} \\
\mathbf{1 4 , 4 6}\end{array}$ & $\begin{array}{l}\mathrm{r}, 7 \circ \\
\mathrm{r}, 50 \\
\mathrm{I}, 78 \\
4,9 \mathrm{I} \\
\mathrm{I}, \mathbf{0 4}\end{array}$ & $\begin{array}{r}25,5 \\
7,4 \\
27,8 \\
5,6 \\
0,5\end{array}$ \\
\hline
\end{tabular}

I) 216 valeurs obtenues en $I$ an sur 4 sujets.

2) 2 expériences, à chaque fois sur 2 génisses; 4 prises de sang à ro h, I r h, I 2 h, I 4 h, soit I6 déterminations au total.

3) 8 déterminations sur 8 aliquots d'un prélèvement d'une scule vache.

\section{D. - Facteurs saisonniers.}

L'importance du rythme d'éclairement a été reconnue d'abord en ce qui concerne les fonctions de reproduction. Les auteurs s'accordent à y voir une influence sur la sécrétion des gonadotrophines hypophysaires, par l'intermédiaire de l'hypothalamus, lui-même stimulé par l'œil. Cependant, Benort et Coll. (I950) ont montré qu'il pouvait y avoir stimulation directe de l'hypothalamus par la lumière, éventualité qui ne semble pas avoir d'incidence pratique chez les mammifères.

La photopériode peut agir, soit par son accroissement (canard), soit par sa diminution (mouton) (YEATES, I949; OR'TAVANT et ThIBAUL,T, I956).

I'influence sur la fonction thyroïdienne est beaucoup moins bien connue; KAyser et Aron (I950) ont décrit un cycle annuel chez les hibernants (hamster), et montré qu'il n'est pas influencé par la température. Sur ce point, leurs résultats s'opposent à ceux de la majorité des chercheurs, qui constatent une augmentation de la sécrétion thyroïdienne lorsque la température baisse, et vice versa. Les travaux de Henneman et Coll. (I955) chez le mouton, et cetix de Sørensen (I958) chez les bovins, sont particulièrement intéressants du fait que ces chercheurs ne se contentent pas d'opposer la sécrétion thyroïdienne du mouton en hiver et en été, mais la mesurent tout au long de l'année. Les courbes qu'ils obtiennent (fig. II) montrent que si effectivement le froid hivernal 
semble maintenir la sécrétion à un niveau élevé, il se superpose aux variations dues à la température un sommet de sécrétion au début du prin-

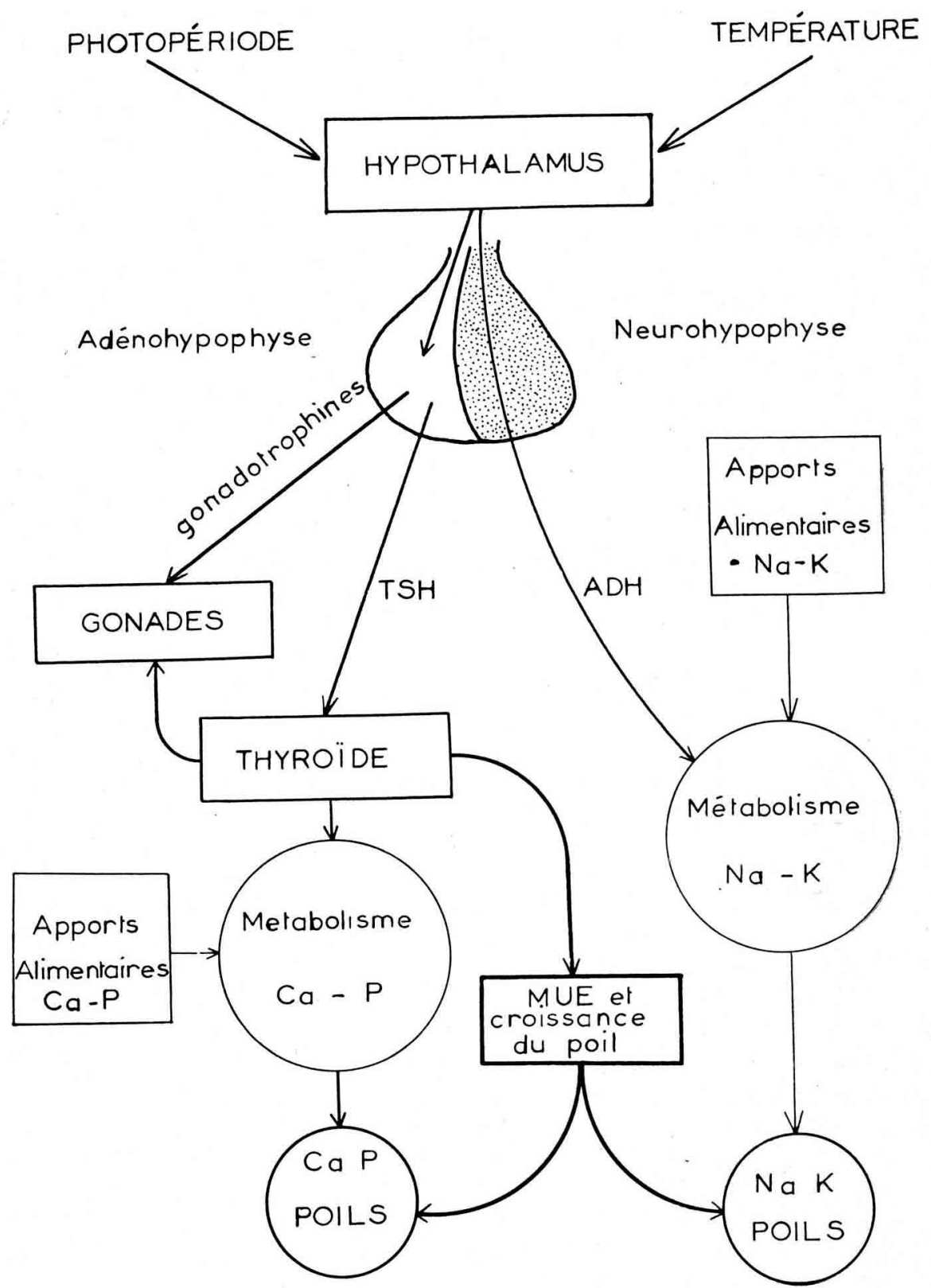

FIG. I3. - Facteurs agissant sur la composition en $\mathrm{Ca}, \mathrm{P}, \mathrm{Na}, \mathrm{K}$ des poils.

temps, qui semble nettement lié à l'augmentation de la photopériode.

Par ailleurs, plusieurs travaux ont montré l'influence de la thyroïde sur la croissance des phanères; HART (I954-55-57), MAQSOOD (I955), 
Ferguson et Coll. (I956, I958), Godfrey (I958) ont trouvé que l'administration de thyroxine accroit la production de laine; GiacominI (I924) et VAN DER MEULEN (I939) ont provoqué la mue chez les volailles, l'un par administration de thyroxine, l'autre par des extraits hypophysaires thyréotropes; MoHr (1956, 1958) a établi que, chez le rat, la thyroxine stimule spécifiquement le remplacement du poil, c'est-à-dire provoque la croissance du nouveau pelage, sans avoir d'action sur le poil relativement âgé. Le mécanisme intime de ces phénomènes n'est pas encore connu, mais ils ont amené YEATES (I954) à formuler 1'hypothèse très vraisemblable selon laquelle la mue serait due à une variation saisonnière de 1'activité thyroïdienne, sous l'influence du complexe hypothalamohypophysaire, lui-même stimulé par la photopériode. Il est très vraisemblable (MAQSOOD, I95I, I952) que la thyroïde intervient également dans le réveil sexuel saisonnier.

Dans le domaine du métabolisme minéral, un cycle saisonnier du métabolisme phospho-calcique a été mis en évidence par MULLICK et coll. (I953) qui ont signalé que la rétention phosphorique est maximum en hiver et au printemps, ce qui correspond bien à l'action de la thyroxine sur le métabolisme phosphorique (OWEN, r948) et à l'évolution saisonnière de 1'activité thyroïdienne. Il est difficile d'apprécier la part qui peut revenir dans le niveau du métabolisme phospho-calcique à 1'activité métabolique intrinsèque et à ses variations saisonnières. Dans nos expériences, le facteur 4 , qui est manifestement le plus lié aux variations saisonnières, u’influence que très faiblement le métabolisme du phosphore, qui paraît surtout contrôlé par l'activité métabolique non saisonnière et l'apport alimentaire en phosphore. Par contre, il existe une influence non négligeable du facteur 4 sur le métabolisme calcique, influence qui paraît correspondre à celle de la thyroxine (OWEN, I948).

Le métabolisme de $\mathrm{Na}$ et $\mathrm{K}$ paraît par contre influencé par la photopériode. On a vu cependant que la brusque élévation de $\mathrm{Na}$ et $\mathrm{K}$ plasmatiques, accompagnée d'une augmentation parallèle de $\mathrm{Na}$ et $\mathrm{K}$ des poils, coïncide avec le maximum d'activité thyroïdienne et avec la mue, ce qui peut correspondre à une action de seuil de la sécrétion thyroïdienne. On arrive ainsi à une conception d'ensemble du rôle des facteurs saisonniers, hypothèse schématisée par la figure I3, et qui permet d'expliquer les corrélations observées entre un certain nombre de phénomènes apparemment indépendants les uns des autres.

\section{E. - Influence des facteurs saisonniers, individuels et alimentaires sur la composition minérale des poils.}

Dans un travail initial (BrocharT, I957) sur les possibilités d'utilisation de l'analyse minérale des poils pour l'exploration de la nutrition phospho-calcique des bovins, nous avions pensé que les poils pourraient 
refléter de façon passive les variations de la composition minérale sanguine. Nous pensions avoir confirmé cette hypothèse de travail par l'observation d'un certain parallélisme entre l'évolution de la calcémie et de la phosphatémie d'une part, et de la teneur en Ca et $\mathrm{P}$ des poils d'autre part. Les résultats du présent travail ne confirment pas, en ce qui concerne $\mathrm{Ca}$ et $\mathrm{P}$, ces conclusions. Cette divergence peut provenir du fait que le parallélisme apparent entre l'évolution des minéraux du sang et des poils, observé dans notre travail initial, semblait exiger que l'on tienne compte dans la traduction au niveau des poils de l'évolution de la composition sanguine d'un temps de latence de deux à quatre mois, ce qui, à l'expérience, s'avère manifestement exagéré. On peut donc considérer que, en ce qui concerne $\mathrm{Ca}$ et $\mathrm{P}$, notre hypothèse initiale était erronée et sa justification non fondée. D'après les résultats du présent travail, la teneur des poils en Ca et $\mathrm{P}$ paraît être fonction du degré variable de compétition pour les éléments minéraux sanguins entre les poils d'une part, et les autres tissus ou liquides organiques (ma melle, squelette, fœetus, urine) d'autre part.

En ce qui concerne $\mathrm{Na}$ et $\mathrm{K}$, dont le rôle dans le métabolisme est fondamentalement différent de Ca et $P$, la teneur des poils en ces éléments paraît bien varier dans le temps parallèlement à celle des minéraux sanguins. Le niveau indiviđuel de minéralisation des poils en $\mathrm{Na}$ et $\mathrm{K}$ dépend, par contre, comme $\mathrm{Ca}$ et $\mathrm{P}$, de l'activité métabolique, donc d'un phénomène de compétition.

Dans les conditions de cette expérience, où les apports en Ca et $\mathrm{P}$ ont été presque toujours constamment supérieurs aux besoins théoriques, le phosphore et le calcium des poils ne paraissent dépendre que du niveau d'activité métabolique et de la saison. Ces résultats doivent être confrontés avec des observations antérieures, où nous avions observé une dépendance de la composition minérale des poils vis-à-vis des apports alimentaires en $\mathrm{Ca}$ et $\mathrm{P}$, au cours d'une étude portant sur $2 \mathrm{I}$ élevages et 278 vaches de race Hollandaise pie-noire (BROCHART, I957).

Les relations suivantes avaient été observées :

$\mathrm{I}^{0}$ Apports faibles en $\mathrm{Ca}$ et $\mathrm{P}(\mathrm{Ca} / \mathrm{P}$ variant de $\mathrm{I}, 5$ à 3,5$)$ : faible valeur du $\mathrm{P}$, forte valeur du $\mathrm{Ca}$ des poils.

$2^{\circ}$ Apport phosphorique faible ou moyen et apport calcique élevé $(\mathrm{Ca} / \mathrm{P}$ variant de 3 à 4$)$ :

fortes valeurs de $\mathrm{Ca}$ et $\mathrm{P}$ des poils.

$3^{\circ}$ Apports phosphorique et calcique supérieurs aux normes, et équilibrés $(\mathrm{Ca} / \mathrm{P}$ variant de $\mathrm{I}, 2$ à 3$)$ :

valeur moyenne du $\mathrm{P}$, valeur faible du Ca des poils.

Les résultats du présent travail suggèrent que ces relations pourraient être le fait, au moins en partie, de l'activité métabolique intrinsèque des animaux, et donc de facteurs héréditaires. I,es interférences 
entre les facteurs génétiques et les facteurs alimentaires apparemment responsables des correspondances précitées sont difficiles à analyser du fait que le type d'apport I) a été observé dans des élevages à production laitière moyenne et fertilité médiocre, le type d'apport 2) dans des élevages à production laitière moyenne et de fertilité mauvaise, et le type 3) dans les élevages d'un haut niveau de sélection, ayant de fortes productions laitières et une bonne fertilité.

Le type d'élevage I) pourrait correspondre à des élevages où l'apport alimentaire est trop faible pour faire face aux potentialités de production, d'où un prélèvement sur les réserves osseuses mobilisées par la parathyroïde, entraînant la baisse du phosphore des poils et la surcharge calcique endogène. C'est en tout cas uniquement chez les sujets de ce groupe que nous avons trouvé une fréquence élevée de déminéralisations squelettiques.

La relation observée avec le type d'élevage 2) tendrait à montrer que l'excès calcique alimentaire réduit l'activité métabolique, d'où la surcharge calcique et phosphorique des poils. I1 a été effectivement démontré chez les animaux de laboratoire (Thompson, I933; TAYLOR, I954) que la surcharge alimentaire calcique réduit l'activité thyroïdienne. On pourrait objecter toutefois qu'il est possible que les vaches des élevages du type 2) étaient des hypothyroïdiennes héréditaires, mais il n'y a pas de raison de penser que ce sont précisément et uniquement des vaches génétiquement hypothyroïdiennes qui recevaient une alimentation trop riche en calcium. Dans l'expérience faisant l'objet du présent travail, nos animaux ont bien été soumis durant certaines périodes à des rations comportant un $\mathrm{Ca} / \mathrm{P}$ élevé, mais ces périodes ont sans doute été trop courtes ( $\mathrm{I}$ à 2 mois) pour permettre la mise en évidence de ce phénomène.

L'existence dans les élevages du type 3) d'un calcium faible et d'un phosphore moyen est en accord avec la relation négative entre charge minérale des poils et activité métabolique observée dans le présent travail.

Ainsi, du point de vue de l'exploration nutritionnelle phospho-calcique, l'analyse minérale des poils semble permettre de différencier :

I $^{0}$ Des sujets potentiellement bons producteurs, mais carencés, avec un phosphore des poils faible et un Ca élevé ;

$2^{\circ}$ Des sujets hypothyroïdiens, soit génétiquement, soit du fait d'une influence alimentaire (excès de calcium, carence en iode, antithyroïdiens naturels, etc...).

$3^{\circ}$ Des sujets à forte potentialité de production et à nutrition minérale équilibrée, présentant un phosphore des poils moyen et un calcium faible. 


\section{F. - Généralisation des résultats obtenus.}

Les corrélations fournies par la matrice globale ont été obtenues à partir de quatre vaches identiques deux à deux puisqu'étant jumelles univitellines. On peut donc considérer que ces corrélations expriment principalement les liens existant entre les deux couples, les variations intra-couples étant beaucoup plus faibles que les variations intercouples. On a vu en effet que les deux couples ont présenté, en ce qui concerne le métabolisme phospho-calcique et la teneur minérale des poils, un comportement profondément différent ; le couple E-S est caractérisé par une forte valeur du $\mathrm{P}$ total sérique, du $\mathrm{P}$ minéral, et du $\mathrm{P}$ urinaire, une faible valeur de la calciurie et de la charge minérale globale des poils; le couple I-III présente des caractéristiques le plus souvent opposées.

Les corrélations significatives parfois élevées obtenues expriment donc surtout ces importantes différences inter couples. On peut dès lors se demander dans quelles mesures ces corrélations expriment des lois générales valables pour une grande population. Il est malheureusement difficile, pour des raisons matérielles, d'entreprendre une expérience analogue à la nôtre sur un grand nombre de sujets. Certains faits, que nous avons déjà signalés antérieurement (voir p. 44) permettent cependant de penser que les deux relations fondamentales mises en évidence dans ce travail, à savoir :

I $^{\circ}$ La relation positive entre 1'activité métabolique et le phosphore total sérique, le phosphore minéral et le $\mathrm{P}$ urinaire;

$2^{\circ}$ La relation négative phosphore minéral sanguin et urinaire-minéralisation globale des poils ont une valeur générale : en effet des corrélations négatives significatives ont été obtenues par nous, dans des populations très diverses, entre la production laitière et le calcium ou le phosphore des poils, ce que l'on peut valablement considérer comme une vérification de la relation négative activité métabolique-charge minérale globale des poils observée dans le présent travail.

Dans 1'appréciation des résultats analytiques, il convient en outre de tenir compte de la saison où les poils ont été prélevés, étant donné l'influence des facteurs saisonniers. Il ne nous est pas actuellement possible de chiffrer la part qui revient aux facteurs saisonniers et aux facteurs individuels dans la variation globale de la teneur en minéraux des poils ; ce problème est à l'étude. Des résultats partiels indiquent que la variation due à la saison est inférieure à la variation due à l'individu.

En ce qui concerne l'exploration nutritionnelle de $\mathrm{Na}$ et $\mathrm{K}$, la composition des poils parait être un reflet fidèle des variations plasmatiques dans le cas du potassium et des apports sodiques dans le cas du sodium. Toutefois, alors qu'il nous a paru possible pour $\mathrm{Ca}$ et $\mathrm{P}$, de proposer 
une interprétation des interactions possibles entre les apports alimentaires et les facteurs héréditaires, il ne nous est pas possible actuellement de proposer un schéma comparable pour Na et $\mathrm{K}$.

\section{RESUMÉ}

Quatre vaches normandes ont été entretenues pendant un an en stabulation permanente. Les apports alimentaires ont peu varié qualitativement au cours de cette période; quantitativement, les apports de $\mathrm{Ca}, \mathrm{P}, \mathrm{K}$ ont évolué parallèlement au cours de l'expérience, selon un cycle approximativement annuel et ont été presque constamment supérieurs aux besoins théoriques. I'apport sodique, représenté surtout par du chlorure de sodium, a évolué indépendamment des apports en $\mathrm{Ca}$, $\mathrm{P}, \mathrm{K}$; la quantité de vitamine $\mathrm{D}$ distribuée a été relativement constante.

Nous avons mesuré chaque semaine, pendant un an, $\mathrm{Ca}$ et $\mathrm{P}$ sérique total, $\mathrm{P}$ minéral du sang total, Na et $\mathrm{K}$ plasmatiques ; la concentration urinaire et fécale de $\mathrm{Ca}$ et $\mathrm{P}$ a été mesurée à partir d'échantillons hebdomadaires prélevés aux heures oì la variabilité de la teneur de ces minéraux est minimum, et en corrélation maxinum avec la moyenne nycthémérale. I,es poils du chignon ont été prélevés tous les deux mois et leur teneur en $\mathrm{Ca}, \mathrm{P}, \mathrm{Mg}, \mathrm{Na}, \mathrm{K}$ déterminée.

Les résultats de ces analyses ont été confrontés avec I) les apports alimentaires en $\mathrm{Ca}, \mathrm{P}, \mathrm{Na}, \mathrm{K}, 2$ ) la température, la durée du jour, la pression atmosphérique, 1'hygrométrie.

L'ensemble des données recueillies, soit 2 I 6 valeurs pour chacune des 26 variables, a été analysé statistiquement grâce à l'utilisation de l'ordinateur 704, dans le but d'établir la matrice globale des coefficients de corrélation, au nombre de 325 . L'interprétation de ces résultats, difficilement utilisables directement en raison des interférences multiples existant entre les variables, a été poursuivie d'abord synthétiquement, au moyen de la technique de l'analyse factorielle, ensuite, analytiquement, par le calcul des coefficients de corrélations partiels.

I, 'analyse factorielle a permis de mettre en évidence quatre facteurs principaux de variation; ceux-ci paraissent être : $\mathrm{I}^{\circ}$ le phosphore alimentaire $; 2^{\circ} 1^{\prime}$ activité thyroïdienne $; 3^{\circ}$ la capacité d'assimilation $; 4^{\circ}$ la photopériode. Ces quatre facteurs interviennent respectivement pour I5,9-I6,2-I2,2 et 5,7 p. Ioo de la variation globale, soit, au total, pour 50 p. roo de celle-ci.

Le phosphore total sérique, le phosphore fécal et le phosphore urinaire sont liés par des corrélations positives au facteur I, dont les variations s'opposent, par contre, à celles du calcium sérique, urinaire et fécal.

Le facteur 2 est lié à l'activité métabolique (croissance, production lai- 
(I, I960) LE MÉTABOLISME DE Ca, P, K, Na

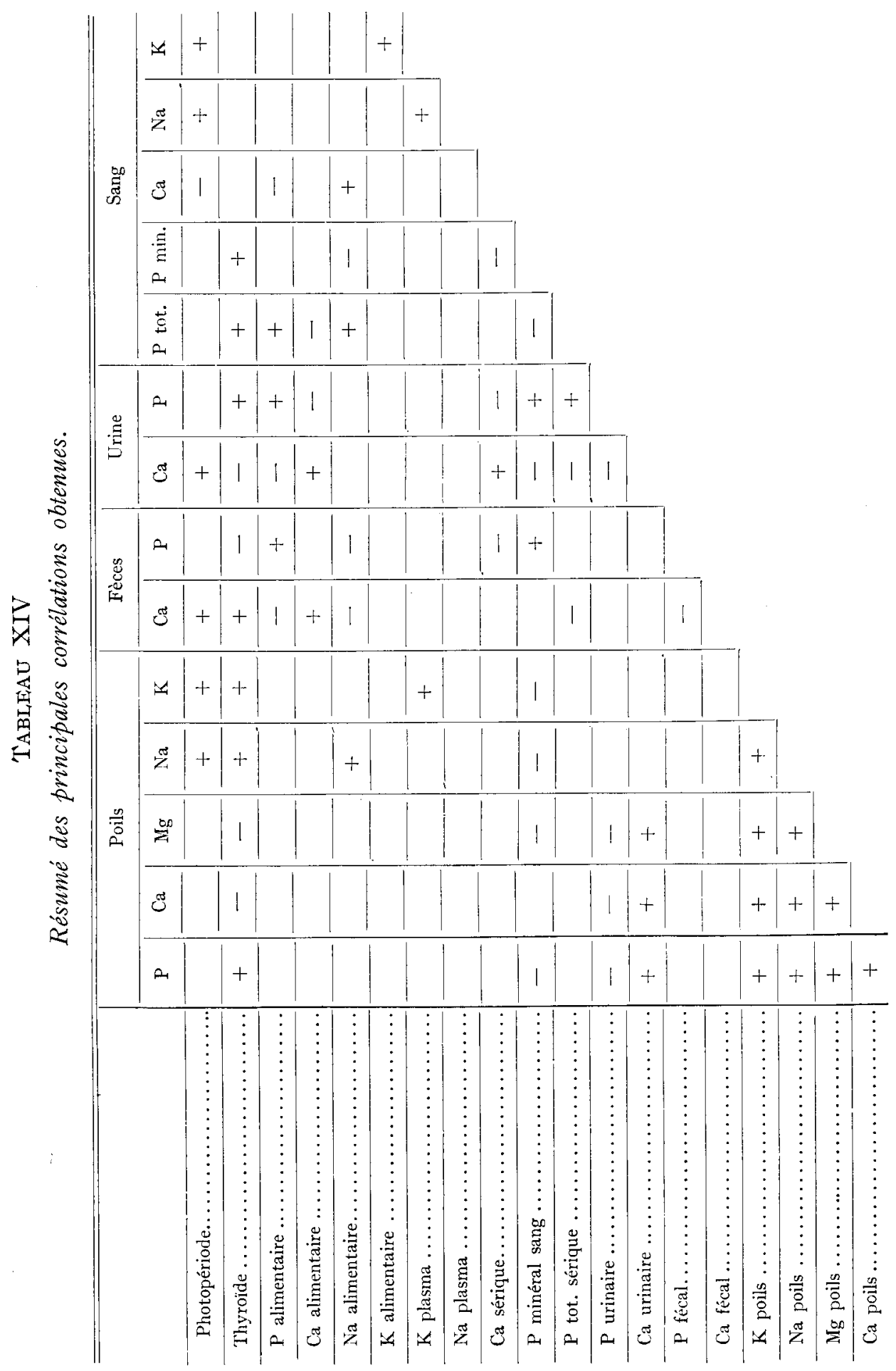


tière) et à la saison; de ce fait, il représente vraisemblablement l'activité thyroïdienne. $L_{1}$ phosphore total sérique et le $\mathrm{P}$ urinaire sont en corrélation positive avec ce facteur, qui est en corrélation négative avec la calciurie.

Le facteur 3 est lié par une corrélation positive au Na alimentaire, et par des corrélations négatives aux apports phosphorique et calcique. I'élimination fécale de $\mathrm{Ca}$ et $\mathrm{P}$ est liée négativement au facteur 3 ; le calcium sérique et le phosphore total sérique sont, par contre, en corrélation positive avec ce dernier. Il existe une corrélation négative entre le facteur 3 et le phosphore minéral sanguin, qui est peut-être due à un mécanisme de régulation acido-basique du sang, rendue nécessaire par l'absorption préférentielle de l'ion $\mathrm{Cl}$ associé au sodium dans le sel.

Le facteur 4 contrôle l'évolution saisonnière de $\mathrm{Na}$ et $\mathrm{K}$ plasmatique, et, dans une moindre mesure, celle de la calcémie; il parait exercer une influence négative sur l'assimilation calcique.

En dehors de ces quatre facteurs principaux, d'autres variables exercent une certaine influence sur le métabolisme de Ca-P ou Na-K :

Le $\mathrm{Ca}$ alimentaire exerce une action négative sur le phosphore total sérique et la phosphaturie, positive sur la calciurie, et nulle sur la calcémie. Le calcium alimentaire n'influence pas le phosphore fécal; le $\mathrm{P}$ alimentaire est en corrélation négative avec le $\mathrm{Ca}$ fécal, ce qui tend à montrer que $\mathrm{P}$ alimentaire influence l'assimilation calcique, mais que $\mathrm{Ca}$ alimentaire n'a pas d'influence sur l'absorption de $P$.

Le sodium alimentaire n'influence pas la natrémie mais contrôle l'amplitude des variations de celle-ci, qui sont importantes quand cet apport est faible et moindres quand l'apport sodique est élevé.

Le $\mathrm{K}$ alimentaire influence positivement le $\mathrm{K}$ plasmatique.

Une part très importante de la variation des minéraux sanguins est due à l'influence de facteurs non systématiques qui ne peuvent être identifiés (variations aléatoires qui se produisent au cours d'une même journée).

Une corrélation négative hautement signiflcative lie le calcium sérique et le $\mathrm{P}$ minéral sanguin ; la constance du produit $\mathrm{Ca} \times \mathrm{P}$ sérique parait être un élément important ce la régulation de ces métabolites au niveau sérique.

On note une relation négative entre $\mathrm{P}$ sérique total et $\mathrm{P}$ minéral sanguin, due, selon toute vraisemblance, à l'influence du chlorure de sodium alimentaire, d'une part, et aux variations de l'activité métabolique d'autre part.

On n'observe aucune relation, au niveau sérique, entre Ca-P d'une part, Na-K de 1'autre.

$\mathrm{Na}$ et $\mathrm{K}$ plasmatiques sont en corrélation élevée entre eux du fait de leur dépendance mutuelle vis-à-vis de la photopériode.

Dans les conditions de l'expérience, où les apports phospho-calciques 
et en vit. $\mathrm{D}$ ont été supérieurs aux besoins, la parathyroïde ne semble pas jouer de rôle, et la concentration urinaire de Ca-P dépend du niveau sanguin de ces minéraux, et peut-être d'une action phosphaturique thyroïdienne. On note également une corrélation négative hautement significative entre $\mathrm{Ca}$ et $\mathrm{P}$ urinaire, ce qui est en accord avec la relative constance du produit $\mathrm{Ca} \times \mathrm{P}$ urinaire.

La corrélation positive observée entre $P$ minéral et $P$ fécal semble confirmer qu'une part importante du $\mathrm{P}$ fécal est endogène.

L e degré de minéralisation globale des poils varie inversement à l'activité métabolique, telle que celle-ci s'exprime par le phosphore minéral sanguin et le phosphore urinaire. Il existe un cycle annuel de la composition minérale des poils dépendant des facteurs saisonniers. Les possibilités d'utilisation de l'analyse minérale des poils pour l'exploration nutritionnelle et la détermination du type métabolique individuel (thyroïdien) sont discutées.

\section{SUMMARY}

Four cows have been kept indoors on dry food only during one year; the vitamin $\mathrm{A}$ and $\mathrm{D}$ intakes have been kept constant. $\mathrm{Ca}, \mathrm{P}, \mathrm{K}$, and $\mathrm{Na}$ intakes have been different during the experiment. Every week, serum $\mathrm{Ca}$ and total $\mathrm{P}$, blood inorganic $\mathrm{P}$, plasma $\mathrm{K}$ and $\mathrm{Na}$, urinary and fecal $\mathrm{Ca}$ and $\mathrm{P}$ have been determined. $\mathrm{Ca}, \mathrm{P}, \mathrm{Na}, \mathrm{K}$ of hairs have been measured every two months. These analytical results have been correlated a) within themselves b) with $\mathrm{Ca}, \mathrm{P}, \mathrm{K}, \mathrm{Na}$ intakes, c) with temperature, length of the day, atmospheric pressure and hygrometry. The 325 coefficients of correlation for the 26 factors studied (2I6 values for each) and a partial factorial analysis have been calculated by an electronic machine.

Four main factors of variation have been tentatively individualized through factorial analysis ; these could be : I) P intake, 2) thyroid activity, 3) intestinal capacity of assimilation, 4) variation in the length of the day, which are responsible respectively for I5, 9-I $6,2-\mathrm{I} 2,2-5,7 \%$ of the total variation.

The variations of factor number $I$ are parallel to those of serum total $\mathrm{P}$, fecal $\mathrm{P}$ and urinary $\mathrm{P}$, and inverse to those of serum and urinary $\mathrm{Ca}$.

Factor number 2 is highly correlated with urinary excretion, positively with $\mathrm{P}$, negatively with $\mathrm{Ca}$; this factor is also positively correlated with serum total $\mathrm{P}$ and blood inorganic $\mathrm{P}$.

Factor number 3 is positively correlated with $\mathrm{Na}$ intake and negatively with $\mathrm{Ca}$ and $\mathrm{P}$ intake.

Factor number 4 is positively correlated with plasma $\mathrm{Na}$ and $\mathrm{K}$, the evolution of which is parallel to variations of the length of the day.

Besides these four factors, a few others are exerting some influetice.

$\mathrm{Ca}$ intake is correlated, negatively, to serum total $\mathrm{P}$, urinary $\mathrm{P}$, positively, to urinary $\mathrm{Ca}$; the correlation with serum $\mathrm{Ca}$ is non significant.

$\mathrm{K}$ intake is positively correlated with plasma $\mathrm{K}$.

$\mathrm{Na}$ intake is not correlated with plasma $\mathrm{Na}$, the intensity of variation of which from day to day being, however, negatively dependent of $\mathrm{Na}$ intake. $\mathrm{Na}$ intake is negatively correlated with blood inorganic $\mathrm{P}$, which may be due 
to an associated assimilation of $\mathrm{Cl}^{-}$(through $\mathrm{ClNa}$ intake), resulting in a reduction of blood $\mathrm{PO}_{4}$.

There is a highly significant negative correlation between serum $\mathrm{Ca}$ and blood inorganic $\mathrm{P}$. The variations of blood or serum $\mathrm{Ca}$ and $\mathrm{P}$ on one hand, and plasma $\mathrm{K}$ and $\mathrm{Na}$ on the other, are independent. Plasma $\mathrm{Na}$ and $\mathrm{K}$ are positively correlated.

Urinary $\mathrm{Ca}$ and $\mathrm{P}$ are highly negatively correlated.

Fecal $\mathrm{P}$ is positively correlated with blood inorganic $\mathrm{P}$; fecal $\mathrm{Ca}$ is correlated only with $\mathrm{Ca}$ intake (positively).

Hair mineral content is negatively correlated with blood inorganic $P$ and urinary $\mathrm{P}$; it shows an annual cycle depending of seasonal influences. The possibilities of utilization of hair mineral analysis for nutritional investigations and determination of the individual metabolic type are discussed.

\section{RÊFÉRENCES BIBLIOGRAPHIQUES}

Abderhalden, - Lehrbuch der Phys. Chem. Cit. p. Liegeors, I953, I9o6. Aines (P. D.) et Smith (S. E.). - J. Dairy Sci., 40, 682, I957.

Allcroft (W. M.) et Green (H. H.). - Rapp. Congr. Vet. Zurich ; fasc. 3 , Cit. p. I_IEGEOrS 1953.

Appleman (R. D.) et Delouche (J. C.). - J. Animal Sci. 17, 326, I958.

Baker (D. G.) et Selleks (E. A.), Canad. J. Biochem. Physiol., 35, 63I, 1957. Barbour (H. G.). - Physiol. Rev., 1, 205, I92I.

Barbour (H. G.), Me KAy (E. A.) et Griffith (W. P.). - Amer. J. Physiol, 140, 9, I943.

BARKER. - Institut voor Moderne Veevoeding "de Schothorst", Amersfoort (Pays-Bas) (communication personnelle), 1959.

Bass (D. E.), Klemman (C. R.), Quinn (M.), Henschei, (A.) et Hegnauer (A. H.) Medicine, Baltimore, 34, 323, I955.

Bass (D. E.) et Hexscher (A.). - Physiol. Rews., 36, I28, I956.

Bass (D. E.), Buskirk (E. R.), Iampietro (P. F.) et Mager (M.). - J. Applied Physiol., 12, I86, I958.

BAzETT (H. C.). - Amer. Heart J., 21, 423, I94I.

Bazett (H. C.), Sunderman (F. W.), Doupe, (J) et Scote (J. O.). - Amer. J. Physiol., 129, 69, I040.

Brisel, (W. R.), Zerzan (C. J.), Rubini (M. E.) et Brythe (W. B.). - Amer. J. Physiol. 195, 357, 1958.

Benort (J.), Waiter (F. X.) et Assenmacher (I).-C.R. Soc. Biol. 144, I206, I950.

Berg (M.), Mayne (A.) et Peteresen (W. F.), Amer. J. Physiol., 130, 9, I940.

BERNDT et BETHMANN. - Biedermann's Zentralblatt, Tierernährung 6, 292, cit. p. OYAERT, I953, I934.

Bianca (N.). - British Vet. J. 113, 227, 1957.

Binet (L.). - La lutte contre le froid. In " Traité de Physiologie normale et pathologique " T VIII, Paris. Masson, Edr. I929.

Boda (J. M.) et Cole (H. H.). - J. Dairy, Sci., 39, IO27, r956.

Bonvallet (M.) et Dell (P.). - Ann. Nutr. Alim., 3, I85, I949.

Bonvallet(M.), Dell (P.), Stutinsky (F. S.) et Beauvallet (M.). - C. R. Soc. Biol., 142, 937, I948.

Brochart (M.). - Ann. Zoot. I. N.R. A. (6), I55, I957.

Brochart (M.), Coleou (J.) et Larvor (P.). -C. R. Acad. A gric., Séance du 6 mai, I959.

Brown (H. R. jr.), Clark (W. F.), Jones (N.), Wal'ther (J.) et Warren (S. I..). - J. Clin. Inv., 22, 47I, I943.

Burkhardt (J.). - J. Agric. Sci., 37, 64, I947. 
Campbeil. (I. L.), et Turner (C. W.), Cités par Boda et Cole, I956, I942. Conley (C. L.) et Nickerson (J. I..). - Amer. J. Physiol., 143, 373, I945. Coulthard (A. J.). - Clin. Chim. Acta., 3, 226, 1958.

Cowie (A. T.) et Tindal (J. S.). - J. Endocrinol., 16, 403, I958.

Craig (A. H.) et Gadd (J. D.). - Cit. par BAzETT, I94I.

Curme (G.), Eaton (H. D.), MatTerson (L. D.), Bliss (C. I.), Helmboldt (C. F.), Brown, (B. A.) et Jungherr (E. L.). - J. Anim. Sci., 8, 639, I949.

Dale (H. E.), Burge (G. J.) et Brody (S.). - Univ. Missouri Agtic. Exp. Stat. Res. Bull. No 608,20 pp. 1956.

Daniel (O.), Hatfield, (E. E.), SchreWsberry (W. C.), Gibson (M. E.) et Mac Vicar (R.). - J. Anim. Sci., 11, 790, I952.

Deb (C.) et Hart (J. S.), Canad. J. Biochem. Physiol., 34, 959, I956.

Dennis (J.) et Harbaugh (F. G.). - Amer. J. Vet. Res., 9, 20, I948.

Dowe ('T. W.), Matsushima (J.) et Arthaud (V. H.). - J. Animal Sci., 16, $8 \mathrm{IX}$, I957.

Dukes (H. H.). - The physiology of domestic animals. $5^{\mathrm{e}}$ et $6^{\mathrm{e}}$ éditions. Comstock publishing company inc. Ithaca New York, I943 et I955.

Duliere (W. L.). - C. R. Soc. Biol., 10\%, 26I, I93I.

Duncan (D. L.). - Nutrit. Abstr. Rev., 28, 695, 1958.

Du Toit (P. J.), Malan (A. I.) et Groenewald (J. W.). - Onderstepoort J. Vet. Sci., 2, 565, I934.

Du Tort (P. J.), Louw, (J. G.) et Malan (A. I.). - Onderstepoort J. Vet. Sci., 14, I23, I940.

Eaton (H. D.) et Avampato (J. F.). - J. Anim. Sci., 11, 76r, I952..

Éckles (C. H.), Palmer (L. S.), Gullickson (T. W. )., Fitch (C. P.), Boyd (W. L.) Bishop (L.) et Nelison (J. W.). - Cornell Vet., 25, 22, I935.

Ellis (B. C.). - S. A fr. J. Med. Sci., 18, 45 , I953.

ENDER (F.) et HELGEBOSTAD (A.). - Nordisk Veterinaermedicin, 9, 88I, I957.

Ferguson (K. A.), Schinckel (P. G.), Carter (H. B.) et Clarke (W. H.). Austr. J. Biol. Sci., 9, 575, 1956.

Ferguson (K. A.). - Proc. New Zealand Soc. An. Product., 18, 128, 1958.

Franciscis (G. de). - Boll. Soc. Ital. Biol. Sperim., 33, I, I957.

Giacomini (E.). - Rpt. 2 nd World's Poultry Congress. p. 45, Cité par Yeates, I954, I924.

Gibson (A.G.). - Quart. J. Med., 3, 52, Igog.

Godfrey (N. W.). - Proc. Austral. Soc. Animal Produc., 2, I29, 1958.

Goding (J. R.) et Derextox (J. A.). - Austr. J. Exper. Biol. Med. Sci., 35 $30 \mathrm{I}, \mathrm{I} 957$.

Groentwald (J. W.). - Onderstepoort. J. Vet. Sci., 4, 93, I935.

Guilitaumin (C. O.). - Bull. Soc. Chim. Biol., 12, 49I, I930.

Guillaumin (C. O.) et Vignes (M.). - C. R. Soc. Biol., 99, 753, rg28.

HAAG (J. R.) et Jonfs (I. R.). - J. Biol. Chem., 110, 439, I935.

Hannon (J. P.), Larson (A. M.) et Young (D. W.). - J. Appl. Physiol., 13, 239, $195^{8}$.

Hansard (S. L.), Comar (C. L.) et Davis (C. K.). - Amer. Physiol. 19ry, I383, I954.

Hansson (A.). - Acta Agric. Suecana, 3, 59, 1948.

HART (D. S.). - Nature, 174, IOI8, I954.

Hart (D. S.). - Proc. N. Z. Soc. An. Prod., 15, $57, \mathrm{I} 955$.

HaR'T (D. S.). - N. Z. Vet. J. Res. Publ., 62, I957.

Hennemain (H. A.), Reineke (E. P.) et Griffin (S. A.). - J. Anim. Sci., 14, 4I9, I955.

Hibbs (J. W.), Pounden (W. D.) et Krauss (W. E.). -- J. Dairy Sci., 30, 564, I 947 .

Higounet (H.). - Bull. Soc. Chim. Biol., 19, 53, I937..

Holcombe (R. B.). - Acra endocrinologica., 26, Suppl. no 34, 1957. 
Huex (D. M.) et Holmes (J. H.). - Fed. Proc., 9, 64, I950.

HÜTTEN (N.) et Uhi,ENBruck (K.). - Dtsche tierärzll. Wschr., 59, 5, I952. JACKSON (R. A.). - Cité par BASS et Coll (I955), I795.

JARI. (F.). - Kgl. Lantbrukshögsk. Ann., 20, I5I, I953.

Kahnt (F. W.), Neher (R.) et WeTt'stein (A.). - Helv. Chim. Acta., 38, I237, I955.

Kayser (C.) et Aron (M.). - Archiv. Anat. Histol. et Embryol., 33, I \& 2 I, I950.

KELLY (F. C.). - Biochem. J., 19, 559, I925.

Kendali (K. A.) et Harshbarger (K. E.). - J. Dairy Sci. (Abstr.), 41, 729, I958.

KISELYEV (G. I.). - Ukr. Biokh. Zh., 30, 724, I958.

Kieiber (M.) et Luick (J. R.). - Ann. N. Y. Acad. Sci., 64, 299, I956.

Kobayashi (O.) et Kodama (B.). - Mei Med. J., 5, I, I955.

Kobayashi (O.) et Kodama (B.).-Mei Med. J., 8, 97 , I958.

KoHL (P.). - Thèse de pharmacie, Paris, I950.

Kunkel (H. O.), Burns, (K. H.) et Camp (B. J.). - J. Anim. Sci. 12, 45 I, I953.

LAING, - Cité par YEATES, N. T. M., I954.

Larvor (P.) et Brochart (M.). - Ann. Zoot. INRA (I), 57, I959.

L.EHManN (G.) et Szakal. (A.). - Arbeistsphysiologie, 10, 608, I938/39.

LENNON (H. D.) et MIXNeR (J. P.). - J. Dairy Sci., 42, 327, I959.

LEUIIER (A.). - Bull. Soc. Chim. Biol., 15, I58, I933.

I.EWIS (J. K.), BurkitT (W. H.) et Wilson (F. S.). - J. Animal Sci., 10, I053, I95I.

Liegeors (F.). - Ann. Méd. Vét., 97, I35, I953.

Liegeois (F.), Derivaux (J.) et Hennaux (L.). - Ann. Med. Vet., 89, I, I 945 .

Linhard (J.), Busson (F.), Trapet (P.), Grraud (P.), Lecoco (F.) et GuyonNET (C.). - Méd. Trop. 13, 530, I953.

I ITTTLE (W. L.) et Mat'Tick (E. C. V.). - Vet. Record., 13, 238, I933.

Long (R. A.), Van ARsdeld, (W. A.), Mac Vicar (R.) et Ross (O. B.). - Oklahoma Agric. Exp. Sta. Tech. Bull. 43, I952.

Lotz, Talmage et Comar. - Proc. Soc. Exptl. Biol. Med. 85, 292, I954, cités par SMrTh, STOTT et WALKER, 1957.

Magnant (G.). - La Clinica Veterinaria, 79, 97, 1956.

Magsood (M.). - Nature, 168, 466, I95I.

MaQsood (M.). - Biological Rev., 2\%, 28I, 1952.

MaqSOOD (M.). - Brit. Vet. J. 111, I63, I955.

MarXer. - Bull. Mens. Soc. Vet. Prat., 6, Cit. p. Liegeors \& Coll., I945,I929.

Maxfield (M. E.), Bazet' (H. C.) et Chambers (C. C.). - Amer. J. Physiol., 101,78, I939.

MCDONALD (I. R.), GodIng (J. R.) et WRIGHT (R. D.). - Austral. J. Exper. Biol. Med. Sci., 36, 83, I958.

Mehrotra (P. N.), Mulitck (D. N.) et Kehar (N. D.). - J. Anim. Sci., 13, I026, I954.

MEIGS (F. B.) et BLATHERWICK (W. R.). - Cités par Boda et Cole, I956, I9I7.

Meigs (F. G.), Turner (W. A.), Swann-Harding (T.), Hartman (A. M.) et Gran's (F. M.). - J. A gric. Res., 32, 833, I926.

Meyer (J. H.), Grunert (R. R.), Zepplin (M. T.), Grummer (R. H.), BohsTED'T (G.) et Phillips (P. H.). - Amer. J. Physiol., 162, I82, I950.

Meyer (J. H.) et Weir (W. C.). - J. Anim. Sci., 13, 443, I954.

MoHn (M. P.). - Anatom. Record. 125, 595, I956.

MoHn (M. P.). - in Biology of hair growth p. 335, Ed. Montagna (W.) et EILIIS (R. A.), New-York, I958.

Morice (E.), et Chartier (F.). - Méthode statistique ( $2^{\mathbf{e}}$ partie) Paris, Imprimerie nationale, I954. 
Mukherjee (D. P.) et Bha't'Tacharya (P.). - Indian J. Vet. Sci., 22, I9I, I952. Mulitick (D. N.), Murty (V. N.) et Kehar (N. D.). - J. Anim. Sci., 12, 95I, I953.

NeHER (R.) et WETTSTEIN (A.). - Acta endocrinologica, 18, 386, I955.

Nelison (A. B.), Mac Vicar (R. W.), Van Arsdeil (W. J.) et Dariow (A. E.). J. Anim. Sci., 10, I058, I95I.

Nicolaysen (R.), Eeg-Larsen (H.) et Malm (D. J.). - Physiol. Rewe., 33, 424, I 953 .

Ortavant (R.) et Thibault (C.). - C. R. Soc. Biol., 150, 358, I956.

Oтто (J. S.). - Onderstepoort J. Vet. Sci., 10, 28I, I938.

OWEN (E. C.). - Biochem. J., 43, 243, I948.

Oyaert (W.). - Ann. Med. Vet., 97, 122, I953.

Palmer (L. S.), Cunningham (W. S.) et Ecki ES (C. H.). - Joum. Dairy. Sci., 13, I74, I 929 .

Palmer (L. S.), Gulimickson (T. W.), Boyd (W. L.), Fitch (C. P.) et NelSoN (J. W.). - J. Dairy. Sci., 24, I99, I94I.

Payne (M. G.), Clark (A. G.), Kingman (H. E.) et Stansbury (W. M.). - J. Agric. Res., 72, 357, I946.

Pearson (P. B.), Gray (J. A.) et Reiser (R.). - J. Anim. Sci., 8, 52, 1949.

Pistor (W. J.), Nesbitt (J. C.) et Cardon (B. P.). - Proc. Ann. Vet. Med. Assoc., 87th Ann. Meet. p. I54, 1950.

RAUSchKol, (E. W.) et Farreir, (G. L.). - Endocrinology, 59, 526, r956.

Rauschkol, (E. W.), Yatsu (F. M.) et Farrei. (G. L.). - Proc. 39th Meeting Endrocrinol. Soc. p. 32 , I957.

Reinberg (A.) et Stolkowski (J.). - Ann. Endocrinol, 18, I37, I957.

Riggs (J. K.), Colby (R. W.) et Smith (H. A.). - J. Anim. Sci., 10, ro6o, I95I.

RigGs (J. K.), Col $b y$ (R. W.) et Seils (L. V.). - J. Anim. Sci., 12, 379, I953.

Robinson (C. S.), HuffMan (C. F.) et BurT (K. L.). - J. Biol. Chem., $\mathbf{y}_{3}$, 477, I 927 .

Rushoff (L. L.). - - J. Anim. Sci, 9, 666, I950.

Rusofy (L. L.) et Piekcy (P. L.). - J. Dairy Sci., 29, 526, I946.

SAARINEN (P.). - Journ. of the Scientific A gricultural Society of Finland, 22, I22, I950.

Salgues (R.). - Bull. Soc. Chim. Biol., 20, I224, 1938.

SEWALI, WRIGHT, - The interpretation of multivariate systems, Statistics and mathematics in biology, Iowa State College Press.

Simpson (B. W.). - Biochem, J., 41, XLV, I947.

Sjos'tRand ('T.). - Physiol. Rei., 33, 202, I953.

SMith (V. R.) et Srot' (G. H.). - J. Dairy Sci., 39, 935, I956.

SMirh (V. R.), Stot'r (G. H.) et WaLkeR (C. W.). J. Anim. Sci., 16, 313, I957.

SORENSEN (P. H.). - 302 beretning fra forsogslaboratoriet, 1958.

Spealman (C. R.), Newton (M.) et Post (R. L.). - Amer. J. Physiol, 150, 628 , I947.

Squibb (R. I.), Guzman (M. A.) et Scrimshaw (N. S.). - J. Nutrition, 52, I 55, I954.

Stedman (I. 'T.), Arier, (I.) et Warren (S. L.). - New England J. Med., 224, 47I, I94I.

StotT (G. H.) et Smith (V. L.). - J. Dairy Sci., 40, 893 et 897 , I957.

Strand (R.), Anderson (W.) et Allcroft (W. R.). - Biochem. J., 28, 642, I934.

TAYLOR (S.). - J. Clin. Endocrinol., 14, I4I2, I954.

Thauer (R.). - Ergebn. Physiol., 41, 607, cité par Bonvalifet et Deli, I949, I939.

Theiler (A.), Green (H. H.) et Du Toit (P. J.). - J. Agric. Sci., 1\%, 29I, 1927. 
Thompson (J.). - Endocrinology, 1\%, 537, I933.

Toussaint (C.), Wolter (R.), et Sibille (P.). - C. R. Soc. Biol., 147, i637, I953.

Treille (G.). - I I888, 6e Congrès International d'Hygiène, Vienne. Cité par Deli, et BONVALLET, I949.

Ungar (F.), Rosenfeid (G.), Rosenberg (E.) et Dorfman (R. I.). - Proc. Soc. Exptl. Biol. Med., 87, 653, I954.

VAN DER HORST (C. J. G.) et HeNDRIKS (H. J.). - Tijdschr. v. Diergeneesk, 83, II62, I 958 .

VAN DER MEUlen (J. B.). - Rpt. 7 th World's poultry Congress. Cité par YeaTES, I954, I939.

WALsk (R. J.), KALDOR (I.) et CotTER (H.). - Austr. J. Exp. Biol. Med. Sci., 34, 59, I956.

Watkins (W. E.) et Knox (J. H.). - J. Agric. Sci., 7, 263, I948.

Webb (R. J.), Lewis (J. M.), Kammlade (W. C.), Fuelleman (R. F.) et HamiTON (T. S.). - J. Anim. Sci., \%, I59, I948.

WESTERLUND (A.). - Lantbrukshögsk. Ann., 4, 55, I937.

WetTstein (A.), Kahnt (F. W.) et Neher (R.). - CIBA Found. Coll. on Endocrinol., 8, I955.

WOODRUFF (L. M.).-Anesthesiology, 2, 4IO, I94I.

Yeates (N. T. M.). - J. Agric. Sci., 39, I, I949.

Yeates (N. T. M.). - - "Progress in the physiology of farm animals " Hammond, Jr. Ed. Butterworth Scientific Publication, London, I954. 